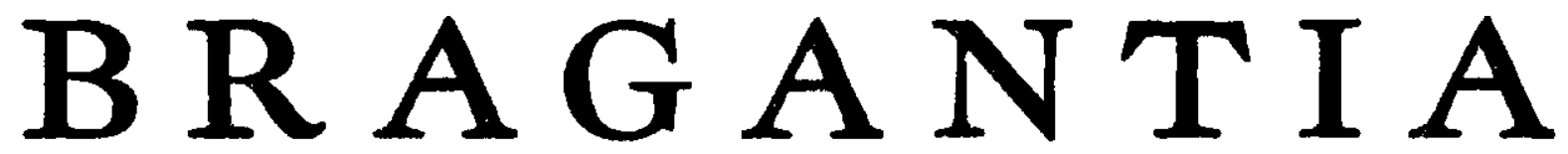

Boletim Técnico do Instituto Agronômıco do Estado de São Paulo

\begin{tabular}{lll} 
Vol. I Campinas, Fevereiro de $1941 \quad$ N. 2 \\
\hline
\end{tabular}

\title{
A SELEÇÃO DO SORGO VASSOURA
}

G. P. Viégas.

\section{I - INTRODUÇÃO}

Procuramos expor aquí, apenas em linhas gerais, nosso trabalho de seleção efetuado em uma planta que ainda tem pouco valor econômico entre nós - o sorgo vassoura. Os dados apresentados são $\circ$ fruto de 6 anos de contínuo labor e prestam-se, sobretudo, a nosso ver, ao estudo crítico do problema: Como medir o progresso da seleção? A literatura sôbre melhoramento de plantas não trata satisfatòriamente dêste assunto. Aplicando, então, métodos modernos de análise estatística ao estudo de caracteres de natureza qualitativa visados pela seleção executada, procuramos provar que conseguimos melhorar, e que existe um processo eficaz de medir, ano a ano, a alteração provocada pela seleção.

Os resultados obtidos são ainda interessantes sob outros aspectos, pois mostram num exemplo frizante, como é perigoso julgar o valor de um indivíduo quando se desconhece a ação das grandes fôrças - hereditariedade e meio ambiente. Uma concepção da interação dêsses fatores é imprescindível no exame final dos dados, porque há sempre o perigo de escolher um indivíduo de potencial hereditário indesejável que se acha acobertado pela ação controladora do meio ambiente.

Desejamos expressar os nossos agradecimentos àqueles que, de uma ou outra forma, cooperaram na elaboração dêste trabalho. Fazemos menção especial ao Sr. C. A. Krug, pela orientação geral e valiosas 
críticas; ao Sr. L. Paoliéri, pela sua excepcional ajuda nos últimos dois anos de serviço; ao Sr. L. A. Nucci, por diversas sugestões; aos Srs. A. G. Gomes e H. Morais, das Estações Experimentais de Ribeirão Preto e Pindorama, respectivamente, pelo cuidado com que conduziram all as experiências por nós instaladas.

\section{II - HISTÓRICO}

O trabalho de melhoramento de sorgo vassoura foi iniciado em 1933-34 pelo Chefe da Seç̧ão de Genética, Sr. C. A. Krug (1) e (2), que elaborou as bases do plano de seleção pelo método das linhas puras. Em fins de 1934 fomos incumbidos do seu posterior desenvolvimento, no que labutamos até agora. Em 1936-37 tivemos a ajuda do Sr. E. B. Germek e nos dois últimos anos, $1938-39$ e 1939-40, o eficaz auxílio do Sr. L. Paoliéri, com quem vimos trabalhando em íntima colaboração. A êle devemos muitos cálculos feitos e ajuda constante na colheita de dados e instalação de experiências.

Com a vinda do Prof. S. C. Harland tivemos a oportunidade de apreciar as vantagens do processo de seleção por família, que, uma vez adaptado ao sorgo, começamos desde então a utilizar. Pomos em relêvo, com isto, um fato importante: no decorrer do trabalho de melhoramento, o julgamento do material nos dois primeiros anos de serviço, não foi feito pelo mesmo método utilizado nos anos posteriores.

\section{III - IMPORTÂNCIA ECONÔMICA}

Não existem dados com que se possa julgar diretamente a importância econômica agrícola do sorgo vassoura no Estado de São Paulo. Não se conhecem grandes culturas desta gramínea. Qual a área plantada, qual a quantidade de palha produzida, são dados que não figuram nas estatísticas oficiais. Entretanto, pode-se apreciar a sua importância : 1) examinando-se a quantidade e o valor da palha importada do estrangeiro; 2) computando-se as estatísticas referentes ao número de fábricas de vassouras.

Para que se forme um juizo da importância econômica do sorgo vassoura transladamos para aquí alguns dados das estatísticas oficiais (3) a (13) (Quadro I). 


\section{QUADRO I}

\section{Importação de palha pelo pôrto de Santos}

\begin{tabular}{l|r|r|r|r|r}
\hline Ano & $\begin{array}{c}\text { Quant. } \\
(\mathrm{Kg.})\end{array}$ & $\begin{array}{c}\text { Valor } \\
\text { (mil réis papel) }\end{array}$ & Ano & $\begin{array}{c}\text { Quant. } \\
(\mathrm{Kg.})\end{array}$ & $\begin{array}{c}\text { Valor } \\
\text { (mil réis papel) }\end{array}$ \\
\hline 1926 & 1.025 .087 & $885: 614 \$ 000$ & 1933 & 1.414 .711 & $1.299: 570 \$ 000$ \\
1927 & 1.299 .549 & $1.137: 960 \$ 000$ & 1934 & 1.064 .317 & $1.229: 687 \$ 000$ \\
1928 & 1.325 .116 & $1.728: 383 \$ 000$ & 1935 & 1.089 .043 & $1.662: 474 \$ 000$ \\
1929 & 1.465 .477 & $2.158: 739 \$ 000$ & 1936 & 1.306 .502 & $1.272: 392 \$ 000$ \\
1930 & 1.289 .958 & $1.232: 902 \$ 000$ & 1937 & 1.458 .652 & $1.250: 630 \$ 000$ \\
1931 & 1.616 .017 & $1.612: 225 \$ 000$ & 1938 & 1.554 .429 & $1.817: 959 \$ 000$ \\
1932 & 885.337 & $614: 809 \$ 000$ & 1939 & 1.849 .385 & $1.999: 477 \$ 000$ \\
\hline
\end{tabular}

A importância dispendida com a importação do sorgo vassoura do exterior, principalmente da Argentina e também da Itália, Uruguai e outros países, é pequena, relativamente d̀ nossas outras importações. Entretanto, diante das nossas ótimas condições de meio para a sua cultura, ante o seu bom rendimento econômico, parece-nos ainda demasiado grande êsse inútil dispêndio de dinheiro.

Quanto às fábricas de vassouras existentes no Estado, encontramolas (14) distribuidas, até 1937, de acôrdo com a seguinte relação:

QUADRO II

Localidade
N. ${ }^{\circ}$ de fábricas existentes

São Paulo ......................... 9

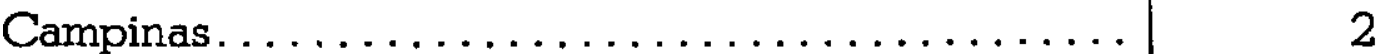

Araraquara . ....................... $\quad 1$

Jundiaí $\ldots \ldots \ldots \ldots \ldots \ldots \ldots \ldots \ldots \ldots \ldots \ldots \ldots \ldots \ldots$

São Carlos.$\ldots \ldots \ldots \ldots \ldots \ldots \ldots \ldots \ldots \ldots \ldots$

Valinhos .......................... 1

Rio Claro ...................... 1

Itápolis $\ldots \ldots \ldots \ldots \ldots \ldots \ldots \ldots \ldots \ldots \ldots \ldots \ldots \ldots \ldots$

Não especificadas $\ldots \ldots \ldots \ldots \ldots \ldots \ldots \ldots \ldots \ldots$ 


\section{IV - A NECESSIDADE DA SELEÇÃO}

Como visamos na cultura do sorgo vassoura a obtenção de elevada quantidade de boas panículas, vulgarmente chamadas "palha", matéria prima para a confecção da vassoura, temos que fazer alguns comentários sôbre a qualidade dessas panículas.

Que é uma panícula ?

A panícula é a inflorescência da planta, composta do raquis ao qual se inserem numerosas ramificações laterais que sustentam as flores, e, depois, os grãos.

Numa boa panícula essas ramificações (fios) devem ter, no mínimo, $50 \mathrm{cms}$. de comprimento. Devem ser finas, roliças, flexíveis, retas, e, até certo ponto, de igual comprimento.

Mas há também panículas defeituosas (15).

Os principais defeitos, na ordem de sua importância, são três, a saber :

Panícula retorcida que designaremos daquí por diante pela letra " $R$ ". Uma panícula retorcida, isto é, com fios mais ou menos engruvinhados, não se presta para o fabrico da vassoura; serve, apenas, para enchimento. Este defeito é mais ou menos frequente; em certos casos, a panícula não se expande acima da fôlha protetora. Trata-se de um defeito determinado por fatores hereditários.

Panícula caída, defeito designado mais adiante pela letra " $C$ ". É defeito muito frequente. Neste caso, a panícula sob seu próprio pêso se inclina, tomando a forma de jota (J) invertido. $O$ agricultor, muita vez, procura evitá-lo dobrando a extremidade superior do colmo para que não apareça a panícula caída. Ėste também é um caráter hereditário.

Panículas com raquis grosso, designado mais adiante como " $\mathrm{M}$ ". Como dissemos, as ramificações numa panícula são aproximadamente tôdas iguais. Mas, frequentemente, aparece um fio mais grosso no eixo central da panícula, como se fôra um prolongamento do raquis. Parece ser um caráter hereditáxio muito influenciado pelas condições do meio (16).

Outros defeitos hereditários notados, são:

1) - desigualdade no comprimento das ramificações ;

2) - fios de grossura desigual ;

3) - fios achatados;

4) - fios que se inserem no raquis em diversos pontos;

5) - fios torcidos, como numa corda. 
Outro caráter importante da palha é a sua côr. O nosso mercado exige a palha amarela ; já nos Estados Unidos dá-se preferência à palha verde que é menos quebradiça, obtida por cuidadosa secagem à sombra.

A variedade existente no Instituto Agronômico, cujas sementes vinham sendo distribuidas aos lavradores, produzia muita palha defeituosa e desigual. Resolveu-se iniciar o melhoramento dessa variedade, originária da Argentina, visando, principalmente, a eliminação dos defeitos. Entretanto, procurando algum material melhor, a Secção de Genética, introduziu diversas variedades de outras procedências, sôbre as quais falaremos a seguir.

\section{V - VARIEDADES INTRODUZIDAS ; SEU COMPORTA- MENTO}

Foram as seguintes as variedades introduzidas:

QUADRO III

\begin{tabular}{|c|c|c|c|}
\hline N. ${ }^{\circ}$ & $\begin{array}{llll}N & O & M & E\end{array}$ & Origem & $\begin{array}{l}\text { Data da } \\
\text { introdução }\end{array}$ \\
\hline 1 & Evergreen (Standard) Broom Corn C. I. 583 & U. S. A. & 1933 \\
\hline 2 & Western Dwart Broom Corn C. I. $599 \ldots .$. & U. S. A. & 1933 \\
\hline 3 & Scarborough Dwarf Broom Corn. Miller's n. 7 & U. S. A. & 1933 \\
\hline 4 & Black Spanish (Standard) Broom Corn C. I. 827 & U. S. A. & 1933 \\
\hline 37 & Variedade local (sem nome) & Argentina & 一 \\
\hline 41 & Sem nome & Itália & 1935 \\
\hline 42 & White Italian Broom Corn & América do Sul & 1936 \\
\hline
\end{tabular}

Esta coleção vem sendo mantida pela Secção, em pequenos canteiros anualmente plantados, onde são feitas observações diversas.

Algumas plantas são escolhidas para autofecundação, a-fim-de evitar o cruzamento entre as diferentes variedades. Como o material trabalhado é depois escolhido, eliminando-se tôdas as panículas defeituosas, tal processo é até certo ponto seletivo e pode conduzir ao melhoramento. Como as sementes das diferentes panículas são misturadas, podemos chamar êste método de seleção massal. Difere do empregado no melhoramento da variedade local, que é por linhas puras. 
Damos, a seguir, um apanhado sôbre os dados obtidos nos diferentes anos de cultura com cada uma das variedades.

QUADRO III a

\begin{tabular}{|c|c|c|c|c|c|c|c|}
\hline \multirow{2}{*}{ 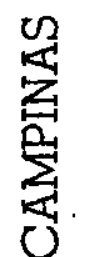 } & \multirow{2}{*}{$\begin{array}{l}\text { N. }{ }^{\circ} \text { da } \\
\text { Varie- } \\
\text { dade }\end{array}$} & \multirow{2}{*}{$\begin{array}{l}\text { Comprimento } \\
\text { Médio da Pa- } \\
\text { nícula (cms.) }\end{array}$} & \multirow[b]{2}{*}{$\mathrm{C}$} & \multirow[b]{2}{*}{$\mathrm{R}$} & \multirow[b]{2}{*}{$\mathbf{M}$} & \multicolumn{2}{|c|}{ PANÍCULAS } \\
\hline & & & & & & $\begin{array}{l}\text { Autofe- } \\
\text { cundadas }\end{array}$ & $\begin{array}{c}\text { Selecio- } \\
\text { nadas }\end{array}$ \\
\hline 1 & 1 & 55 & 23,7 & 3,1 & 21,6 & 12 & 3 \\
\hline ळ & 2 & 43 & 10,3 & 7,5 & 71,7 & 13 & 3 \\
\hline 8 & 3 & 55 & 6,1 & 0,9 & 73,0 & 13 & 2 \\
\hline 労 & 4 & 49 & 12,0 & 4,5 & 63,9 & 11 & 2 \\
\hline
\end{tabular}

QUADRO III b

\begin{tabular}{|c|c|c|c|c|c|}
\hline 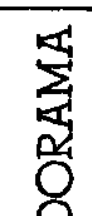 & $\begin{array}{c}\text { N.o da } \\
\text { Varie- } \\
\text { dade }\end{array}$ & $\begin{array}{l}\text { Comprimento } \\
\text { Médio da Pa- } \\
\text { nícula (cms.) }\end{array}$ & $\mathrm{C}$ & $\mathrm{R}$ & $\mathrm{M}$ \\
\hline 1 & 1 & 56 & 35,6 & 8,9 & 40,0 \\
\hline$\stackrel{m}{\dot{m}}$ & 2 & 52 & 0 & 27,3 & 64,7 \\
\hline$\stackrel{0)}{\longrightarrow}$ & 3 & 54 & 21,6 & 7,8 & 56,9 \\
\hline 家 & 4 & 54 & 38,9 & 3,7 & 29,6 \\
\hline
\end{tabular}

QUADRO IV

\begin{tabular}{|c|c|c|c|c|c|c|}
\hline \multirow{3}{*}{ 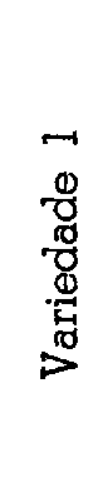 } & Ano & $C$ & $\mathrm{R}$ & $\mathrm{M}$ & Perf. & $\begin{array}{l}\text { N. }{ }^{\circ} \text { Total de } \\
\text { Panículas }\end{array}$ \\
\hline & $\begin{array}{l}1935-36 \\
1936-37 \\
1937-38 \\
1938-39 \\
1939-40\end{array}$ & $\begin{array}{r}7 \\
12 \\
27 \\
1 \\
28\end{array}$ & $\begin{array}{l}3 \\
14 \\
23 \\
21 \\
13\end{array}$ & $\begin{array}{r}39 \\
1 \\
39 \\
34 \\
25\end{array}$ & $\begin{array}{r}45 \\
34 \\
188 \\
44 \\
34\end{array}$ & $\begin{array}{r}94 \\
61 \\
277 \\
100 \\
100\end{array}$ \\
\hline & Total & 75 & 74 & 138 & 345 & 632 \\
\hline
\end{tabular}


QUADRO V

\begin{tabular}{|c|c|c|c|c|c|c|}
\hline \multirow{3}{*}{ 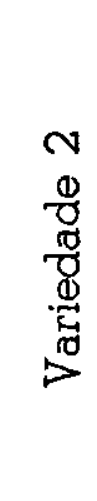 } & Ano & $\mathrm{C}$ & $R$ & $\mathrm{M}$ & Perf. & $\begin{array}{c}\text { N. }{ }^{\circ} \text { Total de } \\
\text { Panículas }\end{array}$ \\
\hline & $\begin{array}{l}1935-36 \\
1936-37 \\
1937-38 \\
1938-39 \\
1939-40\end{array}$ & $\begin{array}{r}4 \\
10 \\
10 \\
0 \\
15\end{array}$ & $\begin{array}{r}0 \\
7 \\
57 \\
4 \\
5\end{array}$ & $\begin{array}{l}39 \\
12 \\
49 \\
72 \\
56\end{array}$ & $\begin{array}{r}51 \\
14 \\
153 \\
24 \\
14\end{array}$ & $\begin{array}{r}94 \\
43 \\
269 \\
100 \\
90\end{array}$ \\
\hline & Total & 39 & 73 & 228 & 256 & 596 \\
\hline
\end{tabular}

QUADRO VI

\begin{tabular}{|c|c|c|c|c|c|c|}
\hline \multirow{3}{*}{$\begin{array}{l}m \\
0 \\
8 \\
0 \\
8 \\
0 \\
\stackrel{10}{0} \\
P\end{array}$} & Ano & $\mathrm{C}$ & $R$ & $M$ & Perf. & $\begin{array}{l}\text { N. Total de } \\
\text { Panículas }\end{array}$ \\
\hline & $\begin{array}{l}1935-36 \\
1936-37 \\
1937-38 \\
1938-39 \\
1939-40 \\
\end{array}$ & $\begin{array}{r}1 \\
0 \\
0 \\
0 \\
10 \\
\end{array}$ & $\begin{array}{r}5 \\
4 \\
19 \\
2 \\
1\end{array}$ & $\begin{array}{l}65 \\
44 \\
47 \\
70 \\
58 \\
\end{array}$ & $\begin{array}{r}26 \\
6 \\
183 \\
28 \\
19 \\
\end{array}$ & $\begin{array}{r}97 \\
54 \\
249 \\
100 \\
88 \\
\end{array}$ \\
\hline & Total & 11 & 31 & 284 & 262 & 588 \\
\hline
\end{tabular}

QUADRO VII

\begin{tabular}{|c|c|c|c|c|c|c|}
\hline \multirow{3}{*}{ 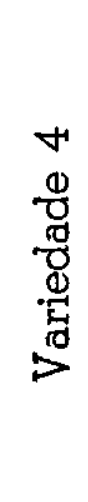 } & Ano & C & $\mathrm{R}$ & $\mathrm{M}$ & Perf. & $\begin{array}{c}\text { N. } .^{\circ} \text { Total de } \\
\text { Panículas }\end{array}$ \\
\hline & $\begin{array}{l}1935-36 \\
1936-37 \\
1937-38 \\
1938-39 \\
1939-40 \\
\end{array}$ & $\begin{array}{r}3 \\
6 \\
40 \\
2 \\
22 \\
\end{array}$ & $\begin{array}{r}6 \\
4 \\
24 \\
19 \\
2 \\
\end{array}$ & $\begin{array}{l}33 \\
15 \\
45 \\
68 \\
54 \\
\end{array}$ & $\begin{array}{r}10 \\
29 \\
177 \\
11 \\
22 \\
\end{array}$ & $\begin{array}{r}52 \\
54 \\
286 \\
100 \\
100 \\
\end{array}$ \\
\hline & Total & 73 & 55 & 215 & 249 & 592 \\
\hline
\end{tabular}




\section{QUADRO VIII}

\begin{tabular}{|c|c|c|c|c|c|c|}
\hline \multirow{3}{*}{ 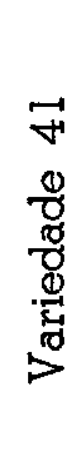 } & Ano & $\mathrm{C}$ & $\mathrm{R}$ & $M$ & Perf. & $\begin{array}{l}\text { N. - Total de } \\
\text { Panículas }\end{array}$ \\
\hline & $\begin{array}{l}1936-37 \\
1937-38 \\
1938-39 \\
1939-40 \\
\end{array}$ & $\begin{array}{r}15 \\
1 \\
3 \\
15 \\
\end{array}$ & $\begin{array}{r}12 \\
42 \\
29 \\
2 \\
\end{array}$ & $\begin{array}{r}9 \\
4 \\
41 \\
16 \\
\end{array}$ & $\begin{array}{r}35 \\
179 \\
27 \\
7 \\
\end{array}$ & $\begin{array}{r}71 \\
226 \\
100 \\
40 \\
\end{array}$ \\
\hline & Total & 34 & 85 & 70 & 248 & 437 \\
\hline
\end{tabular}

QUADRO IX

\begin{tabular}{|c|c|c|c|c|c|c|}
\hline \multirow{3}{*}{ 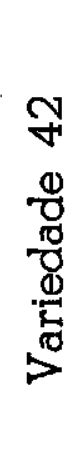 } & Āno & $C$ & $\mathrm{R}$ & $\mathrm{M}$ & Perf. & $\begin{array}{l}\text { N. Potal de } \\
\text { Panículas }\end{array}$ \\
\hline & $\begin{array}{l}1936-37 \\
1937-38 \\
1938-39 \\
1939-40 \\
\end{array}$ & $\begin{array}{r}11 \\
21 \\
0 \\
19 \\
\end{array}$ & $\begin{array}{l}18 \\
42 \\
21 \\
11 \\
\end{array}$ & $\begin{array}{r}2 \\
3 \\
20 \\
27 \\
\end{array}$ & $\begin{array}{r}17 \\
182 \\
60 \\
43 \\
\end{array}$ & $\begin{array}{r}48 \\
248 \\
101 \\
100 \\
\end{array}$ \\
\hline & Total & 51 & 92 & 52 & 302 & 497 \\
\hline
\end{tabular}

Deixando de lado os dados do primeiro ano, utilizaremos os valores dos anos subsequentes para análise. Com os dados colhidos poderemos inquirir :

1) Qual ou quais as melhores variedades introduzidas?

2) Houve algum melhoramento, em consequência da seleção massal anualmente praticada ?

Para responder à primeira questão fazemos um $\chi^{2}$ test (17), (18), (19) e (20) para os dados totais das variedades. $\bigcirc \chi^{2}$ é calculado pela fórmula :

$$
\chi^{2}=\frac{[f(\text { obs. })-f(\text { esp. })]^{2}}{f(\text { esp.) }}
$$

Os valores encontrados figuram no Quadro $\mathrm{X}$ e, ao lado, os valores porcentuais médios dos defeitos de cada variedade, respectivamente. Deve-se acompanhar a leitura dos valores de $\chi^{2}$ com a dos valores porcentuais correspondentes. 


\section{QUADRO X}

\begin{tabular}{|c|c|c|c|c|c|c|c|c|}
\hline \multicolumn{5}{|c|}{ VALORES DE $\chi^{2}$} & \multicolumn{4}{|c|}{ POR CENTO } \\
\hline $\begin{array}{l}\text { N. } \\
\text { Var. }\end{array}$ & $\mathrm{C}$ & $\mathrm{R}$ & M & Perf. & $\% \mathrm{C}$ & $\% \mathrm{R}$ & $\% \mathrm{M}$ & $\%$ Perf. \\
\hline 1 & $8,62^{\circ}$ & $0,16^{\sim}$ & $12,68^{\sim}$ & 3,00 & 11,9 & 11,7 & 21,8 & 54,6 \\
\hline 2 & $2,61 \sim$ & $0,002^{\sim}$ & 15,35 & $5,50^{\sim}$ & 6,5 & 12,2 & 38,3 & 43,0 \\
\hline 3 & $30,22-$ & $23,46^{\sim}$ & $70,11+$ & $3,16^{\sim}$ & 1,9 & 5,3 & 48,3 & 44,6 \\
\hline 4 & 10,43 & $4,29^{\sim}$ & $9,22 \cdot$ & $7,00^{\sim}$ & 12,3 & 9,3 & 36,3 & 42,1 \\
\hline 41 & $0,24^{\sim}$ & 18,38 & $27,03-$ & $4,33^{\circ}$ & 7,8 & 19,5 & 16,0 & 56,8 \\
\hline 42 & 1,89 & $15,79^{\circ}$ & $61,20-$ & $12,17^{\circ}$ & 10,3 & 18,5 & 10,5 & 60,8 \\
\hline
\end{tabular}

NOTA : - Estes sinais significam:

+ acima do normal, estatisticamente;

- dentro do normal, com tendência para mais;

dentro do normal, com tendência para menos;

- abaixo do normal, estatìsticamente.

Para as quatro primeiras variedades $n_{f}=12, \chi^{2}=24,1$; para as duas últimas $n_{\mathfrak{f}}=9 ; \chi^{2}=19,7\left(^{\star}\right)$. (19).

Concluimos: As variedades 1, 2 e 4 são normais para os caracteres examinados. A variedade 3 é ótima para $C$ e ao mesmo tempo péssima para M. Estas conclusões são válidas considerando-se os valores médios de defeitos, para 5 anos de observações, para as duas últimas.

Para responder à segunda pergunta submetemos os dados, obtidos ano a ano, à análise, cujos resultados figuram no quadro seguinte:

(*) Ver tabela 2, de Briezer. 


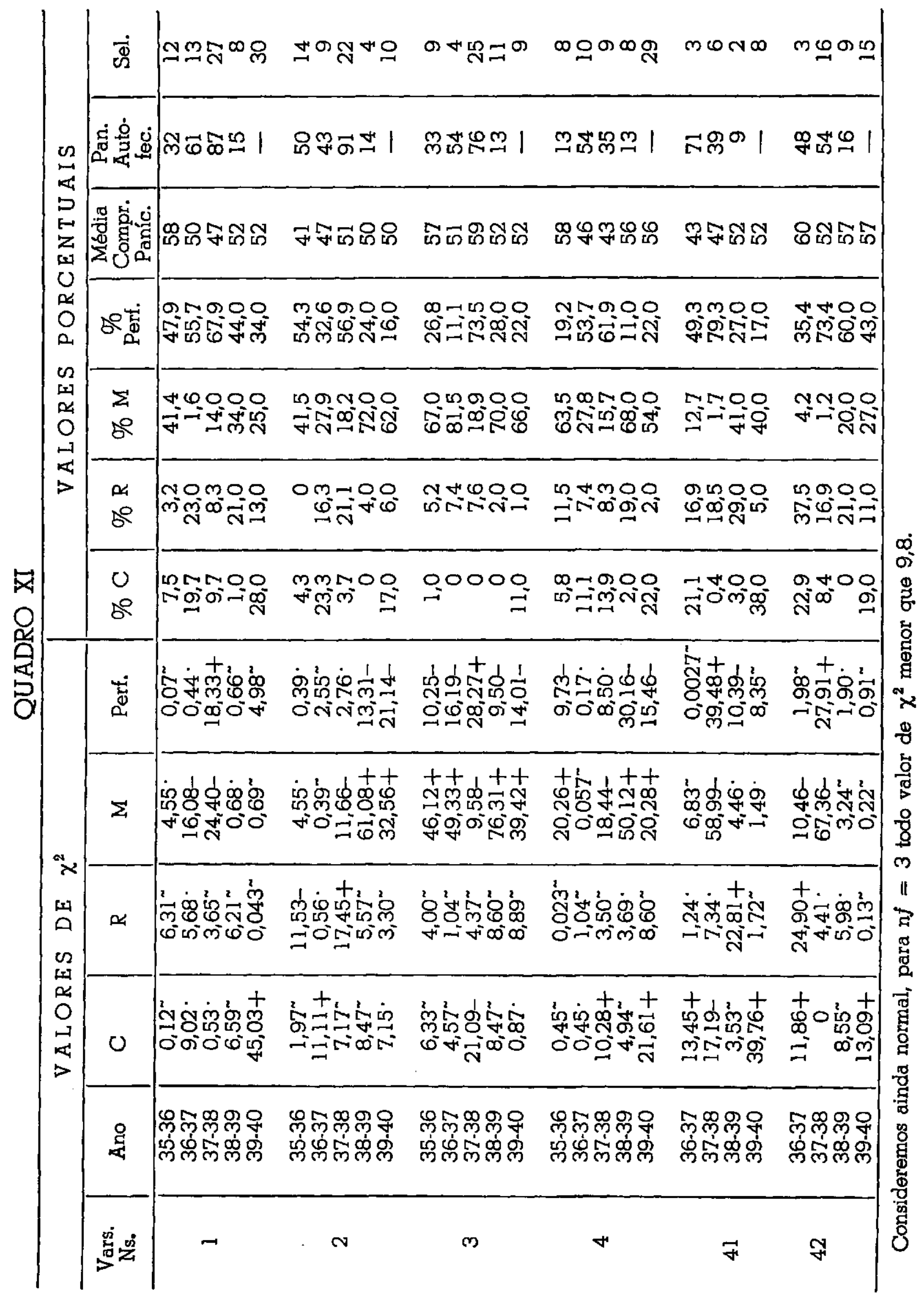


Examinemos os dados do Quadro XI, variedade por variedade.

Variedade 1 - Quanto à variedade 1, caráter $C$, ela esteve normal 4 anos, mas, em 1939-40, subiu acima do normal ; o caráter $\mathrm{R}$ esteve sempre dentro da normalidade; o caráter $\mathrm{M}$ em dois anos, 1936-37 e 1937-38, esteve abaixo do normal. Neste último ano, produziu quantidade de panículas perfeitas acima do normal. Não podemos asseverar que esta variedade tenha melhorado ou não com a seleção massal.

Variedade 2 - Para o caráter C, ela esteve normal, à exceção do ano 1936-37, quando o número de panículas caídas foi excessivo; $R$ esteve inicialmente abaixo do normal, mas, no ano 1937-38, ultrapassou a normalidade; $M$, que era normal, esteve em 1937-38 abaixo do normal, mas nos últimos dois anos de cultura foram muito frequentes panículas que mostravam êste defeito. Isto explica porque o número de panículas perfeitas, nos dois últimos anos, esteve abaixo do normal. É ainda cedo para uma conclusão satisfatória.

Variedade 3 - Para o caráter C esteve sempre normal, exceto no ano 1937-38; $R$ sempre normal, mas com tendência para menos; $\Theta$ é neste caso que se observa que o valor de $\chi^{2}$ vai aumentando progressivamente, a sugerir lento efeito seletivo. $M$, que em todos os anos esteve acima da média, atestando claramente qual o tipo predominante de defeitos nesta variedade, no ano de 1937-38 caíu abaixo do normal. Nesse ano, em consequência justamente dêsse fato, o número de panículas perfeitas passou de péssimo para ótimo!

Variedade $4-A$ quantidade de panículas caídas foi excessiva nos anos $1937-38$ e 1939-40. $R$ esteve sempre normal. $M$ esteve inicial. mente péssimo, depois normal, depois muito bom; nos últimos dois anos voltou a ser péssimo, acima de normal!

Variedade 41 e Variedade 42 - Observamos que C era péssimo, depois passou a ser normal, mas, em 1939-40, voltou a ser péssimo.

O comportamento destas variedades, para o caráter $R$, já não foi idêntico; $M$, parece ter peorado em ambas, no decorrer dos anos.

Examinando êste mesmo quadro sob outro ponto-de-vista, vamos concluir que durante o ano 1939-40 foi sempre alto o número de panículas C. Voltaremos a êste assunto ao comentarmos o efeito da seleção no nosso material da variedade 37, quando procuraremos mostrar, igualmente, que o meio também exerce uma ação específica, mas independente, sôbre o caráter $R$. 
Poderemos dizer, pois, com muita cautela, que a seleção teve um efeito pouco pronunciado sôbre certos caracteres $(R)$ e para certas variedades. Examinemos, a seguir, o resultado da seleção segundo o método das linhas puras, na variedade local.

\section{VI - MELHORAMENTO DA VARIEDADE LOCAL}

\section{a) Generalidades}

Os trabalhos de seleção tiveram início em 1933-34, quando foram autofecundadas, num campo de grande cultura, na Estação Experimental Central de Campinas, cêrca de 100 plantas escolhidas. Estudadas e escolhidas as panículas, foram plantadas, no ano seguinte, 17 linhas ou linhagens correspondentes às 17 panículas selecionadas. $O$ trabalho se processou sempre assim: escolhiam-se na linha as plantas a serem autofecundadas; seguia-se, depois, o exame das panículas para se julgar o valor dessa linhagem. Nas linhas selecionadas, escolhiamos as panículas autofecundadas cujas sementes iam dar origem a novas linhas no ano seguinte, correspondendo cada panícula selecionada a uma nova linha.

\section{b) A técnica de autofecundação}

A técnica de autofecundar, em poucas palavras, foi a seguinte: mandou-se fabricar sacos de papel com $60 \mathrm{~cm}$. de comprimento e 20 $\mathrm{cm}$. de largura ao apontar a panícula na última fôlha, $e$, antes de aparecerem as anteras, era ela protegida com um dêsses sacos, preso ao colmo por um barbante. Antes de se colocar o saco, a última fôlha era eliminada, cortando-se bem rente à lâmina foliar, junto à baínha. É importante cortar nesse ponto para se evitar a "unha" formada pela nervura central da fôlha, que pode rasgar o saco de papel, inutilizando, neste caso, ○ trabalho de autofecundação.

\section{c) 0 julgamento}

O julgamento do material se processava como se segue:

De cada linha colhiamos, em separado, o material trabalhado (autofecundado) do não autofecundado. Tôdas as panículas colhidas eram examinadas registando-se o comprimento (note-se no Quadro XII ○ modo de se obter a distribuição por frequência) e o defeito, se existente, C, R ou M. Damos, a título de exemplo, a cópia dos dados obtidos referentes a uma linhagem (L. 3-5-1-3), em 1937-38. 
Os dados de cada linhagem, assim obtidos, eram condensados, segundo as famílias. Por exemplo, esta linhagem, tendo dado 8 paniculas selecionadas, originou, em 1938-39, 8 linhas, a saber :

\section{QUADROXII}

\begin{tabular}{|c|c|c|c|c|c|}
\hline \multicolumn{3}{|c|}{ COMP PANICULAS (CMS) } & \multicolumn{3}{|c|}{ DEFEITOS } \\
\hline Classes & Frequência & & C & $\mathrm{R}$ & $M$ \\
\hline 40 & & & & & \\
\hline 45 & III & 3 & & $I$ & \\
\hline 50 & IXII IXN II & 12 & II & III & $I$ \\
\hline 55 & $I X I \quad I I I$ & 8 & & II & \\
\hline 60 & IXNI IXN & 10 & $I$ & II & III \\
\hline 65 & IXI IXI I I & 11 & & III & $I$ \\
\hline 70 & $I X I X I$ & 11 & & $I$ & $I$ \\
\hline 75 & $I$ & 1 & $I$ & & \\
\hline & TOTAIS & 56 & 4 & 12 & 6 \\
\hline & $\%$ & & 7 & 21 & 11 \\
\hline Médic & 60 & & & & $=8$ \\
\hline
\end{tabular}




\section{QUADRO XIII}

\begin{tabular}{l|r|r|r|r|r|r|r|r|r|r}
\hline $\begin{array}{c}\text { N. } \\
\text { Linhagens }\end{array}$ & $\begin{array}{c}\text { Comp } \\
\text { Panic. }\end{array}$ & $\mathrm{C}$ & $\% \mathrm{C}$ & $\mathrm{R}$ & $\% \mathrm{R}$ & $\mathrm{M}$ & $\% \mathrm{M}$ & $\begin{array}{c}\mathrm{N}_{\text {Total }}^{\circ} \\
\text { Paníc. }\end{array}$ & $\begin{array}{c}\text { Panic. } \\
\text { Aut. }\end{array}$ & Sel. \\
\hline $3-5-1-3-1$ & 55 & 0 & 0 & 2 & 10,0 & 13 & 65,0 & 20 & 0 & 0 \\
-2 & 58 & 2 & 4,5 & 11 & 25,0 & 20 & 45,5 & 44 & 6 & 0 \\
-3 & 58 & 5 & 9,6 & 14 & 26,9 & 17 & 32,7 & 52 & 11 & 0 \\
-4 & 56 & 1 & 1,9 & 11 & 21,6 & 16 & 31,4 & 51 & 11 & 0 \\
-5 & 57 & 2 & 2,8 & 13 & 18,3 & 28 & 39,4 & 71 & 12 & 0 \\
-6 & 53 & 0 & 0 & 13 & 18,1 & 28 & 38,9 & 72 & 13 & 0 \\
-7 & 54 & 2 & 2,4 & 18 & 21,7 & 30 & 36,1 & 83 & 11 & 0 \\
-8 & 55 & 2 & 2,7 & 11 & 14,7 & 30 & 40,0 & 75 & 11 & 0 \\
\hline Fa. 3-5-1-3- & 14 & 3,0 & 104 & 22,2 & 171 & 36,5 & 468 & \\
Fa. 3-4-2-3- & 46 & 5,9 & 58 & 7,4 & 237 & 30,2 & 783 & \\
\hline
\end{tabular}

Uma outra família deu os valores médios mencionados abaixo do da Fa. 3-5-1-3.

Com estes valores faziamos uma distribuição, por frequência para os três caracteres mencionados, colocando-se cada família segundo sua classe. Podiamos, assim, achar quais as melhores famílias, que eram assinaladas.

Em seguida, faziamos uma distribuição semelhante (Quadro XIV) para as linhagens, utilizando-nos, ao invés do número de filiação, do número de campo, isto é, o número de ordem para aquəle ano. Damos abaixo uma distribuição feita no ano de $1938-39$ para as linhagens, caráter $\mathrm{R}$.

O critério adotado na seleção para cada caráter, é estabelecido individualmente, separando-se aproximadamente metade das linhagens que são selecionadas; a outra metade é não selecionada. Observandose nesta distribuição que a metade das linhagens, em 1937-38, foi alcançada por uma linha que passou entre as classes de 28 e $29 \%$ de R; em 1938-39 passou ela entre 12 e 13\%; em 1939-40, entre 8 e $9 \%$, revelando claramente o progresso da seleção.

Ainda por êste processo, poderemos, grosseiramente, saber quando o material não reagirá mais à seleção, considerando-se que, nessa ocasião, a linha divisória se fixará, com pequenas alterações, em um certo limite. 


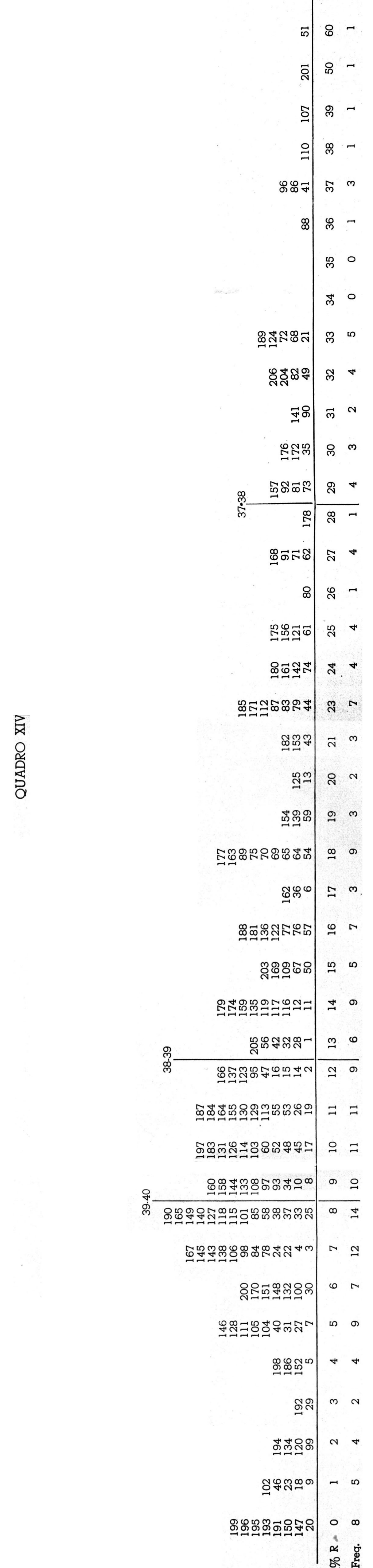


Por outro lado, com êsse processo, não somos nós que estabelecemos os limites para a seleção. Êsse valor é fixado pelo próprio material. Se, num ano, houver um aumento de produção de um defeito para tôdas as linhagens, o limite mudará automàticamente, não havendo o perigo de eliminar algum material bom.

Uma vez estabelecida a seleção para os caracteres considerados, procedemos da seguinte forma:

\begin{tabular}{c|c|c|c}
\hline \multirow{2}{*}{ N. L } & \multicolumn{3}{|c}{ SELECIONADAS } \\
\cline { 2 - 4 } & C & R & M \\
\hline A & sel. & - & - \\
B & sel. & sel. & sel. + \\
C & - & sel. & sel. \\
D & sel. & sel. & - \\
etc. & $\ldots$ & $\ldots$ & $\ldots$ \\
\hline
\end{tabular}

As linhagens selecionadas para os 3 caracteres foram as escolhidas. Iremos ao material autofecundado e tiramos daí o maior número das melhores panículas.

É nesta ocasião que chamamos a atenção para a importância da seleção por famílias. Se escolhemos uma panícula, teremos uma linha no próximo ano. O julgamento desta linhagem pode ser fàcilmente prejudicado por um efeito particular do terreno no lugar em que ela foi acidentalmente plantada. Escolhendo-se o maior número de panículas, podemos julgar o material com maior segurança, porquanto muitas linhagens serão observadas e a média geral calculada (em tôrno da qual as variações muito fortes deverão ser especialmente investigadas) terá muito maior valor comparativo.

Caso haja um número muito pequeno de linhagens para o ano seguinte, voltamos aos dados, e escolhemos linhagens selecionadas sòmente para dois caracteres, em geral, $C$ e $R$, pois $M$ tem menos importância. 


\section{d) Resultados obtidos}

Para que se possa apreciar o progresso do trabalho, incluimos, ano por ano, os resultados obtidos (ver XI. Apenso).

1933-34. Já mencionamos o que foi feito neste ano. Perto de cem plantas foram autofecundadas numa cultura e escolhidas] as 17 melhores panículas (nos. 37-1 a 37-17).

1934-35. Nas 17 linhagens plantadas, uma das quais não germinou, foram autofecundadas mais de 70 plantas e feitas as observações sôbre a qualidade das panículas produzidas em cada linha. Foram selecionadas 32 panículas para prosseguimento dos trabalhos no ano seguinte. Ainda neste ano, fizemos novas seleções numa grande cultura, escolhendo 31 novas panículas que receberam os números 37-18 a 37-48.

De acôrdo com os dados das linhagens, a distribuição dos defeitos observados foi a seguinte: (ver também Quadro XV).

\begin{tabular}{c|c|c|c}
\hline Defeito & Máxima & Mínima & $\begin{array}{c}\text { Média } \\
\text { (aprox.) }\end{array}$ \\
\hline $\mathrm{C}$ & 92 & 9 & 41 \\
$\mathrm{R}$ & 40 & 8 & 18 \\
$\mathrm{M}$ & 60 & 2 & 23 \\
\hline
\end{tabular}

1935-36. Neste ano foram plantadas 63 linhagens; tôdas germinaram bem. Foram efetuadas 876 autofecundações, ou seja cêrca de 14 por linha, selecionando-se, finalmente, 87 panículas autofecundadas.

Notemos a distribuição das porcentagens de defeitos observados:

\begin{tabular}{c|c|c|c}
\hline Defeito & Máxima & Mínima & $\begin{array}{c}\text { Média } \\
\text { (aprox.) }\end{array}$ \\
\hline C & 67 & 0 & 19 \\
R & 52 & 0 & 13 \\
M & 70 & 4 & 25 \\
\hline
\end{tabular}


A julgarmos por estes valores, diremos que houve uma diminuição bastante acentuada do defeito $C$; pequena diminuição de $R$, cuja amplitude de variação foi maior ; aumento de $M$, com aumento de variação.

Foram introduzidas mais 43 linhagens obtidas no material autofecundado das variedades estrangeiras. (nos. 49 a 91).

1936-37. Foram plantadas as 130 linhagens, das quais apenas uma não germinou; efetuaram-se mais de 1.000 autofecundações, selecionando-se 198 panículas.

Os limites de variação e os critérios de seleção (média) adotados foram, para cada defeito, respectivamente:

\begin{tabular}{c|c|c|c}
\hline Defeito & Máxima & Mínima & $\begin{array}{c}\text { Média } \\
\text { (aprox.) }\end{array}$ \\
\hline C & 60 & 0 & 15 \\
R & 58 & 0 & 18 \\
M & 97 & 0 & 15 \\
\hline
\end{tabular}

Para $\mathrm{C}$ e $\mathrm{M}$ houve melhoramento ; $\mathrm{R}$ peorou, pois o limite de seleção adotado foi mais elevado que no ano anterior.

1937-38. As 196 linhagens plantadas germinaram bem; efetuaram-se mais de 2.000 autofecundações, ou cêrca de 10 por linha. Foram escolhidas 206 panículas.

Os extremos de defeitos observados e os limites de seleção foram :

\begin{tabular}{c|c|c|c}
\hline Defeito & Máxima & Mínima & $\begin{array}{c}\text { Média } \\
\text { (aprox.) }\end{array}$ \\
\hline $\mathrm{C}$ & 46 & 0 & 6 \\
$\mathrm{R}$ & 88 & 0 & 28 \\
$\mathrm{M}$ & 55 & 0 & 15 \\
\hline
\end{tabular}

Houve melhoria de $\mathrm{C} ; \mathrm{R}$ peorou consideràvelmente; $\mathrm{M}$ mantevese constante. Em nenhum ano anterior foram observadas tão altas porcen. tagens de $R$. 
1938-39. Foram plantadas 206 linhagens, falhando duas delas; efetuaram-se 1.942 autofecundações e selecionaram-se 268 paní-. culas.

Os extremos de defeitos e os limites de seleção adotados foram :

\begin{tabular}{c|c|c|c}
\hline Defeito & Máxima & Mínima & $\begin{array}{c}\text { Média } \\
\text { (aprox.) }\end{array}$ \\
\hline C & 40 & 0 & 5 \\
R & 60 & 0 & 12 \\
M & 91 & 0 & 34 \\
\hline
\end{tabular}

Houve pequena melhoria de $\mathrm{C}$; considerável melhora para $\mathrm{R} e$ peora para $M$, cuja amplitude de variações foi muito grande.

1939-40. Foram plantadas 268 linhagens, sendo que 3 não germinaram. Autofecundaram-se 1.562 plantas, selecionando-se 114 para o próximo ano. Os extremos observados e os limites de seleção foram :

\begin{tabular}{c|c|c|c}
\hline Defeitos & Máxima & Mínima & Média \\
\hline C & 59 & 0 & 9 \\
R & 41 & 0 & 8 \\
M & 78 & 0 & 40 \\
\hline
\end{tabular}

$O$ limite de seleção para $C$ foi um pouco maior; para $R$ houve melhoramento; peorou para $\mathrm{M}$.

Naturalmente, estas conclusões sôbre o progresso da seleção têm um significado vago e inconsistente, pois o aumento do critério 5 (de 1938-39), por exemplo, para 9 (1939-40), para o caráter $C$, não pode significar, estatìsticamente, uma peora.

Deixamos, pois, para o próximo capítulo um exame mais severo da questão. 


\section{VII - COMO DETERMINAR A EFICACIA DA SELEÇÃo}

Com o objetivo primordial de examinar, sob bases seguras, o efeito progressivo da seleção, tomaremos duas familias, a Fa. 37-3 e Fa. 37-31, que representam, nos últimos anos, a grande maioria do nosso material. Consideremos em primeiro lugar, a Fa. 37.3, com um ano mais de seleção que a outra.

Família 37-3. No Quadro XV damos os valores anuais encontrados para as diferentes progênies desta família, que não foram eliminadas no decorrer da seleção. Calculamos com êsses valores os índices $\chi^{2}$, que foram comparados com o valor normal para $n_{f}=3\left(\chi^{2}=9,8\right)$ e chegamos às seguintes conclusões :

A progênie 37-3-1 produzia, inicialmente, uma certa porcentagem (normal) de panículas perfeitas; no ano seguinte e no subsequente, ela produziu mais panículas perfeitas, e êste mais tem significação estatística, isto é, a progênie realmente melhorou. Em 1938-39 deu um número excessivamente elevado de panículas com $M$, porisso o índice de panículas perfeitas voltou ao seu valor normal; no último ano, em consequência do aumento de panículas caídas, produziu bem menos panículas perfeitas.

A progênie 37-3-3 foi a que peor reagiu à seleção. Em 1935-36 produziu uma quantidade normal de panículas perfeitas. No ano seguinte melhorou, para peorar imediatamente em 1937-38. Nos dois Giltimos anos de seleção retornou à normalidade, mas com tendências para peor.

As progênies 37-3-4 e 37-3-5 portaram-se melhor. Entretanto, em 1939-40 ambas deram uma quantidade realmente muito baixa de paniculas perfeitas.

Examinando-se os dados, sob o ponto-de-vista dos defeitos, somos levados d̀s seguintes conclusões:

No ano de 1939-40 houve um aumento considerável de panículas caídas, mas até esta data observamos que as porcentagens de $\mathrm{C}$ vinham descendo, progressivamente. Como explicar, pois, que apbs cinco anos de constante melhoramento, o material tenha regredido tão bruscamente ? A única interpretação plausível é a de que o ambiente, em 1939-40, tenha sido extremamente favorável à produção do defeito $\mathrm{C}$. 
De modo idêntico interpretamos o fenômeno semelhante observado para o outro caráter $R$, que se apresentou mais frequente no ano de 1937-38. Neste ano, uma única progênie não mostrou intensificação dêsse defeito; foi a progênie 37-3-1. Naturalmente, dotada de um potencial hereditário diferente, reagiu de modo diverso. Por fim, o caráter M apresentou bruscas variações de ano para ano, intensificando-se de um modo geral. Como explicar que, pelo mesmo método de seleção, tenha havido aumento dêsse defeito ? Não discutiremos por ora a questão. Adiante sugerimos uma hipótese para interpretar o fato.

Familia 37-31 Um estudo semelhante foi feito com outra família: Fa. 37-31. (ver Quadro XVI).

Notamos na progênie 31-2, valores elevadíssimos de $\chi^{2}$ para 0 caráter $\mathrm{C}$. Os valores de $\mathrm{R}$ diminuiram de acima do normal, para o normal, indicando efeito da seleção sôbre êste caráter. Quanto a $M$, passamos de valores sub-normais para valores dentro dos limites da normalidade.

Nas outras três progênies, $31-4,31.5$ e $31-6$, observamos que $C$ passa pela sequência : acima de normal, normal, abaixo de normal e normal outra vez. Se nos lembrarmos de que na Fa. 37-3 também houve aumento de panículas $C$ em 39-40, fica esclarecido o maior número de $C$ no último ano. Assim temos também mais uma terceira confirmação da hipótese de que o ambiente tenha tido uma influência particular sôbre a questão do aumento de $\mathrm{C}$ no último ano. Notamos, outrossim, nessas três progênies, o melhoramento com relação a $R$ e peora de $M$.

$\hat{E}$ especialmente sôbre êsse ponto que desejamos fazer mais algumas considerações. Tendo verificado que pelo mesmo método de seleção conseguimos melhorar o material para dois caracteres, aliás, os peores, $C$ e $R$, não conseguindo melhoramento para $M$, procuramos achar uma explicação ao fato. $E$ a hipótese mais razoável que achamos, foi a seguinte: Devido d̀ diminuição da heterosis, pela autofecundação, houve aumento de panículas $M$. Submetemos os dados à mão a exame para ver se tinha havido diminuição do comprimento das panículas, com a idéia de que uma diminuição de seu comprimento pudesse explicar uma possível queda de heterosis. É preciso notar que essa queda de vigor havia de ser pequena por se tratar de sorgo.

Damos a seguir dados do comprimento de panículas para a Fa. 37-3. 


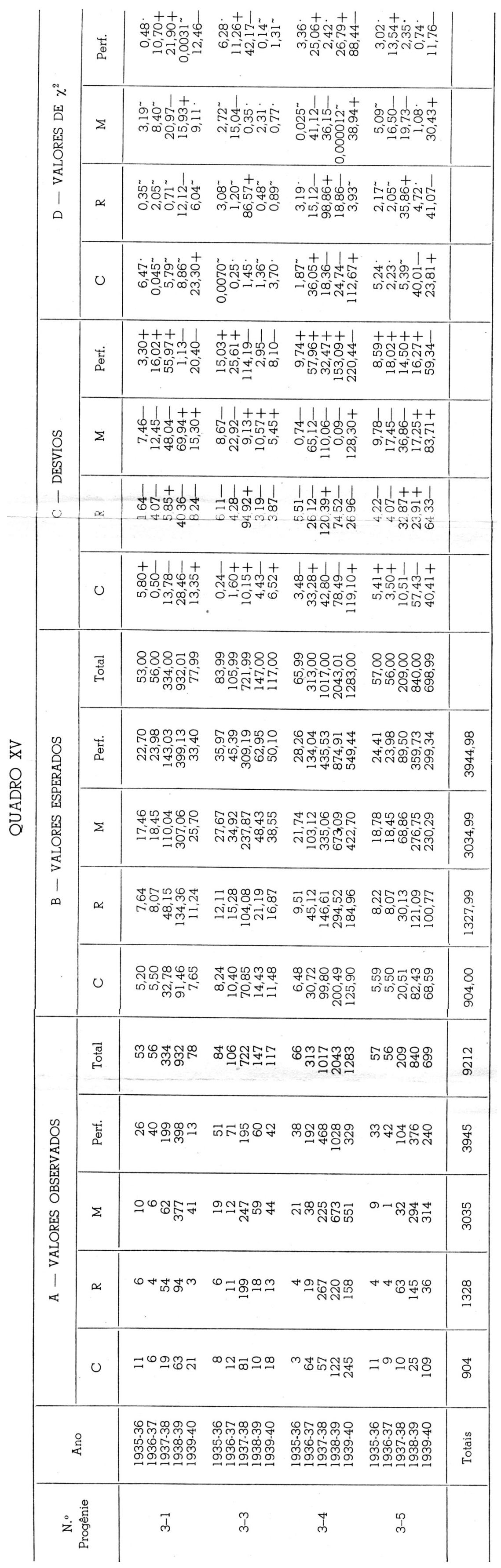




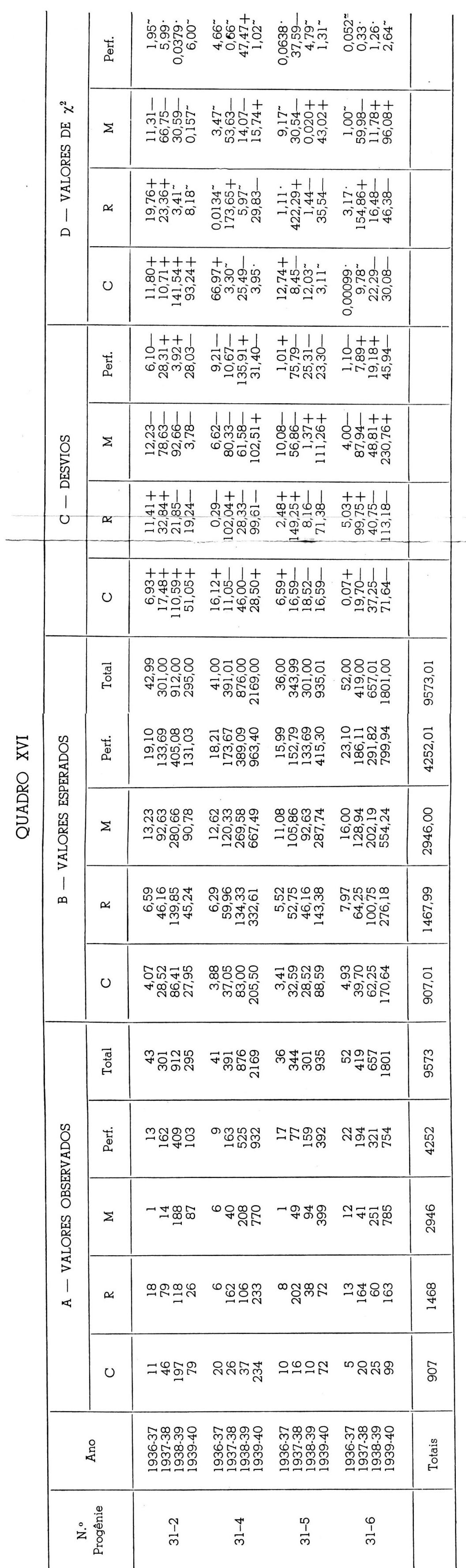




\begin{tabular}{c|r|r|r|r}
\hline Ano & $\begin{array}{c}\text { Compr. } \\
\text { medio }\end{array}$ & s & $\begin{array}{l}\text { Coef. } \\
\text { var. }\end{array}$ & $\begin{array}{c}\text { N.o pan. } \\
\text { obs. }\end{array}$ \\
\hline $1935-36$ & 60,02 & 17,8 & 29,65 & 317 \\
$1936-37$ & 54,41 & 5,1 & 9,37 & 531 \\
$1937-38$ & 57,49 & 7,6 & 13,32 & 2281 \\
$1938-39$ & 54,95 & 6,5 & 11,83 & 3980 \\
$1939-40$ & 54,74 & 7,4 & 13,52 & 2197 \\
\hline
\end{tabular}

Um exame mesmo superficial, dos dados, em face dos valores da média e êrro "standard", mostra que não houve tal diminuição de vigor capaz de explicar o aumento de $\mathrm{M}$.

Uma outra hipótese seria a seguinte : pelo fato da seleção ter sido mais rigorosa para $C$ e $R$, houve um descuido para $M$. Entretanto, é difícil aceitar esta explicação uma vez que, tendo sido feita também seleção para $\mathrm{M}$, devia haver uma diminuição do número de panículas que anualmente aparecem com êste defeito.

\section{VIII - RESULTADOS DOS ENSAIOS COMPARATIVOS E CAMPOS DE AUMENTO}

Tendo observado o melhoramento do material em 1937-38, separamos as linhagens da Fa. 37-3 e fizemos uma mistura de sementes das diferentes linhagens desta família, com as quais plantamos um pequeno lote de aumento. No ano seguinte, com êste material, sementes da variedade primitiva e mistura de sementes de linhagens da mesma família, apenas com mais uma seleção, resolvemos efetuar alguns ensaios comparativos, que passamos a examinar.

1. ${ }^{\circ}$ Ensaio de linhagens (Campinas, 1938-39)

Os tratamentos inclúdos neste ensaio foram:
V. 1
V. 37
L. $37-31$
L. $37-3$
seleção de 1937
L. $37-3$
seleção de 1938 
A V. 1 é a variedade americana Evergreen (Standard) Broom Corn. C. I. N. ${ }^{\circ}$ 583. A V. 37 é a variedade local não selecionada. A L. 37-31 é a mistura de linhagens descendentes da família 37-31. A L. 37-3 também é mistura de linhagens da família 37-3. Desta família 37-3, temos duas seleções : a mistura feita em 1937 e a mistura feita com linhagens em 1938, portanto material que apresentava uma seleção a mais sôbre o anterior.

Outras especificações do ensaio foram :

Plano: Blocos ao acaso

Canteiro: 3 linhas de $10 \mathrm{~m}$. de comprimento (= $76 \mathrm{~m}^{2}$.)

Espaçamento: $1,20 \mathrm{~m}$. entre linhas $\mathrm{x}$ linha corrida

Repetições : 5

Adubação: À base de $300 \mathrm{~kg}$. farinha de ossos por Ha.

Êste ensaio foi plantado em 7 de novembro. Germinou e se portou normalmente. A colheita das panículas foi feita muito tarde, de maneira que os dados referentes à produção de "palha" não têm senão valor comparativo.

Damos a seguir um resumo da análise estatística dos dados obtidos.

QUADRO XVII

Kg. "palha" por canteiro

\begin{tabular}{|c|c|c|c|c|c|}
\hline \multicolumn{2}{|c|}{ V. 1} & V. 37 & L. $37-31$ & L. $37-3(1937)$ & L. 37-3(1938) \\
\hline & 1,73 & 1,80 & 2,27 & 1,73 & 1,49 \\
\hline & 1,02 & 1,45 & 0,68 & 1,70 & 0,92 \\
\hline & 1,18 & 1,06 & 1,49 & 1,16 & 1,41 \\
\hline & 1,31 & 1,18 & 1,57 & 1,70 & 1,04 \\
\hline & 1,46 & 1,45 & 1,22 & 1,18 & 1,28 \\
\hline Total & 6,70 & 6,94 & 7,23 & 7,47 & 6,14 \\
\hline Média & 1,34 & 1,39 & 1,45 & 1,49 & 1,23 \\
\hline
\end{tabular}




\section{QUADRO XVIII}

Análise da variance :

\begin{tabular}{l|c|c|c|c|c|c}
\hline & $\mathrm{Sd}^{2}$ & $\mathrm{n}_{\mathrm{f}}$ & $\mathbf{s}^{2}$ & $\mathbf{s}$ & $\vartheta$ & \\
\hline Total ....... & 2,7538 & 24 & 0,1147 & 0,34 & 1,19 & \\
Tratamentos . & 0,2106 & 4 & 0,0526 & 0,23 & 0,81 & n. s. \\
Repetições ... & 1,2475 & 4 & 0,3119 & 0,56 & 1,96 & \\
Resíduo .... & 1,2957 & 16 & 0,0810 & 0,29 & & \\
\hline
\end{tabular}

${ }^{\mathrm{s}} \overline{\mathrm{v}}=0,14$

n. s. = não significativo

Não houve diferença de produção entre os tratamentos. Como a seleção não visou tal objetivo, isto fica plenamente explicado. Convém notar que o material autofecundado não perdeu sua produtividade.

$\bigcirc$ quadro a seguir resume os outros dados obtidos:

QUADRO XIX

\begin{tabular}{|c|c|c|c|c|c|c|c|c|c|c|}
\hline \multirow{3}{*}{ Tratamento } & \multirow{3}{*}{ 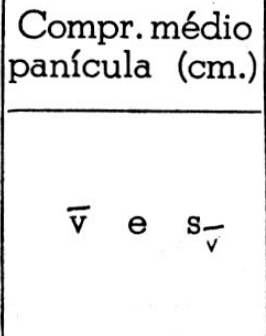 } & \multicolumn{6}{|c|}{ Defeitos } & & & \multirow{3}{*}{$\begin{array}{l}\text { N.o total } \\
\text { paní- } \\
\text { culas } \\
\text { exami- } \\
\text { nadas }\end{array}$} \\
\hline & & \multicolumn{2}{|c|}{ C } & \multicolumn{2}{|c|}{$\mathrm{R}$} & \multicolumn{2}{|c|}{ M } & \multicolumn{2}{|c|}{ Perfeitas } & \\
\hline & & N. ${ }^{\circ}$ & $\%$ & N. ${ }^{\circ}$ & $\%$ & N. ${ }^{\circ}$ & $\%$ & N. ${ }^{\circ}$ & $\%$ & \\
\hline V. 1 & $47,9 \pm 0,5$ & 55 & 9,6 & 53 & 9,3 & 162 & 28,3 & 303 & 52,8 & 573 \\
\hline V. 37 & $52,8 \pm 0,6$ & 23 & 4,2 & 67 & 12,3 & 165 & 30,4 & 288 & 53,1 & 543 \\
\hline L. 37-31 & $59,0 \pm 0,3$ & 25 & 5,6 & 18 & 4,0 & 55 & 12,3 & 349 & 70,1 & 447 \\
\hline L. $37-3$ (1937) & $52,3 \pm 0,7$ & 19 & 2,9 & 22 & 3,4 & 176 & 27,2 & 431 & 66,5 & 648 \\
\hline L. $37-3$ (1938) & $47,4 \pm 0,6$ & 28 & 5,1 & 5 & 0,9 & 141 & 25,8 & 373 & 68,2 & 547 \\
\hline
\end{tabular}

Para podermos julgar a melhoria ou não dêsse material, temos que fazer um $\chi^{2}$ test.

Os valores de $\chi^{2}$ são apresentados no Quadro XX. 


\section{QUADRO XX}

\begin{tabular}{|c|c|c|c|c|}
\hline Tratamento & C & $\mathrm{R}$ & M & Perf. \\
\hline V. 1. & $18,24+$ & $10,22+$ & $1,94^{\circ}$ & $9,72$. \\
\hline V. $37 \ldots$ & $1,44^{\circ}$ & $36,66+$ & $5,45^{\circ}$ & 8,93 \\
\hline L. $37-31$ & $0,020^{\sim}$ & $2,86^{\circ}$ & $29,99-$ & $15,56+$ \\
\hline L. $37-3(1937) \ldots$ & 7,48 & $7,25^{\circ}$ & $0,84^{\circ}$ & $1,10^{\circ}$ \\
\hline L. $37-3(1938) \ldots$ & $0,103^{\sim}$ & 23,48 & 0,041 . & 2,12 . \\
\hline
\end{tabular}

Por estes valores de $\chi^{2}$ podemos concluir que a variedade americana, além de produzir panículas menores, é peor que as linhagens selecionadas da var. 37, para os caracteres $C e R$. Esta var. 37 é peor que as linhagens, apenas com relação ao caráter R. A L. 37-31 apresentou acentuada melhoria, também obtida para a L. 37-3. Julgando por estes dados, ainda poderiamos suspeitar de que um ano de seleção fez diminuir mais o defeito de $\mathrm{R}$.

2. Ensaio de linhagens (Pindorama, 1938-39)

Êste ensaio foi plantado segundo plano idêntico ao de Campinas. Seus resultados passam a ser examinados:

Análise da produção:

\section{QUADRO XXI}

Kg. de palha por canteiro

\begin{tabular}{lr|c|c|c|c}
\hline \multicolumn{2}{c|}{ V. 1 } & V. 37 & L. 37-31 & L. 37-3(1937) & L. 37-3(1938) \\
\hline & 2,12 & 2,61 & 3,73 & 3,01 & 3,35 \\
& 2,79 & 2,90 & 3,03 & 3,70 & 3,32 \\
& 2,63 & 2,52 & 1,59 & 3,48 & 3,67 \\
& 2,77 & 6,06 & 2,88 & 4,40 & 3,23 \\
& 3,36 & 3,83 & 3,91 & 3,91 & 3,95 \\
\hline \multirow{2}{*}{ Total } & 13,67 & 17,92 & 15,14 & 18,50 & 17,52 \\
Média & 2,73 & 3,58 & 3,03 & 3,70 & 3,54 \\
\hline
\end{tabular}




\section{QUADRO XXII}

\section{Análise da variance}

\begin{tabular}{l|r|r|r|r|r|l}
\hline & \multicolumn{1}{|c|}{$\mathrm{Sd}^{2}$} & $\mathrm{n}_{t}$ & $\mathrm{~s}^{2}$ & $\mathrm{~s}$ & $\vartheta$ & \\
\hline Total ...... & 17,6751 & 24 & 0,7365 & 0,858 & 1,12 & \\
Tratamento .. & 3,3822 & 4 & 0,8455 & 0,920 & 1,20 & n. s. \\
Repetições ... & 4,8594 & 4 & 1,2149 & 1,102 & 1,44 & \\
Resíduo .... & 9,4335 & 16 & 0,5896 & 0,768 & & \\
\hline
\end{tabular}

Êste ensaio também não acusou diferenças de produção entre as linhagens.

Os dados colhidos são resumidos a seguir :

\section{QUADRO XXIII}

\begin{tabular}{|c|c|c|c|c|c|c|c|c|c|c|}
\hline \multirow{3}{*}{ Tratamento } & \multirow{3}{*}{$\begin{array}{c}\text { Compr. médio } \\
\text { panícula (cm.) }\end{array}$} & \multicolumn{6}{|c|}{ Defeitos } & \multirow{2}{*}{\multicolumn{2}{|c|}{ Perfeitas }} & \multirow{3}{*}{$\begin{array}{l}\text { N. }{ }^{\circ} \text { de } \\
\text { paní- } \\
\text { culas } \\
\text { exami- } \\
\text { nadas }\end{array}$} \\
\hline & & \multicolumn{2}{|c|}{$\mathrm{C}$} & \multicolumn{2}{|c|}{$\mathrm{R}$} & \multicolumn{2}{|c|}{ M } & & & \\
\hline & & N. ${ }^{\circ}$ & $\%$ & N. ${ }^{\circ}$ & $\%$ & N. ${ }^{\circ}$ & $\%$ & N.o & $\%$ & \\
\hline V. 1 & $50,6 \pm 2,92$ & 421 & 37,5 & 212 & 18,9 & - & - & - & 43,6 & 1.123 \\
\hline V. 37 & $61,3 \pm 1,33$ & 317 & 33,2 & 224 & 23,4 & - & - & - & 43,4 & 956 \\
\hline L. $37-31$ & $62,3 \pm 0,87$ & 200 & 20,7 & 273 & 28,3 & 一 & - & - & 51,0 & 965 \\
\hline L. $37-3$ (1937) & $56,9 \pm 0,94$ & 324 & 27,8 & 273 & 23,4 & - & - & - & 48,8 & 1.165 \\
\hline L. $37-3(1938)$ & $56,7 \pm 0,78$ & 158 & 14,5 & 362 & 33,4 & - & - & 一 & 52,1 & 1.085 \\
\hline
\end{tabular}

Os dados de comprimento de panículas foram colhidos em amostras de 100 panículas para cada variedade, ou melhor, 20 panículas por canteiro.

Fazendo-se um $\chi^{2}$ test dos dados sôbre os defeitos, temos: 


\section{QUADRO XXIV}

\begin{tabular}{l|l|r|r|r|r}
\hline & Tratamento & C & R & Perf. & \\
\hline & V. 1 & $47,63+$ & $18,74-$ & $4,06^{\sim}$ & \\
& V. 37 & $14,31+$ & $1,44^{\sim}$ & $3,84^{\sim}$ & \\
& L. $37-31$ & $13,38-$ & $3,20^{\sim}$ & $2,06 \cdot$ & \\
& L. $37-3(1937)$ & $0,42^{\sim}$ & $1,75^{*}$ & $0,23^{\circ}$ & \\
& L. $37-3(1938)$ & $60,81-$ & $27,20+$ & $4,70^{\circ}$ & \\
\hline
\end{tabular}

Conclusão: Por estes valores vemos, confirmando os dados do primeiro ensaio, que a var. 1 é péssima para C. o valor de R. é contraditório. A V. 37 aparece péssima para $C$ e normal para $R$. A L. 37-31 aparece ótima para C e normal para R. A L. $37-3$ (1938) aparece ótima para $\mathrm{C} e$, contràriamente, péssima para $\mathrm{R}$.

\section{Ensaio de linhagens (Ribeirão Preto, 1938-39)}

Este ensaio foi plantado segundo plano idêntico ao de Campinas e Pindorama, já mencionado. Apenas foi adubado com Renâniafosfatc, ao invés de farinha de ossos.

Os dados de produção foram:

QUADRO XXV

Kg. de palha por canteiro

\begin{tabular}{r|c|c|c|c}
\hline \multicolumn{1}{c|}{ V. I } & V. 37 & L. 37-31 & L. 37-3(1937) & L. 37-3(1938) \\
\hline 3,42 & 2,66 & 2,08 & 3,50 & 3,26 \\
2,30 & 2,15 & 3,00 & 3,40 & 2,85 \\
3,06 & 2,05 & 2,50 & 3,72 & 2,98 \\
2,10 & 1,33 & 2,92 & 2,25 & 2,25 \\
2,56 & 1,22 & 2,35 & 2,44 & 3,20 \\
\hline Total : 13,44 & 9,41 & 12,85 & 15,31 & 14,54 \\
Média : 2,69 & 1,88 & 2,57 & 3,06 & 2,91 \\
\hline
\end{tabular}




\section{QUADRO XXVI}

\section{Análise da variance}

\begin{tabular}{l|r|r|r|r|r|l}
\hline & $\mathrm{Sd}^{2}$ & $\mathrm{n}_{\mathrm{f}}$ & $\mathrm{s}^{2}$ & $\mathrm{~s}$ & $\vartheta$ & \\
\hline Total ...... & 10,2011 & 24 & 0,4250 & 0,652 & 1,37 & \\
Tratamentos . & 4,1578 & 4 & 1,0395 & 1,020 & 2,14 & $\mathrm{s.}$ \\
Repetições ... & 2,3977 & 4 & 0,5994 & 0,774 & 1,62 & \\
Resíduo .... & 3,6455 & 16 & 0,2278 & 0,477 & & \\
\hline
\end{tabular}

$$
\mathrm{s}_{\overline{\mathrm{v}}}=0,239
$$

$\mathbf{s}=$ significativo

Para $\mathrm{P}=0,05 ; \mathrm{n}_{1}=4 ; \mathrm{n}_{2}=160=1,7$

$\mathrm{P}=0,01 ; \mathrm{n}_{1}=4 ; \mathrm{n}_{2}=16 \vartheta=2,1$

Os limites de significância são, respectivamente, para

$P=0,05 \vartheta=0,55$

$P=0,01 \theta=0,80$

Concluimos : a V. 37 mostrou-se inferior às demais quanto à produtividade.

Os outros dados damos a seguir :

\section{QUADRO XXVII}

\begin{tabular}{|c|c|c|c|c|c|c|c|c|c|c|}
\hline \multirow{3}{*}{ Tratamento } & \multirow{3}{*}{$\begin{array}{c}\begin{array}{c}\text { Compr. } \\
\text { médio paní- } \\
\text { culas (cm.) }\end{array} \\
\overline{\mathrm{v}} \otimes \mathrm{s}_{\overline{\mathrm{v}}}\end{array}$} & \multicolumn{6}{|c|}{ Defeitos } & \multirow{2}{*}{\multicolumn{2}{|c|}{ Perfeitas }} & \multirow{3}{*}{$\begin{array}{l}\text { N. }{ }^{\circ} \text { total } \\
\text { de pani- } \\
\text { culas }\end{array}$} \\
\hline & & \multicolumn{2}{|c|}{ C } & \multicolumn{2}{|c|}{$\mathbf{R}$} & \multicolumn{2}{|c|}{$\mathrm{M}$} & & & \\
\hline & & N. ${ }^{\circ}$ & $\%$ & N. ${ }^{\circ}$ & $\%$ & N. ${ }^{\circ}$ & $\%$ & N.。 & $\%$ & \\
\hline V. 1 & $49,7 \pm 0,69$ & 237 & 24,2 & 39 & 4,0 & 409 & 41,6 & 294 & 30,0 & 979 \\
\hline V. 37 & $51,0 \pm 0,94$ & 104 & 18,4 & 44 & 7,8 & 207 & 36,6 & 211 & 37,2 & 566 \\
\hline L. $37-31$ & $58,0 \pm 0,75$ & 81 & 14,8 & 47 & 8,6 & 123 & 22,5 & 296 & 54,1 & 547 \\
\hline L. $37-3$ (1937) & $50,5 \pm 0,96$ & 112 & 13,6 & 99 & 12,0 & 245 & 29,8 & 366 & 44,6 & 822 \\
\hline L. $37-3$ (1938) & $52,4 \pm 0,66$ & 99 & 11,9 & 47 & 5,7 & 283 & 34,1 & 402 & 48,3 & 831 \\
\hline
\end{tabular}


O $\chi^{2}$ test deu os seguintes valores:

\section{QUADRO XXVIII}

\begin{tabular}{|c|c|c|c|c|}
\hline Tratamento & $\mathrm{C}$ & $\mathrm{R}$ & $\mathrm{M}$ & Perfeitas \\
\hline V. $1 \ldots \ldots \ldots \ldots \ldots \ldots$ & $30,91+$ & $15,23-$ & $18,27+$ & $32,90+$ \\
\hline V. 37 & 0,73 & $0,13^{\sim}$ & $1,26^{\circ}$ & $2,88^{\sim}$ \\
\hline L. $37-31$ & $1,42^{\sim}$ & $1,11^{\circ}$ & $20,81-$ & $19,49-$ \\
\hline L. $37-3$ (1937) & $5,22^{\sim}$ & $24,37+$ & $3,94^{\sim}$ & $1,36^{\circ}$ \\
\hline L. $37-3(1938)$ & $12,24-$ & $3,31 \sim$ & $0,0123^{\sim}$ & $8,64^{\circ}$ \\
\hline
\end{tabular}

Conclusão: Neste ensaio, como nos anteriores, a var. 1 aparece péssima para C. De acôrdo com os resultados obtidos em Pindorama e em desacôrdo com os de Campinas, ótima para $R$. Péssima para $M$, sendo que em Campinas havia sido normal. A var. 37 aparece normal para os 3 defeitos. A L. 37-31 aparece normal para $C$ e $R$ e péssima para $M$. A L. 37-3 (1937) aparece normal para $C$, péssima para $R$, e normal para $M$. A L. 37-3 (1938) aparece ótima para $\mathrm{C}$ e normal para $\mathrm{R}$ e $\mathrm{M}$.

Em resumo, podemos optar pela seleção L. 37-31 como a melhor nos 3 ensaios.

\section{4. ${ }^{\circ}$ Ensaio de linhagens (Campinas, 1939-40)}

Justificam estes ensaios, alguns resultados não concordes obtidos nas 3 primeiras experiências.

Plano: Blocos ao acaso com 4 repetições, 3 tratamentos;

Canteiros de 5 linhas de $20 \mathrm{~m}$. de comprimento; espaçadas as linhas a 1,20 m. Adubação empregada à base de 300 quilos de farinha de ossos por Ha.

Os tratamentos incluidos neste ensaio foram:

1) V. 37 variedade local

2) L. $37-3$

3) L. 37-31.

A seguir, passamos ao exame dos dados obtidos: 


\section{QUADRO XXIX}

Kg. palha por canteiro

\begin{tabular}{r|c|c}
\hline V. 37 & L. 37-3 & L. 37-31 \\
\hline 8,8 & 11,4 & 11,7 \\
7,9 & 10,5 & 9,5 \\
8,4 & 12,6 & 10,5 \\
10,5 & 14,4 & 12,1 \\
\hline Total : 35,6 & 48,9 & 43,8 \\
\hline Média: 8,9 & 11,0 & 12,4 \\
\hline
\end{tabular}

QUADRO XXX

Análise da variance:

\begin{tabular}{l|r|r|r|r|r|l}
\hline & $\mathrm{nf}$ & $\mathrm{Sd}^{2}$ & $\mathbf{s}^{2}$ & $\mathbf{s}$ & $\vartheta$ & \\
\hline Total ...... & 11 & 3905 & 355 & 19 & 2,89 & \\
Tratamentos . & 2 & 2251 & 1126 & 34 & 5,18 & $\mathbf{s}$. \\
Repetições .. & 3 & 1402 & 467 & 22 & 3,32 & \\
Resíduo .... & 6 & 252 & 42 & 6 & & \\
\hline
\end{tabular}

$s=3$

Para $P=0,05 ; n_{1}=2 ; n_{2}=60=2,3$

Conclue-se que a variedade V. 36 é inferior às demais, determinando-se as médias e os limites estatísticos da diferença - 1,3 kg.. As linhagens superaram a variedade primitiva em produção. 
Os outros dados do ensaio apresentamos no quadro abaixo:

\section{QUADRO XXXI}

\begin{tabular}{|c|c|c|c|c|c|c|c|c|c|c|}
\hline \multirow{3}{*}{ Tratamento } & \multirow{3}{*}{$\begin{array}{l}\begin{array}{c}\text { Compr. } \\
\text { médio pani- } \\
\text { culas (cm.) }\end{array} \\
\overline{\mathrm{v}} \text { e } \mathrm{s}_{\overline{\mathrm{v}}}\end{array}$} & \multicolumn{6}{|c|}{ Defeitos } & \multirow{2}{*}{\multicolumn{2}{|c|}{ Perfeitas }} & \multirow{3}{*}{$\begin{array}{l}\text { N. }{ }^{\circ} \text { total } \\
\text { paní- } \\
\text { culas } \\
\text { exami- } \\
\text { nadas }\end{array}$} \\
\hline & & \multicolumn{2}{|c|}{ C } & \multicolumn{2}{|c|}{$\mathbf{R}$} & \multicolumn{2}{|c|}{$\mathbf{M}$} & & & \\
\hline & & N. ${ }^{\circ}$ & $\%$ & N.o & $\%$ & N. ${ }^{\circ}$ & $\%$ & N.o & $\%$ & \\
\hline v. 37 & $62 \pm 0,8$ & 315 & 28,5 & 247 & 22,3 & 161 & 14,6 & 382 & 34,6 & 1.105 \\
\hline L. $37-3$ & $57 \pm 1,4$ & 396 & 25,3 & 132 & 8,4 & 392 & 25,0 & 644 & 41,3 & 1.564 \\
\hline L. $37-31$ & $64 \pm 5,9$ & 204 & 15,0 & 177 & 13,4 & 230 & 17,4 & 709 & 54,2 & 1.320 \\
\hline
\end{tabular}

Um exame dos dados à luz do $\chi^{2}$ test dá os seguintes resultados :

\section{QUADRO XXXII}

\begin{tabular}{|c|c|c|c|c|}
\hline Tratamento & $\mathrm{C}$ & $\mathrm{R}$ & M & Perfeitas \\
\hline V. $37 \ldots \ldots \ldots \ldots$ & $14,94+$ & $56,13+$ & $14,41-$ & $20,24-$ \\
\hline L. $37-3$ & 3,87 & $33,93-$ & $23,53+$ & $1,93^{\sim}$ \\
\hline L. $37-31 \ldots \ldots$ & $32,23-$ & $0,27 \simeq$ & $3,27^{\sim}$ & $31,68+$ \\
\hline
\end{tabular}

Conclusão: A var. 37 aparece péssima para $C$ e $R$, ótima para $M$. A 37-3 normal para $C$, ótima para $R$ e péssima para $M$. A 37-31 aparece ótima para $C$, e normal, mas com tendência para menos, de $R$ e $M$; ótima para panículas perfeitas.

\section{Ensaio de linhagens (Ribeirão Preto, 1939-40)}

Plantado segundo plano idêntico ao $4 .^{\circ}$ ensaio de Campinas, as produções obtidas foram: 


\section{QUADRO XXXIII}

\section{Kg. palha por canteiro}

\begin{tabular}{c|r|r}
\hline V. 37 & L. 37-3 & L. 37-31 \\
\hline 8,16 & 6,82 & 8,22 \\
6,69 & 5,76 & 8,36 \\
7,53 & 8,65 & 8,00 \\
9,50 & 8,46 & 8,30 \\
\hline Total : 31,88 & 29,69 & 3288 \\
Média : 7,97 & 7,42 & 8,22 \\
\hline
\end{tabular}

O quadro seguinte ilustra o resultado da análise da variance :

QUADRO XXXIV

Análise da variance

\begin{tabular}{l|r|r|r|r|r|l}
\hline & $\mathrm{Sd}^{2}$ & \multicolumn{1}{c|}{$\mathrm{n}_{\mathrm{f}}$} & \multicolumn{1}{c|}{$\mathrm{s}^{2}$} & $\mathrm{~s}$ & $\vartheta$ & \\
\hline Total ....... & $111.613,9$ & 11 & 10.558 & 102,7 & 1,16 & \\
Tratamentos .. & $13.310,1$ & 2 & 6.655 & 81,6 & 0,92 & n. s. \\
Blocos ..... & $51.184,9$ & 3 & 17.061 & 130,6 & 1,47 & \\
Resíduos ..... & $47.118,9$ & 6 & 7.853 & 88,6 & & \\
\hline
\end{tabular}

$\vartheta$ não foi significativo.

Os outros dados do ensaio damos no seguinte quadro:

QUADRO XXXV

\begin{tabular}{|c|c|c|c|c|c|c|c|c|c|c|}
\hline \multirow{3}{*}{ Tratamento } & \multirow{3}{*}{$\begin{array}{c}\text { Compr. } \\
\text { médio pani- } \\
\text { culas (cms.) } \\
-e \mathrm{~s}_{\vec{v}}\end{array}$} & \multicolumn{6}{|c|}{ Defeitos } & \multirow{2}{*}{\multicolumn{2}{|c|}{ Perfeitas }} & \multirow{3}{*}{$\begin{array}{l}\text { N.o total } \\
\text { de pani- } \\
\text { culas } \\
\text { exami- } \\
\text { nadas }\end{array}$} \\
\hline & & \multicolumn{2}{|c|}{ C } & \multicolumn{2}{|c|}{$R$} & \multicolumn{2}{|c|}{ M } & & & \\
\hline & & N. ${ }^{\circ}$ & $\%$ & N. ${ }^{\circ}$ & $\%$ & N. ${ }^{\circ}$ & $\%$ & N. ${ }^{\circ}$ & $\%$ & \\
\hline v. 37 & $55 \pm 0,10$ & 592 & 43,1 & 128 & $9 ; 3$ & 284 & 20,7 & 369 & 26,9 & 1.373 \\
\hline L. $37-3$ & $52 \pm 0,76$ & 638 & 44,7 & 150 & 10,5 & 318 & 22,3 & 322 & 22,5 & 1.428 \\
\hline L. $37-31$ & $55 \pm 0,70$ & 428 & 30,3 & 180 & 12,7 & 311 & 22,0 & 493 & 34,9 & 1.412 \\
\hline
\end{tabular}


Examinando-se estes dados à luz do $\chi^{2}$ test, obtemos os resultados seguintes :

\section{QUADRO XXXVI}

\begin{tabular}{|c|c|c|c|c|}
\hline Tratamento & $C$ & $\mathrm{R}$ & M & Perfeitas \\
\hline V. 37 & $4,75^{\circ}$ & $3,03^{\sim}$ & $0,62^{\sim}$ & $0,74^{\circ}$ \\
\hline L. $37-3$. & $10,28+$ & $0,18^{-}$ & $0,24^{\circ}$ & 15,68 \\
\hline L. $37.31 \ldots$ & $29,34-$ & $4,57^{\circ}$ & 0,08 & $23,31+$ \\
\hline
\end{tabular}

Conclusão: A var. 37 aparece normal para C, Re M. A L. 37-3 é péssima para $C$, normal para $R$ e M. Finalmente, a L. 37-31 é ótima para $C$ e normal para $R$ e $M$. E a única que é ótima para panículas perfeitas.

\section{6.' Ensaio de linhagens (Pindorama, 1939-40)}

Tratamentos e plano dêste ensaio são os mesmos dos de Ribeirão Preto e Campinas.

Damos a seguir a análise dos dados obtidos:

$$
\text { QUADRO XXXVII }
$$

Kg. palha por canteiro

\begin{tabular}{lc|c|c}
\hline & V. 37 & L. 37-3 & L. 37-31 \\
\hline & 16,98 & 22,30 & 15,80 \\
15,71 & 18,98 & 17,76 \\
& 13,64 & 13,80 & 11,83 \\
& 9,58 & 18,61 & 18,57 \\
\hline Total : & 55,91 & 73,69 & 63,96 \\
\hline Média : & 13,98 & 18,42 & 15,99 \\
\hline
\end{tabular}




\section{QUADRO XXXVIII}

\section{Análise da variance:}

\begin{tabular}{l|r|r|r|r|r|l}
\hline & $\mathrm{Sd}^{2}$ & $\mathrm{n}_{\mathrm{f}}$ & $\mathrm{s}^{2}$ & $\mathrm{~s}$ & $\vartheta$ & \\
\hline Total ....... & 134,98 & 11 & 12,27 & 3,50 & 1,31 & \\
Tratamentos . & 39,63 & 2 & 19,82 & 4,46 & 1,67 & n. s. \\
Repetições ... & 49,02 & 3 & 16,34 & 4,04 & 1,52 & \\
Resíduo .... & 46,32 & 6 & 7,72 & 2,66 & & \\
\hline
\end{tabular}

Não há diferença estatística entre os tratamentos.

\section{QUADRO XXXIX}

\begin{tabular}{|c|c|c|c|c|c|c|c|c|c|c|}
\hline \multirow{3}{*}{ Tratamento } & \multirow{2}{*}{$\begin{array}{l}\text { Compr. } \\
\text { médio paní- } \\
\text { culas }(\mathrm{cm} \text {.) }\end{array}$} & \multicolumn{6}{|c|}{ Defeitos } & \multirow{2}{*}{\multicolumn{2}{|c|}{ Perfeitas }} & \multirow{3}{*}{$\begin{array}{l}\text { N.o total } \\
\text { de paní- } \\
\text { culas } \\
\text { exami- } \\
\text { nadas }\end{array}$} \\
\hline & & \multicolumn{2}{|c|}{ C } & \multicolumn{2}{|c|}{$\mathbf{R}$} & \multicolumn{2}{|c|}{$\mathbf{M}$} & & & \\
\hline & $\begin{array}{lll}\bar{v} & e & s_{\bar{v}}\end{array}$ & N. ${ }^{\circ}$ & $\%$ & N. ${ }^{\circ}$ & $\%$ & N. ${ }^{\circ}$ & $\%$ & N. ${ }^{\circ}$ & $\%$ & \\
\hline v. 37 & $55 \pm 0,8$ & 800 & 55,2 & 194 & 13,4 & 一 & - & 455 & 31,4 & 1.449 \\
\hline L. $37-3$ & $57 \pm 0,8$ & 813 & 45,9 & 148 & 8,4 & - & - & 812 & 35,7 & 1.773 \\
\hline L. $37-31$ & $59 \pm 0,8$ & 604 & 38,2 & 236 & 14,9 & - & - & 741 & 46,9 & 1.583 \\
\hline
\end{tabular}

Calculando-se os valores do $\chi^{2}$ test, temos:

QUADRO XL

\begin{tabular}{c|c|c|c}
\hline Tratamento & C & R & Perfeitas \\
\hline V. 37 & $25,72+$ & $2,21 \cdot$ & $37,53-$ \\
L. $37-3 \ldots$ & $0,035^{\sim}$ & $20,03-$ & $6,75^{-}$ \\
L. $37-31 \ldots$ & $21,68^{-}$ & $11,00+$ & $9,69+$ \\
\hline
\end{tabular}


Conclusão: $\AA$ var. 37 é péssima para $C$ e perfeitas; normal para R. A L. 37-3 é ótima para $C$, ótima para $R$ e normal para panículas perfeitas.

Resumindo-se os resultados dêstes 3 ensaios temos que optar pela L. 37-31, como o melhor material disponível até a presente data. $O$ exame geral das linhagens bem como dados dos campos de aumento conduzem a idêntica conclusão.

\section{***'.}

Em 1938-39 foram feitos campos de aumento das duas linhagens melhores, L. 37-3 e L. 37-31.

Da L. 37-3 foram plantados lotes em Campinas, Ribeirão Preto e Pindorama. Para medição e determinação do número de defeitos, foram tomadas 100 panículas ao acaso.

Damos uma relação dos defeitos encontrados e a comparação entre as linhagens:

\section{QUADRO XLI}

\begin{tabular}{|c|c|c|c|c|c|}
\hline Linhagem & Localidade & $\mathrm{C}$ & $\mathrm{R}$ & Perfeitas & N. ${ }^{\circ}$ total \\
\hline \multirow[t]{3}{*}{$37-3$} & Campinas . . . . . . . & 10 & 14 & 76 & 100 \\
\hline & Ribeirão Preto .. & 8 & 10 & 82 & 100 \\
\hline & Pindorama $\ldots . \ldots \ldots$ & 36 & 95 & 269 & 400 \\
\hline \multirow[t]{2}{*}{$37-31$} & Campinas ......... & 1 & 4 & 95 & 100 \\
\hline & Total : . & 55 & 123 & 522 & 700 \\
\hline
\end{tabular}

Os valores de $\chi^{2}$ são:

QUADRO XLII

\begin{tabular}{|c|c|c|c|c|}
\hline Linhagem & Localidade & $\mathrm{C}$ & $\mathrm{R}$ & Perfeitas \\
\hline \multirow[t]{3}{*}{$37-3$} & Campinas ... & 0,58 & $0,73^{\sim}$ & 0,027 \\
\hline & Ribeirão Preto . . . . . . . . & 0,0025 & $3,26^{-}$ & 0,74 \\
\hline & Pindorama .... & 0,66 & $8,69+$ & $2,88^{\sim}$ \\
\hline $37-31$ & Campinas .. & $6,00^{\sim}$ & $10,48-$ & $5,60^{\circ}$ \\
\hline
\end{tabular}




\section{IX - RESUMO E CONCLUSÖES}

O Estado de São Paulo importa "palha" de sorgo vassoura para a sua indústria, mas pode ser ela produzida, com vantagem, dentro do seu território.

Os principais defeitos da palha, hereditários e que podem ser eliminados até certo ponto pela seleção, são panículas "caídas", "retorcidas" e "raquis grosso".

Diversas variedades estrangeiras introduzidas foram submetidas a exame. Nenhuma superou a variedade local.

Submetida a variedade local à seleção por linhas puras, reagiu favoràvelmente. Suas linhagens, postas em competição com o material primitivo e variedades introduzidas, - que sofreram um processo de aclimatação e seleção massal, - revelaram-se superiores. Sementes destas linhagens selecionadas foram entregues à Seção competente do Instituto Agronômico para o subsequente aumento e distribuição aos lavradores.

Neste trabalho sugere-se a aplicação do conhecido test estatístico denominado $\chi^{2}$ para a comparação de valores e interpretação final dos resultados.

\section{S U M M A R Y}

The State of São Paulo imports straw of Sorghum for its broom industry when this material could be satisfactorily produced in the State.

The principal hereditary defects of the broom-corn which could be eliminated to a certain extent by selection are goose neck panicles, twisted panicles and stemmy panicles.

Various introduced varieties were subjected to comparative field tests along with a local variety which came years ago from Argentine. This variety superseeded all the others when subjected to selection. All the lineages derived from it when tested with the primitive and recently introduced stock revealed far superior in many respects. Seeds of these lineages were furned over to the competent Department of the Instituto Agronomico to be increased in quantity and then distributed to farmers.

In this work the $\chi^{2}$ test is recommend, for analysis and interpretation of the results.

\section{IITERATURA CITADA}

1. Krug, C. A. Relatório da Secção de Genética 1933-1934 : Inst. Agronômico do Est. S. Paulo. Não publicado.

2. Krug, C. A. Sorgo vassoura. Relatório do Inst. Agronômico do Est. S. Paulo. 1934-1935: 32-35. 1935.

3. Anônimo. Estatística do comércio do Pôrto de Santos com os países estrangeiros. Diretoria de Estat., Ind. e Com. da Secret. de Agr. do Est. S. Paulo. 23:20. 1926 .

4. Idem, idem $24: 21$. 1927.

5. „ " 26:21. 1929 .

6. " " $28: 21.1931$.

7. „ " $30: 20.1933$.

8. „ " $31: 20.1934$.

9. ¿ $\quad$ " $32: 22.1935$.

10. " " $33: 35.1936$.

11. ., ", 35:37. 1938. 
12. “ " 36:14. 1939.

13. " " $37: 15.1940$.

14. Anônimo. Estatística industrial do Estado de S. Paulo. Diretoria de Estat. Ind. e Com. 1937 : 64-65. 1939.

15. Cuba, P. Sorgo vassoura. Bol. Inst. Agr. do Est. S. Paulo 4:1-9. 1937.

16. Park, J. B. Selection in broom corn. Jour. of Heredity 14:213-219. 1923.

17. Snedecor, G. W. Em Statistical methods. Pgs. XIII+41. Collegiate Press. Inc. Ames. Iowa. 1937.

18. Goulden, C. H. Em Methods of statistical analysis. Pgs. ,VIII+277. John Wiley \& Sons. Inc. N. York, 1939.

19. Brieger, F. G. - Em Tábuas e fórmulas para estatística. Cia. Melhoramentos de S. Paulo, pgs. 1-46. 1937.

20. Brieger, F. G. Sôbre o " $\chi^{2}$ test". Jour, de Agronomia 3:103-110. 1940. 


\section{4-35}

\begin{tabular}{c|c|c|c|c|c|c|c}
\hline $\begin{array}{c}\text { N. } \\
\text { Linhagens }\end{array}$ & $\begin{array}{c}\text { Comp. } \\
\text { pan. }\end{array}$ & $\% \mathrm{C}$ & $\% \mathrm{R}$ & $\% \mathrm{M}$ & $\%$ Perf. & $\begin{array}{c}\text { N. }{ }^{\circ} \text { pan. } \\
\text { autof. }\end{array}$ & Sel. \\
\hline $37-1$ & 57 & 41 & 11 & 23 & 25 & 8 & 3 \\
2 & 60 & 33 & 14 & 25 & 28 & 1. & 1 \\
3 & 60 & 22 & 8 & 15 & 55 & 10 & 5 \\
4 & 56 & 22 & 15 & 14 & 49 & 3 & 1 \\
5 & 60 & 9 & 18 & 34 & 39 & 1 & 1 \\
6 & 61 & 20 & 18 & 60 & 2 & 6 & 2 \\
7 & 58 & 20 & 15 & 23 & 42 & 4 & 2 \\
8 & 60 & 23 & 18 & 13 & 46 & 11 & 4 \\
9 & 77 & 92 & 13 & 2 & - & 3 & 1 \\
10 & 70 & 83 & 43 & 7 & - & 5 & 2 \\
11 & 63 & 74 & 41 & 17 & - & 6 & 2 \\
12 & 60 & 53 & 42 & 26 & - & 5 & 2 \\
13 & 60 & 30 & 10 & 10 & 50 & 6 & 1 \\
14 & 55 & 66 & 46 & 15 & - & 6 & 3 \\
15 & \multicolumn{2}{|c|}{ Não germinou } & & & & \\
16 & 60 & 66 & 33 & 31 & - & & 1 \\
17 & 54 & 45 & 45 & 39 & - & & \\
\hline
\end{tabular}

\section{5-36}

\begin{tabular}{|c|c|c|c|c|c|c|c|c|c|c|c|c|}
\hline $\begin{array}{c}\text { N.o } \\
\text { Linhagens }\end{array}$ & $\begin{array}{c}\text { Comp. } \\
\text { pan. }\end{array}$ & $\begin{array}{l}\text { N. }{ }^{\circ} \\
\text { pan. }\end{array}$ & $\mathrm{C}$ & $\stackrel{\%}{\mathrm{C}}$ & $\mathrm{R}$ & $\begin{array}{l}\% \\
\mathrm{R}\end{array}$ & $\mathrm{M}$ & $\begin{array}{l}\% \\
M\end{array}$ & Perf. & $\begin{array}{c}\% \\
\text { Perf. }\end{array}$ & autof. & Sel. \\
\hline $37-1 \cdot 1$ & 62 & 56 & 13 & 23 & 26 & 46 & 19 & 34 & 0 & - & 4 & 0 \\
\hline-2 & 66 & 28 & 6 & 21 & 10 & 36 & 9 & 32 & 3 & 11 & 3 & 0 \\
\hline-3 & 61 & 42 & 8 & 19 & 11 & 26 & 20 & 48 & 3 & 7 & 5 & 0 \\
\hline 2.1 & 65 & 68 & 17 & 25 & 7 & 10 & 27 & 40 & 17 & 25 & 10 & 0 \\
\hline 3.1 & 61 & 53 & 11 & 21 & 6 & 11 & 10 & 19 & 26 & 49 & 9 & 1 \\
\hline-2 & 64 & 57 & 13 & 23 & 11 & 19 & 4 & 7 & 29 & 51 & 8 & 0 \\
\hline-3 & 64 & 84 & 8 & 10 & 6 & 7 & 19 & 23 & 51 & 60 & 19 & 2 \\
\hline-4 & 62 & 66 & 3 & 5 & 4 & 6 & 21 & 32 & 38 & 57 & 19 & 6 \\
\hline .5 & 62 & 57 & 11 & 19 & 4 & 7 & 9 & 16 & 33 & 58 & 7 & l \\
\hline 4-1 & 63 & 80 & 8 & 10 & 8 & 10 & 21 & 26 & 43 & 54 & 18 & 4 \\
\hline 5-1 & 61 & 54 & 5 & 9 & 13 & 24 & 15 & 28 & 21 & 39 & 18 & 0 \\
\hline $6-1$ & 67 & 56 & 2 & 4 & 6 & 11 & 28 & 50 & 20 & 35 & 18 & 2 \\
\hline-2 & 65 & 80 & 13 & 16 & 4 & 5 & 26 & 33 & 37 & 46 & 18 & 2 \\
\hline 7.1 & 72 & 77 & 6 & 8 & 30 & 39 & 28 & 36 & 13 & 17 & 26 & l \\
\hline .2 & 69 & 65 & 6 & 9 & 3 & 5 & 17 & 26 & 39 & 60 & 17 & 2 \\
\hline $8-1$ & 67 & 75 & 4 & 5 & 10 & 13 & 18 & 24 & 43 & 58 & 19 & 3 \\
\hline 2 & 69 & 68 & 20 & 29 & 18 & 26 & 14 & 21 & 16 & 24 & 31 & 0 \\
\hline-3 & 67 & 78 & 15 & 19 & 7 & 9 & 16 & 21 & 40 & 51 & 15 & 0 \\
\hline-4 & 76 & 58 & 6 & 10 & 3 & 5 & 18 & 31 & 31 & 54 & 25 & 4 \\
\hline $9-1$ & 67 & 54 & 13 & 24 & 17 & 31 & 25 & 46 & 0 & - & 25 & 1 \\
\hline $10-1$ & 82 & 46 & 26 & 57 & 10 & 22 & 4 & 9 & 6 & 13 & 15 & 0 \\
\hline $11-1$ & 71 & 53 & 23 & 43 & 12 & 23 & 10 & 19 & 8 & 15 & 6 & 0 \\
\hline-2 & 67 & 63 & 39 & 62 & 18 & 29 & 15 & 24 & 0 & - & 8 & 0 \\
\hline $12-1$ & 69 & 45 & 30 & 67 & 8 & 18 & 7 & 16 & 0 & - & 7 & 0 \\
\hline .2 & 63 & 40 & 14 & 35 & 11 & 28 & 8 & 20 & 7 & 17 & 5 & 0 \\
\hline
\end{tabular}




\begin{tabular}{|c|c|c|c|c|c|c|c|c|c|c|c|c|}
\hline $\begin{array}{c}\text { N. }{ }^{\circ} \\
\text { Linhagens }\end{array}$ & $\begin{array}{c}\text { Comp. } \\
\text { pan. }\end{array}$ & $\begin{array}{l}\text { N. } \\
\text { pan. }\end{array}$ & $\mathrm{C}$ & $\stackrel{\%}{\mathrm{C}}$ & $\mathrm{R}$ & $\begin{array}{l}\% \\
\mathrm{R}\end{array}$ & $\mathbf{M}$ & $\begin{array}{l}\% \\
M\end{array}$ & Perf. & $\begin{array}{c}\% \\
\text { Perf. }\end{array}$ & $\begin{array}{l}\text { N.o } \\
\text { autof. }\end{array}$ & Sel. \\
\hline $\begin{array}{r}13-1 \\
-2 \\
14-1 \\
16-1 \\
-2 \\
-3 \\
17-1 \\
18 \\
19 \\
20 \\
21 \\
22 \\
23 \\
24 \\
25 \\
26 \\
27 \\
28 \\
29 \\
30 \\
31 \\
32 \\
33 \\
34 \\
35 \\
36 \\
37 \\
38 \\
39 \\
40 \\
41 \\
42 \\
43 \\
44 \\
45 \\
46 \\
47 \\
48\end{array}$ & $\begin{array}{l}76 \\
63 \\
63 \\
66 \\
80 \\
77 \\
78 \\
68 \\
63 \\
68 \\
67 \\
64 \\
68 \\
66 \\
61 \\
57 \\
61 \\
68 \\
63 \\
61 \\
64 \\
55 \\
75 \\
48 \\
64 \\
53 \\
63 \\
63 \\
63 \\
63 \\
60 \\
64 \\
64 \\
65 \\
60 \\
68 \\
63 \\
60\end{array}$ & $\begin{array}{r}88 \\
84 \\
102 \\
70 \\
63 \\
62 \\
65 \\
109 \\
74 \\
83 \\
95 \\
99 \\
83 \\
70 \\
62 \\
82 \\
83 \\
79 \\
92 \\
93 \\
107 \\
65 \\
72 \\
111 \\
96 \\
71 \\
57 \\
75 \\
92 \\
98 \\
68 \\
88 \\
87 \\
62 \\
63 \\
25 \\
60 \\
80\end{array}$ & $\begin{array}{r}45 \\
36 \\
21 \\
45 \\
38 \\
39 \\
30 \\
36 \\
12 \\
19 \\
40 \\
6 \\
19 \\
20 \\
5 \\
8 \\
3 \\
15 \\
2 \\
7 \\
7 \\
5 \\
39 \\
7 \\
23 \\
7 \\
13 \\
8 \\
8 \\
9 \\
12 \\
16 \\
24 \\
0 \\
4 \\
6 \\
6 \\
3\end{array}$ & $\begin{array}{r}51 \\
43 \\
21 \\
64 \\
60 \\
63 \\
46 \\
33 \\
16 \\
23 \\
42 \\
6 \\
23 \\
29 \\
8 \\
10 \\
4 \\
19 \\
2 \\
8 \\
7 \\
8 \\
54 \\
6 \\
24 \\
10 \\
23 \\
11 \\
9 \\
9 \\
18 \\
18 \\
28 \\
0 \\
6 \\
24 \\
10 \\
4\end{array}$ & $\begin{array}{r}15 \\
11 \\
15 \\
6 \\
7 \\
10 \\
7 \\
12 \\
5 \\
1 \\
13 \\
17 \\
11 \\
7 \\
10 \\
4 \\
17 \\
4 \\
3 \\
8 \\
9 \\
11 \\
4 \\
14 \\
18 \\
1 \\
2 \\
18 \\
10 \\
9 \\
9 \\
4 \\
17 \\
16 \\
9 \\
13 \\
11 \\
2\end{array}$ & $\begin{array}{r}17 \\
13 \\
15 \\
9 \\
11 \\
16 \\
11 \\
11 \\
7 \\
1 \\
14 \\
17 \\
13 \\
10 \\
16 \\
5 \\
20 \\
5 \\
3 \\
9 \\
8 \\
17 \\
6 \\
13 \\
19 \\
1 \\
4 \\
24 \\
11 \\
9 \\
13 \\
5 \\
20 \\
26 \\
14 \\
52 \\
18 \\
3\end{array}$ & $\begin{array}{r}15 \\
16 \\
21 \\
13 \\
8 \\
9 \\
10 \\
21 \\
36 \\
20 \\
9 \\
5 \\
12 \\
22 \\
10 \\
26 \\
26 \\
28 \\
35 \\
19 \\
33 \\
34 \\
19 \\
4 \\
24 \\
38 \\
40 \\
10 \\
56 \\
17 \\
23 \\
26 \\
25 \\
5 \\
17 \\
9 \\
11 \\
51\end{array}$ & $\begin{array}{r}17 \\
19 \\
21 \\
19 \\
13 \\
15 \\
15 \\
19 \\
49 \\
24 \\
9 \\
5 \\
14 \\
31 \\
16 \\
32 \\
31 \\
35 \\
38 \\
20 \\
31 \\
52 \\
26 \\
4 \\
25 \\
54 \\
70 \\
13 \\
61 \\
17 \\
34 \\
30 \\
29 \\
8 \\
27 \\
36 \\
18 \\
64\end{array}$ & $\begin{array}{r}13 \\
21 \\
45 \\
6 \\
10 \\
4 \\
18 \\
40 \\
21 \\
43 \\
33 \\
71 \\
41 \\
21 \\
37 \\
44 \\
37 \\
32 \\
52 \\
59 \\
58 \\
15 \\
10 \\
86 \\
31 \\
25 \\
2 \\
39 \\
18 \\
63 \\
24 \\
42 \\
21 \\
41 \\
33 \\
0 \\
32 \\
24\end{array}$ & $\begin{array}{r}15 \\
25 \\
43 \\
8 \\
16 \\
6 \\
28 \\
37 \\
28 \\
52 \\
35 \\
72 \\
48 \\
30 \\
60 \\
23 \\
43 \\
41 \\
57 \\
63 \\
54 \\
23 \\
14 \\
77 \\
32 \\
35 \\
3 \\
52 \\
19 \\
65 \\
35 \\
47 \\
23 \\
66 \\
53 \\
54 \\
29\end{array}$ & $\begin{array}{r}23 \\
17 \\
20 \\
14 \\
23 \\
19 \\
9 \\
11 \\
15 \\
21 \\
16 \\
28 \\
19 \\
16 \\
8 \\
17 \\
8 \\
9 \\
24 \\
9 \\
28 \\
9 \\
10 \\
11 \\
14 \\
6 \\
25 \\
12 \\
16 \\
6 \\
7 \\
19 \\
15 \\
8 \\
4 \\
2 \\
9 \\
4\end{array}$ & $\begin{array}{r}0 \\
1 \\
0 \\
0 \\
0 \\
1 \\
0 \\
0 \\
1 \\
1 \\
1 \\
4 \\
4 \\
1 \\
5 \\
3 \\
2 \\
1 \\
10 \\
4 \\
7 \\
0 \\
0 \\
0 \\
0 \\
0 \\
1 \\
1 \\
1 \\
0 \\
1 \\
5 \\
0 \\
0 \\
1 \\
0\end{array}$ \\
\hline & & & & & & & & & & & 876 & 87 \\
\hline
\end{tabular}

1936-37

\begin{tabular}{r|r|r|r|r|r|r|r|r|r|r|r|r}
\hline $\begin{array}{c}\text { N.o } \\
\text { Linhagens }\end{array}$ & $\begin{array}{c}\text { Comp. } \\
\text { pan. }\end{array}$ & $\begin{array}{c}\text { N.o } \\
\text { pan. }\end{array}$ & $\mathrm{C}$ & $\begin{array}{c}\% \\
\mathrm{C}\end{array}$ & $\mathrm{R}$ & $\begin{array}{c}\% \\
\mathrm{R}\end{array}$ & $\mathrm{M}$ & $\begin{array}{r}\% \\
\mathrm{M}\end{array}$ & Perf. & $\begin{array}{c}\% \\
\text { Perf. }\end{array}$ & $\begin{array}{c}\text { N.o } \\
\text { autof. }\end{array}$ & Sel. \\
\hline $37-3-1-1$ & 55 & 56 & 6 & 11 & 4 & 7 & 6 & 11 & 40 & 71 & 7 & 4 \\
$3-3-1$ & 54 & 69 & 10 & 14 & 9 & 13 & 6 & 9 & 44 & 64 & 10 & 9 \\
-2 & 52 & 37 & 2 & 5 & 2 & 5 & 6 & 16 & 27 & 74 & 11 & 5 \\
$3-4-1$ & 55 & 59 & 13 & 22 & 2 & 3 & 4 & 7 & 40 & 68 & 8 & 7 \\
-2 & 51 & 40 & 4 & 10 & 4 & 10 & 4 & 10 & 28 & 70 & 3 & 3
\end{tabular}


(Continuação)

\begin{tabular}{|c|c|c|c|c|c|c|c|c|c|c|c|c|}
\hline $\begin{array}{c}\text { N.o } \\
\text { Linhagens }\end{array}$ & $\begin{array}{c}\text { Comp. } \\
\text { pan. }\end{array}$ & $\begin{array}{l}\text { N. }{ }^{\circ} \\
\text { pan. }\end{array}$ & $C$ & $\%$ & $\mathbf{R}$ & $\begin{array}{l}\% \\
\mathrm{R}\end{array}$ & $\mathrm{M}$ & $\begin{array}{l}\% \\
M\end{array}$ & Perf. & $\begin{array}{c}\% \\
\text { Perf. }\end{array}$ & $\begin{array}{l}\text { N.o } \\
\text { autof. }\end{array}$ & Sel. \\
\hline-3 & 55 & 46 & 7 & 15 & 3 & 7 & 5 & 11 & 31 & 67 & 5 & \\
\hline-4 & 56 & 50 & 16 & 32 & 2 & 4 & 2 & 4 & 30 & 60 & 7 & $\begin{array}{l}4 \\
5\end{array}$ \\
\hline-5 & 55 & 64 & 18 & 28 & 5 & 8 & 11 & 17 & 30 & 47 & 3 & 0 \\
\hline-6 & 54 & 54 & 6 & 11 & 3 & 6 & 12 & 22 & 33 & 61 & 4 & 1 \\
\hline 3-5-1 & 56 & 56 & 9 & 16 & 4 & 7 & 1 & 2 & 42 & 75 & 7 & 6 \\
\hline $37-4-1-1$ & 57 & 38 & 1 & 3 & $\hat{1}$ & 3 & 5 & 13 & 31 & 81 & 2 & 2 \\
\hline-2 & 61 & 48 & 10 & 21 & 12 & 25 & 0 & 0 & 26 & 54 & 6 & 4 \\
\hline-3 & 59 & 48 & 5 & 10 & 15 & 31 & 5 & 10 & 23 & 49 & 8 & 0 \\
\hline-4 & 61 & 55 & 0 & 0 & 27 & 49 & 5 & 9 & 23 & 42 & 5 & 0 \\
\hline $37-6-1-1$ & 59 & 43 & 1 & 2 & 4 & 9 & 20 & 47 & 18 & 42 & 8 & 0 \\
\hline 6-1-2 & 60 & 26 & 0 & 0 & 7 & 27 & 8 & 31 & 11 & 42 & 2 & 1 \\
\hline $2-1$ & 59 & 37 & 8 & 22 & 15 & 41 & 3 & 8 & 11 & 29 & 6 & 0 \\
\hline $2-2$ & 61 & 50 & 9 & 18 & 17 & 34 & 7 & 14 & 17 & 34 & 4 & 0 \\
\hline $37-7-1-1$ & 49 & 49 & 6 & 12 & 26 & 53 & 13 & 27 & 4 & 8 & 4 & 0 \\
\hline 2.1 & 48 & 48 & 6 & 12 & 8 & 17 & 10 & 21 & 24 & 50 & 8 & 6 \\
\hline $37-7-2-2$ & 61 & 39 & 19 & 49 & 9 & 23 & 1 & 3 & 10 & 25 & 5 & 0 \\
\hline 8-1-1 & 60 & 59 & 21 & 36 & 11 & 19 & 2 & 3 & 25 & 42 & 9 & 0 \\
\hline 2 & 57 & 54 & 5 & 9 & 15 & 28 & 0 & 0 & 34 & 63 & 9 & 4 \\
\hline 3 & 59 & 56 & 9 & 16 & 24 & 43 & 5 & 9 & 18 & 32 & 3 & 0 \\
\hline $8-4-1$ & 61 & 66 & 19 & 29 & 16 & 24 & 17 & 26 & 14 & 21 & 12 & 0 \\
\hline-2 & 65 & 50 & 21 & 42 & 6 & 12 & 5 & 10 & 18 & 36 & 4 & 0 \\
\hline-3 & 65 & 47 & 9 & 19 & 8 & 17 & 6 & 13 & 24 & 51 & 11 & 4 \\
\hline-4 & 64 & 50 & 12 & 24 & 16 & 32 & 3 & 6 & 19 & 38 & 3 & 0 \\
\hline 9-1 & 59 & 41 & 3 & 7 & 12 & 29 & 7 & 17 & 19 & 47 & 6 & 0 \\
\hline $13-2-1$ & 59 & 26 & 3 & 12 & 2 & 8 & 2 & 8 & 19 & 72 & 6 & 1 \\
\hline $16-3-1$ & 61 & 16 & 5 & 31 & 5 & 31 & 4 & 25 & 2 & 13 & 3 & 0 \\
\hline $19-1$ & 54 & 49 & 6 & 12 & 12 & 24 & 13 & 27 & 18 & 37 & 5 & 0 \\
\hline $20-1$ & 60 & 59 & 10 & 17 & 9 & 15 & 4 & 7 & 36 & 61 & 2 & 2 \\
\hline $21-2$ & 60 & 60 & 29 & 48 & 32 & 53 & 3 & 5 & 0 & - & $\overline{5}$ & 0 \\
\hline $22-1$ & 59 & 35 & 1 & 3 & 9 & 26 & 6 & 17 & 19 & 54 & 5 & 1 \\
\hline-2 & 60 & 50 & 3 & 6 & 15 & 30 & 4 & 8 & 28 & 56 & 10 & 8 \\
\hline-3 & 55 & 39 & 7 & 18 & 5 & 13 & 13 & 33 & 14 & 36 & 4 & 0 \\
\hline-4 & 58 & 36 & 9 & 25 & 18 & 50 & 1 & 3 & 8 & 22 & 5 & 0 \\
\hline $23-1$ & 54 & 51 & 18 & 35 & 5 & 10 & 3 & 6 & 25 & 59 & 2 & 1 \\
\hline-2 & 57 & 54 & 10 & 19 & 10 & 19 & 10 & 19 & 24 & 43 & 4 & 2 \\
\hline-3 & 53 & 65 & 17 & 26 & 13 & 20 & 0 & 0 & 35 & 54 & 4 & 0 \\
\hline-4 & 54 & 55 & 16 & 29 & 7 & 13 & 0 & 0 & 32 & 58 & 12 & 6 \\
\hline $24-1$ & 59 & 40 & 18 & 45 & 10 & 25 & 2 & 5 & 10 & 25 & 5 & 0 \\
\hline $25-1$ & 58 & 45 & 3 & 7 & 10 & 22 & 3 & 7 & 29 & 64 & 4 & 4 \\
\hline-2 & 57 & 57 & 4 & 7 & 13 & 23 & 2 & 4 & 38 & 66 & 3 & 2 \\
\hline-3 & 57 & 34 & 2 & 6 & 14 & 41 & 2 & 6 & 16 & 47 & 5 & \\
\hline-4 & 57 & 57 & 0 & 0 & 20 & 35 & 3 & 5 & 34 & 60 & 7 & 6 \\
\hline-5 & 58 & 35 & 1 & 3 & 10 & 29 & 5 & 14 & 19 & 54 & 6 & 0 \\
\hline $26 \cdot 1$ & 54 & 66 & 7 & 11 & 19 & 29 & 3 & 5 & 37 & 55 & 1 & 1 \\
\hline-2 & 50 & 47 & 6 & 13 & 10 & 21 & 8 & 17 & 23 & 49 & 7 & 4 \\
\hline-3 & 54 & 63 & 0 & 0 & 28 & 44 & 6 & 10 & 29 & 46 & 6 & 0 \\
\hline $27-1$ & 57 & 43 & 3 & 7 & 14 & 33 & 15 & 35 & 11 & 25 & 6 & 0 \\
\hline-2 & 62 & 26 & 1 & 4 & 8 & 31 & 3 & 12 & 14 & 53 & 7 & 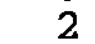 \\
\hline $28-1$ & 63 & 22 & 3 & 14 & 3 & 14 & 11 & 50 & 17 & 22 & 6 & 0 \\
\hline $29-1$ & 52 & 50 & 1 & 2 & 14 & 28 & 12 & 24 & 23 & 46 & 10 & U \\
\hline-2 & 58 & 52 & 2 & $\overline{4}$ & 11 & 21 & 14 & 27 & 25 & 48 & 8 & $U$ \\
\hline-3 & 56 & 42 & 4 & 10 & 5 & 12 & 15 & 36 & 18 & 42 & 8 & \\
\hline-4 & 57 & 59 & 2 & 3 & 11 & 19 & 9 & 15 & 37 & 63 & 9 & 4 \\
\hline
\end{tabular}


(Continuação)

\begin{tabular}{|c|c|c|c|c|c|c|c|c|c|c|c|c|}
\hline $\begin{array}{c}\text { N.o } \\
\text { Linhagens }\end{array}$ & $\begin{array}{l}\text { Comp. } \\
\text { pan. }\end{array}$ & $\begin{array}{l}\text { N. }{ }^{\circ} \\
\text { pan. }\end{array}$ & $C$ & $\stackrel{\%}{\mathrm{C}}$ & $R$ & $\stackrel{\%}{\mathrm{R}}$ & M & $\begin{array}{l}\% \\
M\end{array}$ & Perf. & $\begin{array}{c}\% \\
\text { Perf. }\end{array}$ & $\begin{array}{l}\text { N.॰ } \\
\text { autof. }\end{array}$ & Sel. \\
\hline 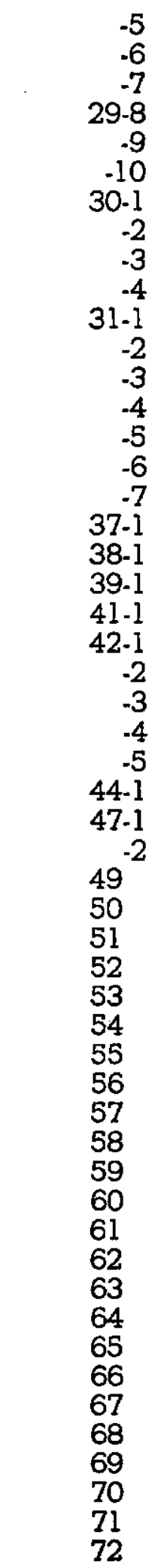 & $\begin{array}{l}56 \\
60 \\
57 \\
59 \\
55 \\
55 \\
62 \\
58 \\
56 \\
58 \\
57 \\
59 \\
58 \\
56 \\
59 \\
60 \\
60 \\
56 \\
58 \\
58 \\
59 \\
62 \\
58 \\
56 \\
58 \\
56 \\
53 \\
56 \\
55 \\
51 \\
49 \\
51 \\
50 \\
53 \\
49 \\
50 \\
55 \\
55 \\
55 \\
57 \\
55 \\
46 \\
50 \\
53 \\
50 \\
50 \\
46 \\
47 \\
47 \\
51\end{array}$ & $\begin{array}{l}27 \\
63 \\
58 \\
48 \\
58 \\
45 \\
49 \\
61 \\
45 \\
57 \\
58 \\
43 \\
41 \\
41 \\
36 \\
52 \\
42 \\
65 \\
41 \\
52 \\
55 \\
33 \\
64 \\
60 \\
49 \\
39 \\
52 \\
41 \\
52 \\
15 \\
17 \\
15 \\
14 \\
18 \\
18 \\
20 \\
29 \\
19 \\
32 \\
19 \\
24 \\
22 \\
26 \\
16 \\
15 \\
13 \\
10 \\
25 \\
14 \\
20 \\
20 \\
27\end{array}$ & $\begin{array}{r}0 \\
4 \\
1 \\
7 \\
3 \\
2 \\
29 \\
18 \\
17 \\
11 \\
10 \\
11 \\
9 \\
20 \\
10 \\
5 \\
9 \\
11 \\
8 \\
10 \\
7 \\
9 \\
15 \\
6 \\
8 \\
9 \\
20 \\
4 \\
2 \\
9 \\
6 \\
6 \\
3 \\
3 \\
1 \\
4 \\
7 \\
5 \\
10 \\
7 \\
2 \\
4 \\
2 \\
3 \\
3 \\
0 \\
0 \\
0 \\
0 \\
5 \\
3\end{array}$ & $\begin{array}{r}0 \\
6 \\
2 \\
15 \\
5 \\
4 \\
59 \\
30 \\
38 \\
19 \\
17 \\
26 \\
22 \\
49 \\
28 \\
10 \\
21 \\
17 \\
20 \\
19 \\
13 \\
27 \\
23 \\
10 \\
16 \\
23 \\
38 \\
10 \\
4 \\
60 \\
35 \\
40 \\
21 \\
17 \\
6 \\
20 \\
24 \\
26 \\
31 \\
37 \\
8 \\
18 \\
8 \\
19 \\
20 \\
0 \\
0 \\
0 \\
0 \\
25 \\
\end{array}$ & 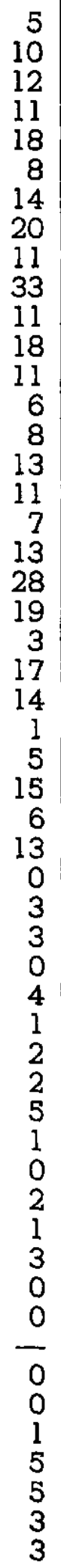 & $\begin{array}{r}19 \\
16 \\
21 \\
23 \\
31 \\
18 \\
29 \\
33 \\
24 \\
58 \\
19 \\
42 \\
27 \\
15 \\
22 \\
25 \\
26 \\
11 \\
32 \\
54 \\
35 \\
9 \\
27 \\
23 \\
2 \\
13 \\
29 \\
15 \\
25 \\
0 \\
18 \\
20 \\
0 \\
22 \\
6 \\
10 \\
76 \\
15 \\
11\end{array}$ & $\begin{array}{r}10 \\
26 \\
18 \\
14 \\
28 \\
14 \\
2 \\
5 \\
0 \\
8 \\
11 \\
1 \\
3 \\
6 \\
1 \\
12 \\
4 \\
33 \\
5 \\
6 \\
3 \\
1\end{array}$ & $\begin{array}{r}37 \\
41 \\
31 \\
29 \\
48 \\
31 \\
4 \\
8 \\
0 \\
14 \\
19 \\
2 \\
7 \\
15 \\
3 \\
23 \\
10 \\
51 \\
12 \\
12 \\
5 \\
3 \\
6 \\
5 \\
12 \\
13 \\
6 \\
2 \\
12 \\
13 \\
18 \\
20 \\
14 \\
22 \\
17 \\
35 \\
21 \\
5 \\
9 \\
16 \\
13 \\
55 \\
77 \\
56 \\
67 \\
100 \\
100 \\
92 \\
43 \\
30 \\
30 \\
44\end{array}$ & $\begin{array}{r}12 \\
23 \\
27 \\
16 \\
9 \\
21 \\
4 \\
18 \\
17 \\
5 \\
26 \\
13 \\
18 \\
9 \\
17 \\
22 \\
18 \\
14 \\
15 \\
8 \\
26 \\
20 \\
28 \\
37 \\
34 \\
20 \\
14 \\
30 \\
31 \\
4 \\
5 \\
3 \\
9 \\
7 \\
13 \\
7 \\
14 \\
8 \\
18 \\
9 \\
17 \\
5 \\
1 \\
4 \\
2 \\
0 \\
0 \\
1 \\
3 \\
6 \\
9\end{array}$ & $\begin{array}{r}44 \\
43 \\
46 \\
33 \\
26 \\
47 \\
8 \\
29 \\
38 \\
9 \\
45 \\
30 \\
44 \\
21 \\
44 \\
42 \\
43 \\
21 \\
36 \\
15 \\
47 \\
61 \\
43 \\
62 \\
70 \\
51 \\
27 \\
73 \\
59 \\
26 \\
29 \\
20 \\
65 \\
39 \\
71 \\
35 \\
48 \\
43 \\
57 \\
47 \\
71 \\
22 \\
3 \\
25 \\
13 \\
30 \\
0 \\
0\end{array}$ & $\begin{array}{r}6 \\
13 \\
12 \\
7 \\
4 \\
10 \\
3 \\
7 \\
13 \\
12 \\
1 \\
10 \\
21 \\
12 \\
8 \\
11 \\
16 \\
20 \\
19 \\
9 \\
10 \\
14 \\
14 \\
10 \\
13 \\
14 \\
12 \\
6 \\
6 \\
14 \\
13 \\
10 \\
12 \\
99 \\
18 \\
13 \\
15 \\
11 \\
11 \\
11 \\
10 \\
7 \\
17 \\
20 \\
23 \\
21 \\
17 \\
\end{array}$ & $\begin{array}{l}0 \\
0 \\
0 \\
7 \\
0 \\
4 \\
0 \\
0 \\
0 \\
6 \\
0 \\
9 \\
0 \\
0 \\
0 \\
0 \\
0 \\
0 \\
0 \\
0 \\
0 \\
0 \\
0 \\
0 \\
0 \\
0\end{array}$ \\
\hline
\end{tabular}


(Continuação)

\begin{tabular}{|c|c|c|c|c|c|c|c|c|c|c|c|c|}
\hline $\begin{array}{c}\text { N.o } \\
\text { Linhagens }\end{array}$ & $\begin{array}{l}\text { Comp. } \\
\text { pan. }\end{array}$ & $\begin{array}{l}\text { N.o } \\
\text { pan. }\end{array}$ & $\mathrm{C}$ & $\stackrel{\%}{\mathrm{C}}$ & $\mathrm{R}$ & $\stackrel{\%}{\mathrm{R}}$ & $\mathrm{M}$ & $\begin{array}{l}\% \\
\mathrm{M}\end{array}$ & Perf. & $\begin{array}{c}\% \\
\text { Perf. }\end{array}$ & $\begin{array}{l}\text { N. } \\
\text { autof. }\end{array}$ & Sel. \\
\hline $\begin{array}{l}73 \\
74 \\
75 \\
76 \\
77 \\
78 \\
79 \\
80 \\
81 \\
82 \\
83 \\
84 \\
85 \\
86 \\
87 \\
88 \\
89 \\
90 \\
91\end{array}$ & $\begin{array}{l}49 \\
48 \\
54 \\
55 \\
58 \\
44 \\
58 \\
59 \\
48 \\
51 \\
56 \\
55 \\
54 \\
51 \\
55 \\
33 \\
59 \\
54 \\
55\end{array}$ & $\begin{array}{r}23 \\
24 \\
6 \\
6 \\
17 \\
24 \\
19 \\
11 \\
15 \\
12 \\
12 \\
7 \\
21 \\
28 \\
19 \\
20 \\
7 \\
34 \\
21\end{array}$ & $\begin{array}{r}10 \\
2 \\
0 \\
0 \\
0 \\
0 \\
1 \\
0 \\
0 \\
1 \\
1 \\
1 \\
9 \\
7 \\
3 \\
10 \\
1 \\
11 \\
7\end{array}$ & $\begin{array}{r}43 \\
8 \\
0 \\
0 \\
0 \\
0 \\
6 \\
0 \\
0 \\
8 \\
8 \\
14 \\
43 \\
25 \\
16 \\
50 \\
14 \\
32 \\
33\end{array}$ & $\begin{array}{l}2 \\
4 \\
1 \\
1\end{array}$ & $\begin{array}{r}9 \\
17 \\
17 \\
17 \\
0 \\
4 \\
16 \\
9 \\
7 \\
8 \\
8 \\
0 \\
24 \\
0 \\
5 \\
0 \\
14 \\
6 \\
0\end{array}$ & $\begin{array}{r}4 \\
15 \\
2 \\
3 \\
12 \\
23 \\
11 \\
7 \\
14 \\
8 \\
7 \\
3 \\
1 \\
15 \\
3 \\
2 \\
2 \\
9 \\
3\end{array}$ & $\begin{array}{r}17 \\
63 \\
33 \\
50 \\
71 \\
96 \\
58 \\
64 \\
93 \\
67 \\
58 \\
43 \\
5 \\
54 \\
16 \\
10 \\
28 \\
26 \\
14\end{array}$ & $\begin{array}{r}7 \\
3 \\
3 \\
2 \\
5 \\
0 \\
4 \\
3 \\
0 \\
2 \\
3 \\
3 \\
6 \\
6 \\
12 \\
8 \\
3 \\
12 \\
11\end{array}$ & $\begin{array}{r}31 \\
15 \\
50 \\
23 \\
29 \\
0 \\
20 \\
27 \\
0 \\
17 \\
26 \\
43 \\
28 \\
21 \\
63 \\
40 \\
44 \\
36 \\
53\end{array}$ & $\begin{array}{r}28 \\
17 \\
19 \\
3 \\
13 \\
12 \\
11 \\
12 \\
4 \\
15 \\
14 \\
- \\
7 \\
11 \\
9 \\
9 \\
6 \\
8 \\
8\end{array}$ & $\begin{array}{l}0 \\
0 \\
3 \\
0 \\
2 \\
0 \\
0 \\
0 \\
0 \\
4 \\
0 \\
0 \\
0 \\
0 \\
6 \\
0 \\
0 \\
0 \\
7\end{array}$ \\
\hline & & & & & & & & & & & 1173 & 196 \\
\hline
\end{tabular}

1937-38

\begin{tabular}{r|r|r|r|r|r|r|r|r|r|r|r|r}
\hline $\begin{array}{c}\text { N.o } \\
\text { Linhagens }\end{array}$ & $\begin{array}{c}\text { Comp. } \\
\text { pan. }\end{array}$ & $\begin{array}{r}\text { N.o } \\
\text { pan. }\end{array}$ & $\mathrm{C}$ & $\begin{array}{r}\% \\
\mathrm{C}\end{array}$ & $\mathrm{R}$ & $\begin{array}{c}\% \\
\mathrm{R}\end{array}$ & $\mathrm{M}$ & $\begin{array}{c}\% \\
\mathrm{M}\end{array}$ & Perf. & $\begin{array}{c}\% \\
\text { Perf. }\end{array}$ & $\begin{array}{r}\text { N. } \\
\text { autof. }\end{array}$ & Sel. \\
\hline $37-3-1-1-1$ & 55 & 87 & 7 & 8 & 12 & 14 & 21 & 24 & 48 & 58 & 16 & 0 \\
-2 & 55 & 100 & 0 & 0 & 20 & 20 & 15 & 15 & 65 & 65 & 16 & 6 \\
-3 & 53 & 90 & 5 & 6 & 14 & 16 & 14 & 16 & 57 & 62 & 18 & 8 \\
-4 & 56 & 57 & 6 & 11 & 8 & 14 & 12 & 21 & 31 & 54 & 6 & 0 \\
$37-3-3-1-1$ & 60 & 56 & 5 & 9 & 17 & 30 & 17 & 30 & 17 & 31 & 11 & 0 \\
-2 & 56 & 61 & 4 & 7 & 16 & 26 & 28 & 46 & 13 & 21 & 9 & 0 \\
-3 & 60 & 49 & 4 & 8 & 16 & 33 & 10 & 20 & 19 & 39 & 14 & 0 \\
-4 & 57 & 68 & 9 & 13 & 18 & 26 & 29 & 43 & 12 & 18 & 17 & 0 \\
-5 & 60 & 36 & 1 & 3 & 18 & 50 & 0 & 0 & 17 & 47 & 12 & 2 \\
-6 & 61 & 25 & 6 & 24 & 5 & 20 & 7 & 28 & 7 & 18 & 3 & 0 \\
-7 & 55 & 75 & 6 & 8 & 25 & 33 & 37 & 49 & 7 & 0 & 10 & 0 \\
-8 & 59 & 68 & 13 & 19 & 18 & 26 & 10 & 15 & 27 & 40 & 10 & 0 \\
-9 & 62 & 47 & 7 & 15 & 18 & 38 & 16 & 34 & 6 & 13 & 8 & 0 \\
$37-3-3-2-1$ & 56 & 67 & 3 & 4 & 7 & 10 & 31 & 46 & 26 & 40 & 17 & 0 \\
-2 & 62 & 38 & 1 & 3 & 6 & 16 & 16 & 42 & 15 & 39 & 8 & 0 \\
-3 & 61 & 22 & 2 & 9 & 4 & 18 & 7 & 32 & 9 & 41 & 3 & 0 \\
-4 & 57 & 69 & 11 & 16 & 14 & 20 & 34 & 49 & 10 & 15 & 20 & 0 \\
-5 & 58 & 40 & 0 & 0 & 17 & 43 & 5 & 13 & 18 & 44 & 18 & 0 \\
$37-3-4-1-1$ & 57 & 46 & 2 & 4 & 9 & 20 & 22 & 48 & 13 & 28 & 14 & 0 \\
-2 & 56 & 54 & 4 & 7 & 6 & 11 & 20 & 37 & 24 & 45 & 10 & 0 \\
-3 & 58 & 44 & 3 & 7 & 10 & 23 & 9 & 20 & 22 & 50 & 16 & 0 \\
-4 & 57 & 52 & 5 & 10 & 11 & 21 & 16 & 31 & 20 & 38 & 19 & 0 \\
-5 & 60 & 37 & 1 & 3 & 11 & 30 & 7 & 19 & 18 & 48 & 19 & 0 \\
-6 & 56 & 79 & 4 & 5 & 22 & 28 & 16 & 20 & 37 & 47 & 16 & 0
\end{tabular}


(Continuação)

\begin{tabular}{|c|c|c|c|c|c|c|c|c|c|c|c|c|}
\hline $\begin{array}{c}\text { N.o } \\
\text { Linhagens }\end{array}$ & $\begin{array}{c}\text { Comp. } \\
\text { pan. }\end{array}$ & $\begin{array}{l}\text { N.o } \\
\text { pan. }\end{array}$ & $\mathrm{C}$ & $\stackrel{\%}{\mathrm{C}}$ & $\mathrm{R}$ & $\stackrel{\%}{\mathrm{R}}$ & M & $\begin{array}{l}\% \\
M\end{array}$ & Perf. & $\begin{array}{c}\% \\
\text { Perf. }\end{array}$ & $\begin{array}{l}\text { N.o } \\
\text { autof. }\end{array}$ & Sel. \\
\hline-7 & 58 & 55 & 1 & 2 & 16 & 29 & 5 & 9 & 33 & 60 & 11 & 5 \\
\hline $37-3-4 \cdot 2-1$ & 58 & 74 & 1 & 1 & 28 & 38 & 21 & 28 & 24 & 33 & 21 & 0 \\
\hline-2 & 64 & 22 & 4 & 18 & 10 & 45 & 1 & 5 & 7 & 32 & 3 & 0 \\
\hline-3 & 59 & 62 & 3 & 5 & 21 & 34 & 5 & 8 & 33 & 53 & 22 & 11 \\
\hline $37-3-4-3-1$ & 56 & 78 & 7 & 9 & 18 & 23 & 29 & 37 & 24 & 31 & 16 & 0 \\
\hline-2 & 58 & 34 & 0 & 0 & 12 & 35 & 5 & 15 & 17 & 50 & 14 & 6 \\
\hline-3 & 57 & 55 & 3 & 5 & 13 & 24 & 16 & 29 & 23 & 42 & 16 & 0 \\
\hline-4 & 56 & 40 & 2 & 5 & 7 & 18 & 10 & 25 & 21 & 52 & 12 & 2 \\
\hline $37-3-4-4-1$ & 60 & 46 & 3 & 7 & 7 & 15 & 5 & 11 & 31 & 67 & 12 & 3 \\
\hline-2 & 58 & 45 & 2 & 4 & 13 & 29 & 3 & 7 & 27 & 60 & 15 & 4 \\
\hline-3 & 55 & 55 & 7 & 13 & 9 & 16 & 7 & 13 & 32 & 48 & 13 & 0 \\
\hline-4 & 58 & 44 & 2 & 5 & 2 & 5 & 13 & 30 & 27 & 60 & 9 & 2 \\
\hline-5 & 64 & 39 & 1 & 3 & 17 & 44 & 3 & 8 & 18 & 45 & 11 & 3 \\
\hline $37-3-4-6-1$ & 55 & 56 & 2 & 4 & 25 & 45 & 12 & 21 & 17 & 30 & 14 & 0 \\
\hline $37-3-5-1-1$ & 59 & 36 & 2 & 6 & 18 & 50 & 0 & 0 & 16 & 44 & 9 & 2 \\
\hline-2 & 55 & 54 & 2 & 4 & 12 & 22 & 13 & 24 & 27 & 50 & 11 & 5 \\
\hline-3 & 60 & 56 & 4 & 7 & 12 & 21 & 6 & 11 & 34 & - & 14 & 8 \\
\hline-4 & 64 & 22 & 2 & 9 & 12 & 55 & 1 & 5 & 7 & 31 & 7 & 0 \\
\hline-5 & 61 & 14 & 0 & 0 & 6 & 43 & 0 & 0 & 8 & 57 & 4 & 1 \\
\hline-6 & 57 & 27 & 0 & 0 & 3 & 11 & 12 & 44 & 12 & 45 & 4 & 0 \\
\hline 37-4-1-1-1 & 59 & 38 & 0 & 0 & 19 & 50 & 13 & 34 & 6 & 16 & 7 & 0 \\
\hline-2 & 62 & 23 & 0 & 0 & 6 & 26 & 3 & 13 & 9 & 61 & 0 & 0 \\
\hline $37-4-1-2-1$ & 57 & 35 & 4 & 11 & 16 & 46 & 3 & 9 & 12 & 34 & 6 & 0 \\
\hline-2 & 57 & 57 & 6 & 11 & 15 & 26 & 3 & 5 & 33 & 58 & 13 & 2 \\
\hline-3 & 62 & 35 & 1 & 3 & 13 & 37 & 0 & 0 & 21 & 60 & 6 & 3 \\
\hline-4 & 55 & 46 & 3 & 7 & 12 & 26 & 12 & 26 & 19 & 41 & 9 & 0 \\
\hline $37-6-1-2-i$ & 64 & 44 & 4 & 9 & 11 & 25 & 16 & 36 & 13 & 30 & 6 & 0 \\
\hline $37-7-2-1-1$ & 63 & 75 & 8 & 11 & 15 & 20 & 21 & 28 & 31 & 41 & 12 & 0 \\
\hline-2 & 67 & 45 & 3 & 7 & 20 & 44 & 5 & 11 & 17 & 38 & 9 & 0 \\
\hline-3 & 61 & 53 & 3 & 6 & 24 & 45 & 22 & 42 & 4 & 7 & 10 & 0 \\
\hline-4 & 57 & 47 & 3 & 6 & 14 & 30 & 26 & 55 & 4 & 9 & 8 & 0 \\
\hline-5 & 61 & 62 & 13 & 21 & 19 & 31 & 25 & 40 & 5 & 8 & 15 & 0 \\
\hline-6 & 59 & 52 & 5 & 10 & 15 & 29 & 17 & 33 & 15 & 28 & 10 & 0 \\
\hline $37-8-1-2-1$ & 62 & 52 & 6 & 12 & 16 & 31 & 10 & 19 & 20 & 38 & 14 & 0 \\
\hline-2 & 67 & 35 & 3 & 9 & 14 & 40 & 3 & 9 & 18 & 42 & 9 & 0 \\
\hline .3 & 63 & 49 & 12 & 24 & 20 & 41 & 7 & 14 & 10 & 21 & 10 & 0 \\
\hline-4 & 62 & 41 & 5 & 12 & 20 & 49 & 2 & 5 & 14 & 34 & 7 & 0 \\
\hline $37-8-4-3-1$ & 59 & 58 & 10 & 17 & 20 & 34 & 20 & 34 & 8 & 15 & 7 & 0 \\
\hline-2 & 64 & 57 & 17 & 30 & 13 & 23 & 6 & 11 & 21 & 36 & 6 & 0 \\
\hline-3 & 63 & 34 & 4 & 12 & 10 & 29 & 8 & 24 & 12 & 35 & 5 & 0 \\
\hline-4 & 66 & 21 & 8 & 38 & 3 & 14 & 1 & 5 & 9 & 43 & 5 & 0 \\
\hline $37-13-2 \cdot 1-1$ & 62 & 34 & 4 & 12 & 18 & 53 & 4 & 12 & 8 & 23 & 13 & 0 \\
\hline $37-20-1-1$ & 67 & 21 & 3 & 14 & 11 & 52 & 1 & 5 & 6 & 29 & 9 & 0 \\
\hline & 63 & 42 & 6 & 14 & 16 & 38 & 0 & 0 & 20 & 48 & 3 & 0 \\
\hline 37-22-1-1 & 60 & 53 & 4 & 8 & 31 & 58 & 3 & 6 & 15 & 28 & 13 & 0 \\
\hline $37-22-2-1$ & 59 & 69 & 8 & 12 & 41 & 59 & 26 & 38 & 0 & - & 8 & 0 \\
\hline-2 & 61 & 57 & 8 & 14 & 28 & 49 & 7 & 12 & 14 & 25 & 16 & 0 \\
\hline-3 & 64 & 48 & 2 & 4 & 34 & 71 & 10 & 21 & 2 & 4 & 13 & 0 \\
\hline-4 & 60 & 57 & 10 & 18 & 21 & 37 & 31 & 54 & 0 & - & 5 & 0 \\
\hline-5 & 65 & 28 & 1 & 4 & 15 & 54 & 2 & 7 & 10 & 35 & 8 & 0 \\
\hline-6 & 57 & 64 & 4 & 6 & 24 & 38 & 28 & 44 & 8 & 12 & 11 & 0 \\
\hline .7 & 57 & 60 & 5 & 8 & 24 & 40 & 24 & 40 & 7 & 12 & 14 & 0 \\
\hline-8 & 55 & 62 & 6 & 10 & 15 & 24 & 29 & 47 & 12 & 29 & 15 & 0 \\
\hline
\end{tabular}


(Continuação)

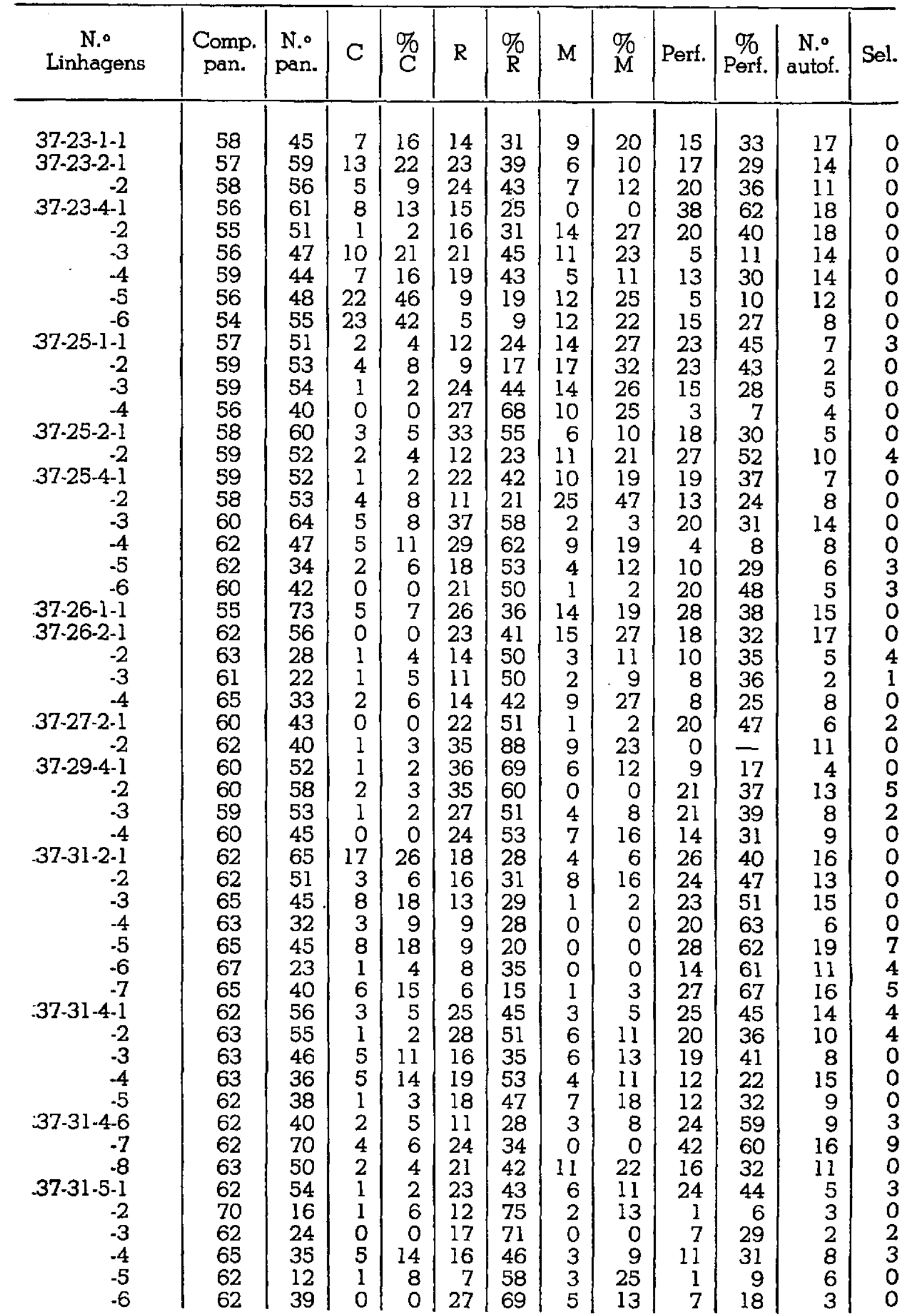


(Continuação)

\begin{tabular}{|c|c|c|c|c|c|c|c|c|c|c|c|c|}
\hline $\begin{array}{c}\text { N. }{ }^{\circ} \\
\text { Linhagens }\end{array}$ & $\begin{array}{c}\text { Comp. } \\
\text { pan. }\end{array}$ & $\begin{array}{l}\text { N.o } \\
\text { pan. }\end{array}$ & $\mathrm{C}$ & $\%$ & $\mathrm{R}$ & $\stackrel{\%}{\mathrm{R}}$ & $\mathrm{M}$ & $\begin{array}{l}\% \\
M\end{array}$ & Perf. & $\begin{array}{c}\% \\
\text { Perf. }\end{array}$ & $\begin{array}{l}\text { N. }{ }^{\circ} \\
\text { autof. }\end{array}$ & Sel. \\
\hline-7 & 58 & 70 & 3 & 4 & 42 & 60 & 17 & 24 & 8 & 12 & 9 & 0 \\
\hline .8 & 62 & 51 & 3 & 6 & 30 & 59 & 7 & 14 & 11 & 21 & 5 & 0 \\
\hline-9 & 59 & 43 & 2 & 5 & 28 & 65 & 6 & 14 & 7 & 16 & 7 & 0 \\
\hline $37-31-6-1$ & 65 & 37 & 4 & 11 & 23 & 62 & 4 & 11 & 6 & 16 & 7 & 0 \\
\hline-2 & 56 & 62 & 2 & 3 & 17 & 27 & 17 & 27 & 26 & 43 & 8 & 0 \\
\hline-3 & 57 & 49 & 0 & 0 & 22 & 45 & 0 & 0 & 27 & 55 & 6 & 5 \\
\hline-4 & 58 & 40 & 1 & 3 & 18 & 45 & 2 & 5 & 19 & 47 & 2 & 1 \\
\hline-5 & 59 & 41 & 5 & 12 & 14 & 34 & 1 & 2 & 21 & 52 & 10 & 0 \\
\hline-6 & 64 & 38 & 1 & 3 & 11 & 29 & 0 & 0 & 26 & 68 & 8 & 5 \\
\hline-7 & 58 & 59 & 1 & 2 & 22 & 37 & 8 & 14 & 28 & 47 & 4 & 2 \\
\hline-8 & 59 & 47 & 5 & 11 & 15 & 32 & 7 & 15 & 20 & 42 & 5 & 0 \\
\hline-9 & 61 & 46 & 1 & 2 & 20 & 43 & 2 & 4 & 23 & 51 & 5 & 3 \\
\hline $37-37-1-1$ & 55 & 64 & 3 & 5 & 36 & 56 & 3 & 5 & 22 & 34 & 5 & 0 \\
\hline & 64 & 16 & 0 & 0 & 6 & 38 & 2 & 13 & 8 & 49 & 0 & 0 \\
\hline $37-37-2-1$ & 56 & 29 & 1 & 3 & 10 & 34 & 3 & 10 & 15 & 53 & 0 & 0 \\
\hline .2 & 60 & 11 & 0 & 0 & 5 & 45 & 0 & 0 & 6 & 55 & 0 & 0 \\
\hline-3 & 63 & 15 & 1 & 7 & 9 & 60 & 1 & 7 & 4 & 26 & 0 & 0 \\
\hline-4 & 53 & 20 & 0 & 0 & 3 & 15 & 1 & 5 & 16 & 80 & 5 & 2 \\
\hline $37-42 \cdot 2-1$ & 53 & 49 & 5 & 10 & 2 & 4 & 4 & 8 & 38 & 78 & 8 & 2 \\
\hline-2 & 52 & 39 & 2 & 5 & 1 & 3 & 9 & 23 & 27 & 69 & 11 & 5 \\
\hline-3 & 50 & 54 & 3 & 6 & 6 & 11 & 8 & 15 & 37 & 68 & 16 & 7 \\
\hline-4 & 51 & 48 & 6 & 12 & 3 & 6 & 6 & 12 & 33 & 70 & 15 & 0 \\
\hline .5 & 54 & 43 & 3 & 7 & 3 & 7 & 6 & 14 & 31 & 72 & 11 & 6 \\
\hline .6 & 51 & 57 & 8 & 14 & 2 & 4 & 2 & 4 & 45 & 78 & 15 & 7 \\
\hline-7 & 50 & 55 & 4 & 7 & 7 & 13 & 8 & 15 & 36 & 65 & 16 & 0 \\
\hline $37-42-4-1$ & 49 & 65 & 7 & 11 & 11 & 17 & 3 & 5 & 44 & 67 & 23 & 0 \\
\hline .2 & 48 & 61 & 2 & 3 & 11 & 18 & 6 & 10 & 42 & 69 & 16 & 0 \\
\hline$-\overline{3}$ & 52 & 60 & $\overline{9}$ & 15 & 11 & 18 & 3 & 5 & 37 & 62 & 16 & 0 \\
\hline & 55 & 37 & 5 & 14 & 5 & 14 & l & 3 & 26 & 69 & 19 & 0 \\
\hline $37-47-2-1$ & 54 & 57 & 10 & 18 & 8 & 14 & 11 & 19 & 28 & 49 & 19 & 0 \\
\hline & 54 & 49 & 10 & 20 & 10 & 20 & 9 & 18 & 20 & 42 & 18 & 0 \\
\hline $37-47-3$ & 57 & 41 & 4 & 10 & 2 & 5 & 3 & 7 & 32 & 78 & 18 & 0 \\
\hline-4 & 55 & 38 & 3 & 8 & 8 & 21 & 0 & 0 & 27 & 71 & 15 & 0 \\
\hline-5 & 52 & 79 & 5 & 6 & 16 & 20 & 16 & 20 & 42 & 54 & 20 & 0 \\
\hline-6 & 51 & 74 & 7 & 9 & 16 & 22 & 10 & 14 & 41 & 55 & 17 & 0 \\
\hline $37-50-1$ & 55 & 43 & 2 & 5 & 8 & 19 & 5 & 12 & 28 & 64 & 14 & 0 \\
\hline-2 & 52 & 39 & 2 & 5 & 2 & 5 & 6 & 15 & 29 & 75 & 14 & 0 \\
\hline-3 & 56 & 17 & 4 & 24 & I & 6 & 0 & 0 & 12 & 70 & 3 & 0 \\
\hline-4 & 54 & 52 & 6 & 12 & 7 & 13 & 1 & 2 & 38 & 73 & 11 & 0 \\
\hline-5 & 54 & 61 & 7 & 11 & 14 & 23 & 8 & 13 & 32 & 53 & 17 & 0 \\
\hline .6 & 49 & 8 & 0 & 0 & 2 & 29 & 1 & 14 & 5 & 57 & 4 & 0 \\
\hline-7 & 52 & 43 & 5 & 12 & 4 & 9 & 14 & 33 & 20 & 66 & 14 & 0 \\
\hline .8 & 54 & 14 & 5 & 36 & 3 & 21 & 2 & 14 & 4 & 29 & 7 & 0 \\
\hline-9 & 56 & 39 & 4 & 10 & 3 & 8 & $1 \overline{1}$ & 28 & 21 & 54 & 19 & 0 \\
\hline $3-75-1$ & 55 & 72 & 2 & 3 & 1 & 1 & 34 & 47 & 35 & 49 & 15 & 0 \\
\hline-2 & 59 & 40 & 1 & 3 & 2 & 5 & 11 & 28 & 26 & 64 & 12 & 2 \\
\hline-3 & 55 & 46 & 0 & 0 & 1 & 2 & 8 & 17 & 37 & 81 & 18 & 7 \\
\hline $3-77-1$ & 58 & 51 & 4 & 8 & 3 & 6 & 22 & 43 & 22 & 43 & 18 & 0 \\
\hline-2 & 56 & 81 & l & 1 & 4 & 5 & 27 & 33 & 49 & 61 & 19 & 2 \\
\hline $3-82-1$ & 56 & 32 & 2 & 6 & 4 & 13 & 10 & 31 & 16 & 50 & 7 & 0 \\
\hline-2 & 55 & 55 & 1 & 2 & 2 & 4 & 15 & 27 & 37 & 67 & 16 & 0 \\
\hline .3 & 53 & 89 & 3 & 3 & 4 & 4 & 43 & 48 & 39 & 45 & 19 & 0 \\
\hline-4 & 53 & 60 & 0 & 0 & 8 & 13 & 16 & 27 & 36 & 60 & 17 & 0 \\
\hline
\end{tabular}


(Continuação)

\begin{tabular}{|c|c|c|c|c|c|c|c|c|c|c|c|c|}
\hline $\begin{array}{c}\text { N.॰ } \\
\text { Linhagens }\end{array}$ & $\begin{array}{c}\text { Comp. } \\
\text { pan. }\end{array}$ & $\begin{array}{l}\text { N. }{ }^{\circ} \\
\text { pan. }\end{array}$ & C & $\stackrel{\%}{\mathrm{C}}$ & $\mathbf{R}$ & $\begin{array}{l}\% \\
\mathrm{R}\end{array}$ & $\mathrm{M}$ & $\begin{array}{l}\% \\
M\end{array}$ & Perf. & $\begin{array}{c}\% \\
\text { Perf. }\end{array}$ & $\begin{array}{l}\text { N.o } \\
\text { autof. }\end{array}$ & Sel. \\
\hline $\begin{array}{r}4-87-1 \\
-2 \\
-3 \\
-4 \\
-5 \\
-6 \\
4-91-1 \\
-2 \\
-3 \\
-4 \\
-5 \\
-6 \\
-7\end{array}$ & $\begin{array}{l}59 \\
54 \\
58 \\
55 \\
56 \\
54 \\
52 \\
54 \\
56 \\
56 \\
54 \\
58 \\
49\end{array}$ & $\begin{array}{l}47 \\
64 \\
33 \\
64 \\
49 \\
62 \\
56 \\
67 \\
47 \\
72 \\
49 \\
70 \\
64\end{array}$ & $\begin{array}{r}5 \\
7 \\
3 \\
11 \\
3 \\
5 \\
3 \\
4 \\
9 \\
2 \\
3 \\
9 \\
14\end{array}$ & $\begin{array}{r}11 \\
11 \\
9 \\
17 \\
6 \\
8 \\
5 \\
6 \\
19 \\
3 \\
6 \\
13 \\
22\end{array}$ & $\begin{array}{r}2 \\
13 \\
1 \\
7 \\
0 \\
1 \\
6 \\
5 \\
2 \\
10 \\
3 \\
9 \\
3\end{array}$ & $\begin{array}{r}4 \\
20 \\
3 \\
11 \\
0 \\
2 \\
11 \\
7 \\
4 \\
14 \\
6 \\
13 \\
5\end{array}$ & $\begin{array}{r}15 \\
17 \\
9 \\
23 \\
22 \\
15 \\
17 \\
21 \\
12 \\
29 \\
15 \\
11 \\
11\end{array}$ & $\begin{array}{l}32 \\
27 \\
27 \\
36 \\
45 \\
24 \\
30 \\
31 \\
26 \\
40 \\
31 \\
16 \\
17\end{array}$ & $\begin{array}{l}25 \\
27 \\
20 \\
23 \\
24 \\
41 \\
30 \\
37 \\
24 \\
31 \\
28 \\
41 \\
36\end{array}$ & $\begin{array}{l}53 \\
42 \\
61 \\
36 \\
49 \\
66 \\
54 \\
56 \\
51 \\
43 \\
57 \\
58 \\
56\end{array}$ & $\begin{array}{l}16 \\
15 \\
15 \\
19 \\
17 \\
19 \\
17 \\
20 \\
10 \\
15 \\
18 \\
17 \\
17\end{array}$ & $\begin{array}{l}0 \\
0 \\
0 \\
0 \\
6 \\
0 \\
0 \\
0 \\
0 \\
0 \\
0 \\
0 \\
0\end{array}$ \\
\hline & & & & & & & & & & & 2188 & 206 \\
\hline
\end{tabular}

1938-39

\begin{tabular}{|c|c|c|c|c|c|c|c|c|c|c|c|c|}
\hline $\begin{array}{c}\text { N.º } \\
\text { Linhagens }\end{array}$ & $\begin{array}{c}\text { Comp. } \\
\text { pan. }\end{array}$ & $\begin{array}{l}\text { N. } \\
\text { pan. }\end{array}$ & C & $\stackrel{\%}{\mathrm{C}}$ & $\mathrm{R}$ & $\begin{array}{l}\% \\
\mathrm{R}\end{array}$ & M & $\begin{array}{l}\% \\
M\end{array}$ & Perf. & $\begin{array}{c}\% \\
\text { Perf. }\end{array}$ & $\begin{array}{l}\text { N.o } \\
\text { autof. }\end{array}$ & Sel. \\
\hline $\begin{array}{r}37-3-1-1-2-1 \\
-2 \\
-3 \\
-4 \\
-5 \\
-6 \\
37-3-1-1-3-1 \\
-2 \\
-3 \\
-4 \\
-5 \\
-6 \\
-7 \\
-8 \\
37-3-3-1-5-1 \\
-2 \\
-2 \\
37-3-4-1-7-1 \\
-2 \\
-3 \\
-4 \\
-5 \\
37-3-4-2-3-1 \\
-2 \\
-3 \\
-3 \\
-4 \\
-5 \\
-6\end{array}$ & $\begin{array}{l}55 \\
54 \\
53 \\
55 \\
51 \\
56 \\
52 \\
51 \\
51 \\
54 \\
53 \\
52 \\
54 \\
54 \\
57 \\
55 \\
55 \\
53 \\
54 \\
55 \\
52 \\
56 \\
56 \\
54 \\
57 \\
55 \\
55 \\
55 \\
55 \\
55\end{array}$ & $\begin{array}{l}70 \\
59 \\
71 \\
69 \\
81 \\
64 \\
58 \\
68 \\
80 \\
55 \\
76 \\
59 \\
65 \\
57 \\
73 \\
74 \\
62 \\
82 \\
55 \\
28 \\
12 \\
85 \\
80 \\
71 \\
83 \\
75 \\
44 \\
86 \\
61 \\
63\end{array}$ & $\begin{array}{r}10 \\
5 \\
2 \\
6 \\
6 \\
4 \\
5 \\
4 \\
1 \\
4 \\
3 \\
4 \\
4 \\
5 \\
8 \\
2 \\
5 \\
8 \\
5 \\
4 \\
1 \\
9 \\
4 \\
0 \\
7 \\
3 \\
6 \\
4 \\
6 \\
2\end{array}$ & $\begin{array}{r}14 \\
8 \\
3 \\
9 \\
7 \\
6 \\
9 \\
6 \\
1 \\
7 \\
4 \\
7 \\
6 \\
9 \\
11 \\
3 \\
8 \\
10 \\
9 \\
14 \\
8 \\
11 \\
5 \\
0 \\
8 \\
4 \\
14 \\
5 \\
10 \\
3\end{array}$ & $\begin{array}{r}9 \\
7 \\
5 \\
5 \\
3 \\
11 \\
3 \\
6 \\
1 \\
5 \\
11 \\
8 \\
13 \\
7 \\
9 \\
9 \\
6 \\
1 \\
6 \\
0 \\
4 \\
6 \\
1 \\
5 \\
7 \\
8 \\
2 \\
11 \\
2 \\
4\end{array}$ & $\begin{array}{r}13 \\
12 \\
7 \\
7 \\
4 \\
17 \\
5 \\
9 \\
1 \\
9 \\
14 \\
14 \\
20 \\
12 \\
12 \\
12 \\
10 \\
1 \\
11 \\
0 \\
33 \\
7 \\
1 \\
7 \\
8 \\
11 \\
5 \\
13 \\
3 \\
6\end{array}$ & $\begin{array}{r}20 \\
32 \\
30 \\
28 \\
31 \\
21 \\
23 \\
33 \\
36 \\
26 \\
36 \\
22 \\
19 \\
20 \\
25 \\
34 \\
22 \\
34 \\
25 \\
12 \\
4 \\
22 \\
24 \\
27 \\
19 \\
26 \\
21 \\
26 \\
15 \\
20\end{array}$ & $\begin{array}{l}29 \\
54 \\
42 \\
41 \\
38 \\
33 \\
40 \\
49 \\
45 \\
47 \\
47 \\
37 \\
29 \\
35 \\
34 \\
46 \\
35 \\
41 \\
45 \\
43 \\
33 \\
26 \\
30 \\
38 \\
23 \\
35 \\
48 \\
30 \\
25 \\
32\end{array}$ & $\begin{array}{r}31 \\
15 \\
34 \\
30 \\
41 \\
28 \\
27 \\
25 \\
42 \\
20 \\
26 \\
25 \\
29 \\
25 \\
31 \\
29 \\
29 \\
39 \\
19 \\
12 \\
3 \\
48 \\
51 \\
39 \\
50 \\
38 \\
15 \\
45 \\
38 \\
37\end{array}$ & $\begin{array}{l}44 \\
26 \\
48 \\
43 \\
51 \\
44 \\
46 \\
36 \\
53 \\
39 \\
35 \\
40 \\
45 \\
44 \\
43 \\
39 \\
47 \\
48 \\
35 \\
43 \\
26 \\
56 \\
64 \\
55 \\
61 \\
50 \\
33 \\
52 \\
62 \\
59\end{array}$ & $\begin{array}{r}9 \\
12 \\
15 \\
15 \\
11 \\
7 \\
9 \\
9 \\
12 \\
9 \\
10 \\
10 \\
6 \\
10 \\
7 \\
11 \\
10 \\
11 \\
9 \\
10 \\
6 \\
13 \\
0 \\
10 \\
13 \\
8 \\
4 \\
9 \\
9 \\
6\end{array}$ & $\begin{array}{l}0 \\
0 \\
2 \\
0 \\
0 \\
0 \\
0 \\
0 \\
0 \\
0 \\
0 \\
0 \\
0 \\
0 \\
4 \\
0 \\
0 \\
0 \\
0 \\
0 \\
0 \\
0 \\
5 \\
2 \\
3 \\
0 \\
0 \\
0 \\
6\end{array}$ \\
\hline
\end{tabular}


(Continuação)

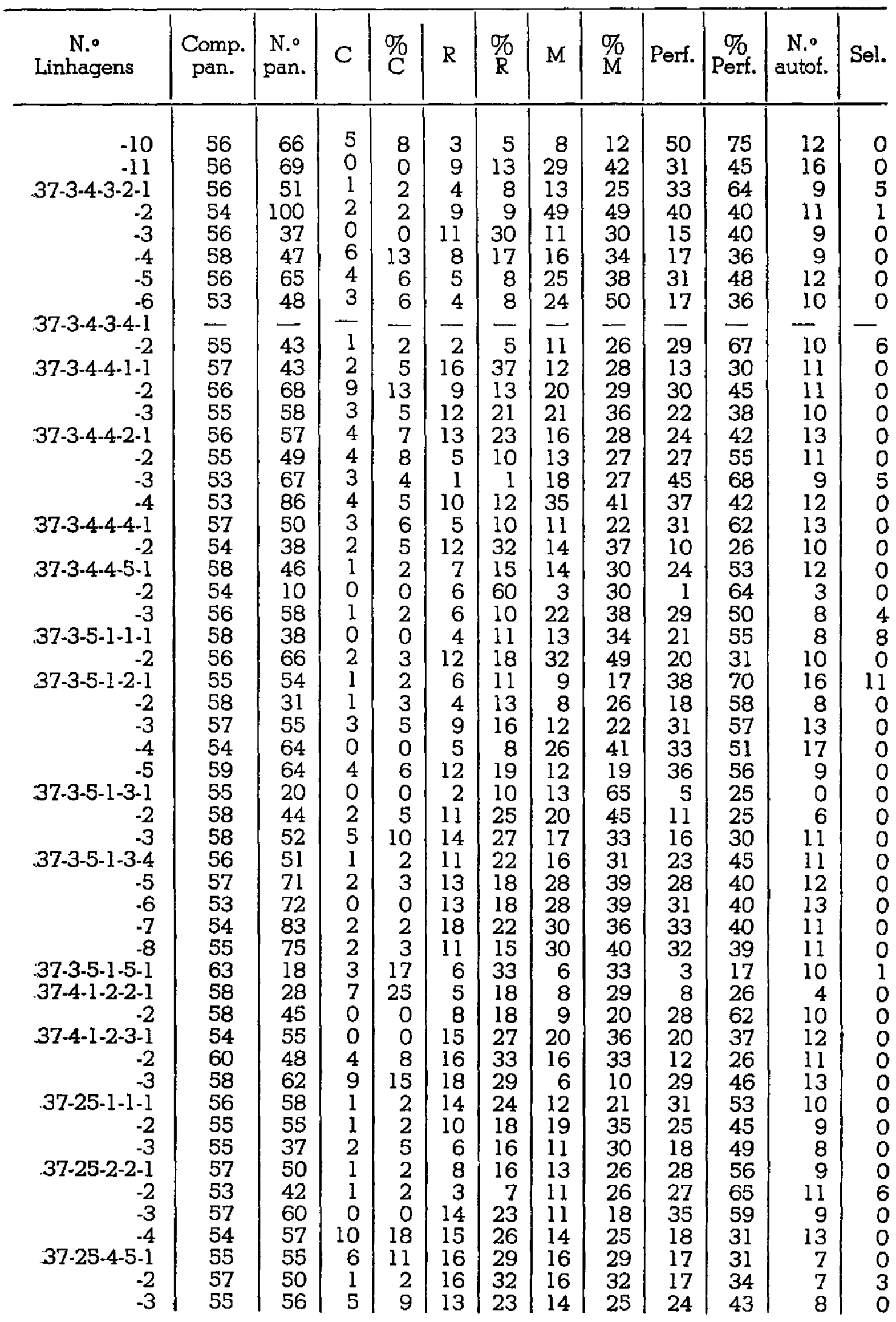


(Continuação)

\begin{tabular}{|c|c|c|c|c|c|c|c|c|c|c|c|c|}
\hline $\begin{array}{c}\text { N.० } \\
\text { Linhagens }\end{array}$ & $\begin{array}{l}\text { Comp. } \\
\text { pan. }\end{array}$ & $\begin{array}{l}\text { N. }{ }^{\circ} \\
\text { pan. }\end{array}$ & $\mathrm{C}$ & $\stackrel{\%}{\mathrm{C}}$ & $\mathrm{R}$ & $\begin{array}{l}\% \\
\mathrm{R}\end{array}$ & $M$ & $\begin{array}{l}\% \\
\mathrm{M}\end{array}$ & Perf. & $\begin{array}{l}\% \\
\text { Perf. }\end{array}$ & $\begin{array}{l}\text { N. } \\
\text { autof. }\end{array}$ & Sel. \\
\hline $\begin{array}{r}37-25 \cdot 4-6-1 \\
-2 \\
-3 \\
37-26-2-2-1 \\
-2 \\
-3 \\
-4 \\
37-26-2-3-1 \\
37-27-2-1-1 \\
-2 \\
37-29-4-2-1 \\
-2 \\
-3 \\
-4 \\
-5 \\
37-29-4-3-1 \\
-2 \\
37-31-2-5-1 \\
-2 \\
-3 \\
-4 \\
-5 \\
-6 \\
-7 \\
37\end{array}$ & $\begin{array}{l}53 \\
55 \\
56 \\
59 \\
56 \\
57 \\
59 \\
54 \\
58 \\
55 \\
59 \\
56 \\
62 \\
59 \\
59 \\
57 \\
62 \\
61 \\
60 \\
64 \\
63 \\
60 \\
62 \\
67 \\
59 \\
66 \\
63 \\
60 \\
61 \\
60 \\
58 \\
61 \\
64 \\
69 \\
59 \\
65 \\
60 \\
62 \\
62 \\
61 \\
60 \\
57 \\
57 \\
60 \\
58 \\
61 \\
61 \\
61 \\
60 \\
61 \\
58 \\
61 \\
61\end{array}$ & $\begin{array}{l}60 \\
59 \\
73 \\
44 \\
44 \\
33 \\
54 \\
45 \\
48 \\
53 \\
54 \\
50 \\
57 \\
46 \\
73 \\
86 \\
47 \\
79 \\
67 \\
62 \\
42 \\
60 \\
46 \\
61 \\
56 \\
66 \\
42 \\
63 \\
61 \\
54 \\
52 \\
52 \\
49 \\
49 \\
48 \\
22 \\
48 \\
51 \\
51 \\
50 \\
49 \\
59 \\
39 \\
37 \\
60 \\
55 \\
36 \\
31 \\
32 \\
47 \\
53 \\
21 \\
38\end{array}$ & $\begin{array}{r}0 \\
6 \\
7 \\
11 \\
6 \\
7 \\
3 \\
3 \\
1\end{array}$ & $\begin{array}{r}0 \\
10 \\
10 \\
25 \\
14\end{array}$ & $\begin{array}{r}4 \\
5 \\
27 \\
10 \\
16 \\
6 \\
17 \\
12 \\
14 \\
5\end{array}$ & $\begin{array}{r}7 \\
8 \\
37 \\
23 \\
36 \\
18 \\
31 \\
27 \\
29 \\
99 \\
22 \\
12 \\
37 \\
9 \\
7 \\
2\end{array}$ & $\begin{array}{r}19 \\
15 \\
18 \\
9 \\
12 \\
6 \\
26 \\
18 \\
20 \\
20 \\
28 \\
22 \\
35 \\
19 \\
46 \\
48 \\
19\end{array}$ & 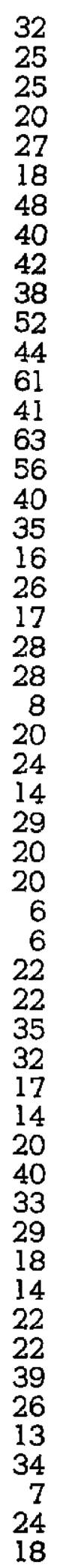 & 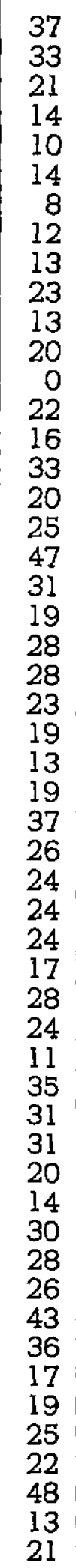 & 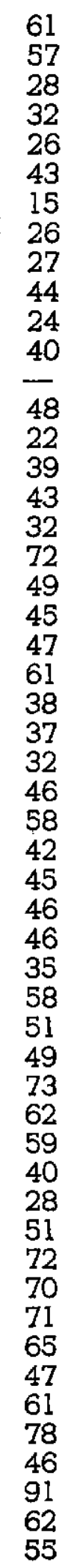 & $\begin{array}{r}10 \\
5 \\
8 \\
6 \\
6 \\
7 \\
7 \\
10 \\
8 \\
9 \\
10 \\
9 \\
9 \\
13 \\
10 \\
7 \\
7 \\
10 \\
8 \\
10 \\
10 \\
11 \\
10 \\
12 \\
10 \\
19 \\
10 \\
8 \\
12 \\
8 \\
9 \\
8 \\
12 \\
10 \\
11 \\
10 \\
10 \\
10 \\
9 \\
9 \\
11 \\
14 \\
10 \\
10 \\
14 \\
10 \\
10 \\
8 \\
10 \\
9 \\
8 \\
8 \\
11\end{array}$ & $\begin{array}{l}0 \\
0 \\
0 \\
0 \\
0 \\
0 \\
0 \\
0 \\
0 \\
0 \\
7 \\
0 \\
4 \\
0 \\
0 \\
0 \\
0 \\
0 \\
0 \\
0 \\
0 \\
2 \\
5 \\
3 \\
4 \\
0 \\
0 \\
0 \\
0 \\
0 \\
9 \\
3 \\
11 \\
3 \\
9 \\
7 \\
0 \\
0 \\
4 \\
7 \\
0\end{array}$ \\
\hline
\end{tabular}


(Continuação)

\begin{tabular}{|c|c|c|c|c|c|c|c|c|c|c|c|c|}
\hline $\begin{array}{c}\text { N.o } \\
\text { Linhagens }\end{array}$ & $\begin{array}{c}\text { Comp. } \\
\text { pan. }\end{array}$ & $\begin{array}{l}\text { N. } \\
\text { pan. }\end{array}$ & $\mathrm{C}$ & $\stackrel{\%}{\mathrm{C}}$ & $\mathbf{R}$ & $\stackrel{\%}{\mathrm{R}}$ & M & $\begin{array}{l}\% \\
M\end{array}$ & Perf. & $\begin{array}{c}\% \\
\text { Perf. }\end{array}$ & $\begin{array}{l}\text { N. } \\
\text { autof. }\end{array}$ & Sel. \\
\hline $37-31-5-1-1$ & 63 & 43 & 1 & 2 & 5 & 12 & 8 & 19 & 29 & 67 & 7 & \\
\hline-2 & 62 & 46 & 0 & 0 & 3 & 7 & 25 & 54 & 18 & 39 & 7 & 3 \\
\hline & 62 & 31 & 1 & 3 & 6 & 19 & 12 & 39 & 12 & 39 & 9 & 0 \\
\hline $37-31-5-3-1$ & 58 & 26 & 0 & 0 & 2 & 8 & 14 & 54 & 10 & 38 & 8 & 7 \\
\hline & 61 & 16 & 1 & 6 & 5 & 31 & 5 & 31 & 5 & 32 & 6 & 0 \\
\hline $37-31-5-4-1$ & 65 & 38 & 2 & 5 & 9 & 24 & 11 & 29 & 16 & 42 & 9 & 0 \\
\hline & 61 & 55 & 2 & 4 & 4 & 7 & 12 & 22 & 37 & 67 & 9 & 9 \\
\hline-3 & 60 & 46 & 3 & 7 & 4 & 9 & 7 & 15 & 32 & 69 & 14 & 9 \\
\hline $37-31-6-3-1$ & 57 & 58 & 3 & 5 & 4 & 7 & 24 & 41 & 27 & 47 & 8 & 2 \\
\hline & 54 & 40 & 1 & 3 & 2 & 5 & 11 & 28 & 26 & 64 & 8 & 7 \\
\hline-3 & 52 & 60 & 0 & 0 & 0 & 0 & 17 & 28 & 43 & 72 & 8 & 6 \\
\hline-4 & 54 & 31 & 1 & 3 & 2 & 6 & 15 & 45 & 13 & 50 & 3 & 1 \\
\hline-5 & 57 & 50 & 0 & 0 & 4 & 8 & 18 & 36 & 28 & 55 & 10 & 10 \\
\hline $37-31-6-4-1$ & 59 & 29 & 4 & 14 & 0 & 0 & 7 & 24 & 18 & 62 & 8 & 8 \\
\hline $37-31-6-6-1$ & 58 & 50 & 1 & 2 & 3 & 6 & 19 & 38 & 27 & 54 & 9 & 9 \\
\hline-2 & 58 & 49 & 5 & 10 & 2 & 4 & 16 & 33 & 26 & 53 & 9 & 0 \\
\hline-3 & 60 & 34 & 1 & 3 & 7 & 21 & 13 & 38 & 13 & 38 & 8 & 2 \\
\hline-4 & 61 & 54 & 4 & 7 & 10 & 19 & 23 & 43 & 17 & 31 & 7 & 0 \\
\hline-5 & 58 & 56 & 0 & 0 & 6 & 11 & 30 & 54 & 20 & 35 & 11 & 5 \\
\hline $37-31-6-7-1$ & 61 & 8 & 0 & 0 & 2 & 25 & 0 & 0 & 6 & 75 & 8 & 0 \\
\hline & 58 & 24 & 0 & 0 & 7 & 29 & 1 & 4 & 16 & 67 & 7 & 0 \\
\hline $37-31-6-9-1$ & 58 & 70 & 3 & 4 & 6 & 9 & 30 & 43 & 31 & 44 & 12 & 9 \\
\hline-2 & 58 & 22 & 3 & 14 & 3 & 14 & 5 & 23 & 11 & 49 & 6 & 4 \\
\hline-3 & 56 & 22 & 0 & 0 & 2 & 9 & 12 & 55 & 8 & 36 & 7 & 5 \\
\hline $37-37-2-4-1$ & 52 & 25 & 0 & 0 & 6 & 24 & 13 & 52 & 6 & 24 & 10 & 0 \\
\hline-2 & 51 & 47 & 8 & 17 & 8 & 17 & 14 & 30 & 17 & 36 & 11 & 0 \\
\hline $37-42-2-1-1$ & 54 & 56 & 9 & 16 & 10 & 18 & 18 & 32 & 19 & 34 & 10 & 0 \\
\hline & 49 & 37 & 5 & 14 & 4 & 11 & 16 & 43 & 12 & 32 & 9 & 0 \\
\hline $37-42-2-2-1$ & 49 & 60 & 10 & 17 & 5 & 8 & 21 & 35 & 24 & 40 & 11 & 0 \\
\hline-2 & 50 & 43 & 12 & 28 & 5 & 12 & 10 & 23 & 16 & 27 & 10 & 0 \\
\hline-3 & 48 & 45 & 7 & 16 & 3 & 7 & 16 & 36 & 19 & 41 & 9 & 0 \\
\hline-4 & 51 & 51 & 6 & 12 & 14 & 27 & 20 & 39 & 11 & 22 & 11 & 0 \\
\hline-5 & 48 & 53 & 6 & 11 & 8 & 15 & 24 & 45 & 15 & 74 & 8 & 0 \\
\hline $37-42-2-3-1$ & 53 & 36 & 5 & 14 & 2 & 6 & 15 & 42 & 14 & 38 & 10 & 0 \\
\hline-2 & 52 & 31 & 2 & 6 & 7 & 23 & 10 & 32 & 12 & 39 & 11 & 0 \\
\hline-3 & 51 & 37 & 0 & 0 & 11 & 30 & 17 & 46 & 9 & 24 & 8 & 0 \\
\hline-4 & 50 & 32 & 1 & 3 & 7 & 22 & 16 & 50 & 8 & 25 & 9 & 0 \\
\hline-5 & 50 & 44 & 1 & 2 & 6 & 14 & 24 & 55 & 13 & 2 & 11 & 0 \\
\hline-6 & 51 & 61 & 4 & 7 & 15 & 25 & 26 & 43 & 16 & 2 & 10 & 0 \\
\hline-7 & 50 & 43 & 2 & 5 & 13 & 30 & 21 & 49 & 7 & 16 & 9 & 0 \\
\hline $37-42-2-5-1$ & 50 & 22 & 1 & 5 & 4 & 18 & 10 & 45 & 7 & 32 & 11 & 0 \\
\hline-2 & 51 & 40 & 0 & 0 & 11 & 28 & 24 & 60 & 5 & 12 & 7 & 0 \\
\hline-3 & 52 & 42 & 3 & 7 & 6 & 14 & 19 & 45 & 14 & 34 & 10 & 0 \\
\hline-4 & 51 & 33 & 2 & 6 & 8 & 24 & 16 & 48 & 7 & 22 & 11 & 0 \\
\hline-5 & 50 & 32 & 1 & 3 & 5 & 16 & 19 & 59 & 7 & 22 & 9 & \\
\hline-6 & 51 & 39 & 5 & 13 & 8 & 21 & 21 & 54 & 5 & 12 & 10 & \\
\hline $37-42-2-6-1$ & 50 & 62 & 2 & 3 & 6 & 10 & 34 & 55 & 20 & 32 & 7 & \\
\hline-2 & 52 & 55 & 2 & 4 & 6 & 11 & 16 & 29 & 31 & 56 & 8 & \\
\hline-3 & 51 & 44 & 7 & 16 & 10 & 23 & 18 & 41 & 9 & 20 & 10 & \\
\hline-4 & 49 & 55 & 6 & 11 & 2 & 4 & 10 & 18 & 37 & 67 & 10 & \\
\hline-5 & 49 & 79 & 15 & 19 & 9 & 11 & 2 & 29 & 32 & 41 & 8 & \\
\hline-6 & 50 & 55 & 8 & 15 & 9 & 16 & 23 & 42 & 15 & 27 & 8 & \\
\hline-7 & 52 & 27 & 6 & 22 & 9 & 33 & 5 & 19 & 7 & 26 & 8 & \\
\hline
\end{tabular}


(Continuação)

\begin{tabular}{|c|c|c|c|c|c|c|c|c|c|c|c|c|}
\hline $\begin{array}{c}\text { N.o } \\
\text { Linhagens }\end{array}$ & $\begin{array}{c}\text { Comp. } \\
\text { pan. }\end{array}$ & $\begin{array}{l}\text { N.o } \\
\text { pan. }\end{array}$ & C & $\stackrel{\%}{\mathrm{C}}$ & $\mathbf{R}$ & $\stackrel{\%}{\mathrm{R}}$ & $\mathrm{M}$ & $\begin{array}{l}\% \\
M\end{array}$ & Perf. & $\begin{array}{c}\% \\
\text { Perf. }\end{array}$ & $\begin{array}{l}\text { N.o } \\
\text { autof. }\end{array}$ & Sel. \\
\hline $\begin{array}{r}3-75-2-1 \\
-2 \\
75-3-1-1 \\
-2 \\
-3 \\
-4 \\
-5 \\
-6 \\
-7 \\
3-77-2-1 \\
-2 \\
4-87-5-1 \\
-2 \\
-3 \\
-4 \\
-5 \\
-6\end{array}$ & $\begin{array}{l}51 \\
51 \\
53 \\
53 \\
53 \\
54 \\
52 \\
55 \\
51 \\
56 \\
53 \\
58 \\
57 \\
53 \\
55 \\
54\end{array}$ & $\begin{array}{r}62 \\
64 \\
65 \\
82 \\
54 \\
41 \\
62 \\
59 \\
46 \\
35 \\
54 \\
2 \\
39 \\
22 \\
40 \\
19\end{array}$ & $\begin{array}{l}0 \\
2 \\
2 \\
1 \\
1 \\
3 \\
2 \\
2 \\
2 \\
1 \\
0 \\
0 \\
5 \\
3 \\
6 \\
1\end{array}$ & $\begin{array}{r}0 \\
3 \\
3 \\
1 \\
2 \\
7 \\
3 \\
3 \\
4 \\
3 \\
0 \\
0 \\
13 \\
14 \\
15 \\
5\end{array}$ & $\begin{array}{l}5 \\
0 \\
2 \\
0 \\
1 \\
0 \\
0 \\
6 \\
2 \\
0 \\
3 \\
1 \\
6 \\
7 \\
5 \\
6\end{array}$ & $\begin{array}{r}8 \\
0 \\
3 \\
0 \\
2 \\
0 \\
0 \\
10 \\
4 \\
0 \\
6 \\
50 \\
15 \\
32 \\
13 \\
32\end{array}$ & $\begin{array}{l}50 \\
45 \\
56 \\
73 \\
38 \\
30 \\
56 \\
36 \\
42 \\
24 \\
43 \\
1 \\
31 \\
16 \\
28 \\
15\end{array}$ & $\begin{array}{l}81 \\
70 \\
86 \\
89 \\
70 \\
73 \\
90 \\
61 \\
91 \\
69 \\
80 \\
50 \\
79 \\
73 \\
70 \\
79\end{array}$ & $\begin{array}{r}7 \\
17 \\
5 \\
8 \\
14 \\
8 \\
4 \\
15 \\
0 \\
10 \\
8 \\
0 \\
\\
0 \\
0 \\
1 \\
0\end{array}$ & $\begin{array}{r}11 \\
27 \\
8 \\
10 \\
26 \\
20 \\
7 \\
26 \\
1 \\
28 \\
15 \\
0 \\
- \\
- \\
-3 \\
-\end{array}$ & $\begin{array}{r}9 \\
10 \\
11 \\
13 \\
13 \\
10 \\
13 \\
13 \\
9 \\
11 \\
10 \\
- \\
- \\
8 \\
7 \\
9 \\
6\end{array}$ & $\begin{array}{l}0 \\
0 \\
0 \\
0 \\
0 \\
0 \\
0 \\
0 \\
0 \\
0 \\
0 \\
- \\
- \\
5 \\
0 \\
5 \\
0\end{array}$ \\
\hline & & & & & & & & & & & 1942 & 268 \\
\hline
\end{tabular}

$1939-40$

\begin{tabular}{|c|c|c|c|c|c|c|c|c|c|c|c|c|}
\hline $\begin{array}{c}\text { N.o } \\
\text { Linhagens }\end{array}$ & $\begin{array}{c}\text { Comp. } \\
\text { pan. }\end{array}$ & $\begin{array}{l}\text { N. } \\
\text { pan. }\end{array}$ & $\mathrm{C}$ & $\stackrel{\%}{\mathrm{C}}$ & $\mathrm{R}$ & $\begin{array}{l}\% \\
\mathrm{R}\end{array}$ & $\mathrm{M}$ & $\begin{array}{l}\% \\
\mathrm{M}\end{array}$ & Perf. & $\begin{array}{c}\% \\
\text { Perf. }\end{array}$ & $\begin{array}{l}\text { N.o } \\
\text { autof. }\end{array}$ & Sel. \\
\hline $\begin{array}{r}37-3-1-1-2-4-1 \\
-2 \\
37-3-3-1-5-2-1 \\
-2 \\
-3 \\
-4 \\
37-3-4-2-3-3-1 \\
-2 \\
-3 \\
-4 \\
-5 \\
37-3-4-2-3-4-1 \\
-2 \\
37-3-4-2-3-5-1 \\
-2 \\
-3 \\
37-3-4-2-3-9-1 \\
-2 \\
-3 \\
-4 \\
-5 \\
-6 \\
37-3-4-3-2-1-1 \\
-2 \\
-3 \\
-4\end{array}$ & $\begin{array}{l}52 \\
55 \\
57 \\
56 \\
57 \\
51 \\
56 \\
52 \\
55 \\
57 \\
52 \\
53 \\
58 \\
56 \\
56 \\
54 \\
55 \\
57 \\
54 \\
56 \\
57 \\
56 \\
54 \\
56 \\
53 \\
54\end{array}$ & $\begin{array}{l}38 \\
40 \\
21 \\
34 \\
29 \\
33 \\
31 \\
33 \\
30 \\
45 \\
31 \\
49 \\
35 \\
35 \\
38 \\
31 \\
23 \\
40 \\
26 \\
33 \\
39 \\
35 \\
38 \\
36 \\
46 \\
41\end{array}$ & $\begin{array}{r}7 \\
14 \\
3 \\
6 \\
5 \\
4 \\
7 \\
6 \\
7 \\
6 \\
5 \\
9 \\
7 \\
7 \\
11 \\
9 \\
7 \\
7 \\
6 \\
7 \\
13 \\
10 \\
8 \\
5 \\
7 \\
7\end{array}$ & $\begin{array}{l}18 \\
35 \\
14 \\
18 \\
17 \\
12 \\
23 \\
18 \\
23 \\
13 \\
16 \\
18 \\
20 \\
20 \\
29 \\
29 \\
30 \\
18 \\
23 \\
21 \\
33 \\
29 \\
21 \\
14 \\
15 \\
17\end{array}$ & $\begin{array}{l}3 \\
0 \\
2 \\
5 \\
3 \\
3 \\
2 \\
3 \\
1 \\
6 \\
7 \\
2 \\
2 \\
3 \\
2 \\
2 \\
3 \\
4 \\
5 \\
4 \\
4 \\
6 \\
2 \\
5 \\
4 \\
5\end{array}$ & $\begin{array}{r}8 \\
0 \\
10 \\
15 \\
10 \\
9 \\
6 \\
9 \\
3 \\
13 \\
23 \\
4 \\
6 \\
9 \\
5 \\
6 \\
13 \\
8 \\
19 \\
12 \\
10 \\
17 \\
5 \\
14 \\
9 \\
12\end{array}$ & $\begin{array}{r}21 \\
20 \\
10 \\
10 \\
7 \\
17 \\
13 \\
16 \\
11 \\
14 \\
15 \\
20 \\
11 \\
13 \\
7 \\
5 \\
4 \\
15 \\
6 \\
11 \\
10 \\
5 \\
19 \\
15 \\
27 \\
23\end{array}$ & $\begin{array}{l}55 \\
50 \\
48 \\
29 \\
24 \\
52 \\
42 \\
48 \\
37 \\
31 \\
48 \\
41 \\
31 \\
37 \\
18 \\
16 \\
17 \\
38 \\
23 \\
33 \\
26 \\
14 \\
50 \\
42 \\
59 \\
56\end{array}$ & $\begin{array}{r}7 \\
6 \\
6 \\
13 \\
14 \\
9 \\
9 \\
8 \\
11 \\
19 \\
4 \\
18 \\
15 \\
12 \\
18 \\
15 \\
9 \\
14 \\
9 \\
11 \\
12 \\
14 \\
9 \\
11 \\
8 \\
6\end{array}$ & $\begin{array}{l}19 \\
15 \\
28 \\
38 \\
49 \\
27 \\
29 \\
25 \\
37 \\
43 \\
13 \\
37 \\
43 \\
34 \\
48 \\
41 \\
40 \\
36 \\
35 \\
34 \\
31 \\
40 \\
24 \\
30 \\
17 \\
15\end{array}$ & $\begin{array}{r}6 \\
10 \\
5 \\
7 \\
6 \\
5 \\
6 \\
5 \\
7 \\
6 \\
8 \\
7 \\
6 \\
8 \\
8 \\
6 \\
7 \\
7 \\
7 \\
7 \\
8 \\
8 \\
6 \\
9 \\
8 \\
7\end{array}$ & \\
\hline
\end{tabular}


VoL. I

(Continuação)

\begin{tabular}{|c|c|c|c|c|c|c|c|c|c|c|c|c|}
\hline $\begin{array}{c}\text { N. } \\
\text { Linhagens }\end{array}$ & $\begin{array}{l}\text { Comp. } \\
\text { pan. }\end{array}$ & $\begin{array}{l}\text { N.o } \\
\text { pan. }\end{array}$ & C & $\stackrel{\%}{\mathrm{C}}$ & $R$ & $\begin{array}{l}\% \\
\mathrm{R}\end{array}$ & M & $\begin{array}{l}\% \\
\mathrm{M}\end{array}$ & Perf. & $\begin{array}{c}\% \\
\text { Perf. }\end{array}$ & $\begin{array}{l}\text { N.o } \\
\text { autof. }\end{array}$ & Sel. \\
\hline-5 & 55 & 34 & 5 & 15 & 0 & 0 & 14 & 41 & 15 & 43 & 7 & \\
\hline $37-3-4 \cdot 3-2-2-1$ & 54 & 32 & 4 & 13 & 7 & 22 & 15 & 47 & 6 & 18 & 5 & \\
\hline $37-3-4-3-4-2-1$ & 53 & 33 & 14 & 42 & 2 & 6 & 14 & 42 & 3 & 10 & 7 & \\
\hline-2 & 52 & 21 & 3 & 14 & 3 & 14 & 9 & 43 & 6 & 29 & 5 & \\
\hline-3 & 52 & 30 & 4 & 13 & 4 & 13 & 15 & 50 & 7 & 24 & 4 & \\
\hline-4 & 51 & 54 & 8 & 15 & 3 & 6 & 36 & 67 & 7 & 12 & 6 & \\
\hline-5 & 52 & 35 & 7 & 20 & 0 & 0 & 15 & 43 & 13 & 37 & 6 & \\
\hline-6 & 55 & 45 & 2 & 4 & 6 & 13 & 26 & 58 & 11 & 25 & 7 & \\
\hline $37-3-4-4-2-3-1$ & - & - & - & - & - & - & - & - & - & - & & - \\
\hline-2 & 57 & 28 & 10 & 36 & 6 & 21 & 13 & 46 & 0 & - & 4 & \\
\hline-3 & 56 & 27 & 3 & 11 & 8 & 30 & 10 & 37 & 6 & 22 & 8 & \\
\hline-4 & 57 & 45 & 7 & 16 & 2 & 4 & 30 & 67 & 6 & 11 & 6 & \\
\hline-5 & 55 & 27 & 11 & 41 & 2 & 7 & 10 & 37 & 4 & 15 & 6 & \\
\hline $37-3-4-4-5-3-1$ & 57 & 41 & 3 & 7 & 2 & 5 & 22 & 54 & 14 & 34 & 10 & 7 \\
\hline $37-3-4-4-5-3-2$ & 57 & 47 & 6 & 13 & 3 & 6 & 22 & 47 & 16 & 34 & 10 & \\
\hline-3 & 58 & 47 & 3 & 6 & 3 & 6 & $2 \overline{6}$ & 55 & 15 & 33 & 9 & \\
\hline-4 & 54 & 42 & 4 & 10 & 3 & 7 & 14 & 33 & 21 & 50 & 8 & \\
\hline $37-3-5-1-1-1-1$ & 54 & 34 & 4 & 12 & 2 & 6 & 16 & 47 & 12 & 35 & 9 & \\
\hline-2 & 57 & 51 & 6 & 12 & 0 & 0 & 21 & 41 & 24 & 47 & 9 & \\
\hline-3 & 55 & 38 & 6 & 16 & 0 & 0 & 18 & 47 & 14 & 37 & 5 & \\
\hline-4 & 54 & 32 & 4 & 13 & 2 & 6 & 25 & 78 & 1 & 3 & 6 & \\
\hline-5 & 60 & 33 & 3 & 9 & 1 & 3 & 18 & 55 & Il & 33 & 8 & \\
\hline-6 & 58 & 45 & 4 & 9 & 4 & 9 & 28 & 62 & 9 & 20 & 10 & \\
\hline-7 & 55 & 12 & 0 & 0 & 1 & 8 & 7 & 58 & 4 & 34 & 4 & \\
\hline-8 & 59 & 35 & 4 & 11 & 0 & 0 & 11 & 31 & 20 & 58 & 8 & \\
\hline $37-3-5-1-2-1-1$ & 53 & 38 & 3 & 8 & 4 & 11 & 17 & 45 & 14 & 36 & 8 & \\
\hline-2 & 50 & 40 & 2 & 5 & 5 & 13 & 18 & 45 & 15 & 37 & 5 & \\
\hline-3 & 54 & 37 & 5 & 14 & 1 & 3 & 14 & 38 & 17 & 45 & 8 & \\
\hline-4 & 52 & 24 & 5 & 21 & 3 & 13 & 6 & 25 & 10 & 41 & 2 & \\
\hline-5 & 52 & 45 & 12 & 27 & 1 & 2 & 20 & 44 & 12 & 27 & 8 & \\
\hline-6 & 51 & 27 & 6 & 22 & 1 & 4 & 8 & 30 & 12 & 44 & 5 & \\
\hline-7 & 53 & 32 & 2 & 6 & 6 & 19 & 13 & 41 & 11 & 34 & 6 & \\
\hline-8 & 52 & 26 & 7 & 27 & 1 & 4 & 11 & 42 & 7 & 27 & 5 & \\
\hline-9 & 55 & 25 & 10 & 40 & 2 & 8 & 4 & 16 & 9 & 36 & 7 & \\
\hline-10 & 54 & 47 & 6 & 13 & 1 & 2 & 26 & 55 & 14 & 32 & 7 & \\
\hline-11 & 55 & 40 & 8 & 20 & 1 & 3 & 15 & 38 & 16 & 39 & 9 & \\
\hline $37-3-5-1-5-1-1$ & 57 & 38 & 12 & 32 & 0 & $\mathrm{O}$ & 18 & 47 & 8 & 21 & 4 & \\
\hline $37-25-2-2-2-1$ & 58 & 15 & 1 & 7 & 3 & 20 & 3 & 20 & 8 & 53 & 3 & \\
\hline-2 & 56 & 27 & 5 & 19 & 4 & 15 & 6 & 22 & 12 & 44 & 7 & \\
\hline-3 & 56 & 26 & 1 & 4 & 3 & 12 & 5 & 19 & 17 & 65 & 5 & \\
\hline-4 & 56 & 14 & 2 & 14 & 4 & 29 & 2 & 14 & 6 & 43 & 0 & \\
\hline-5 & 56 & 27 & 3 & 11 & 8 & 30 & 6 & 22 & 10 & 37 & 3 & \\
\hline-6 & 55 & 39 & I & 3 & 10 & 26 & 8 & 21 & 20 & 50 & 7 & \\
\hline $37-25-4-5-2-1$ & 54 & 29 & 2 & 7 & 2 & 7 & 6 & 21 & 19 & 65 & 5 & 2 \\
\hline . $\quad-2$ & 52 & 29 & 2 & 7 & 5 & 17 & 4 & 14 & 18 & 62 & 5 & \\
\hline-3 & 55 & 35 & 2 & 6 & 3 & 9 & 12 & 34 & 18 & 51 & 8 & \\
\hline $37-25-4-6-1-1$ & 55 & 36 & $\overline{1}$ & 3 & 5 & 14 & 9 & 25 & 21 & 58 & 7 & \\
\hline-2 & 56 & 45 & 1 & 2 & 7 & 16 & 14 & 31 & 23 & 51 & 8 & \\
\hline-3 & 56 & 37 & 3 & 8 & 10 & 27 & 10 & 27 & 14 & 38 & 6 & \\
\hline-4 & 55 & 28 & 0 & 0 & 4 & 14 & 6 & 21 & 18 & 65 & 9 & \\
\hline-5 & 57 & 16 & 2 & 13 & 3 & 19 & 2 & 13 & 9 & 55 & 5 & \\
\hline & 52 & 36 & 6 & 17 & 8 & 22 & 8 & 22 & 14 & 39 & 5 & \\
\hline $37-29-4-2-2-1$ & 57 & 30 & 0 & 0 & 3 & 10 & 13 & 43 & 14 & 47 & 7 & 2 \\
\hline
\end{tabular}


(Continuação)

\begin{tabular}{|c|c|c|c|c|c|c|c|c|c|c|c|c|}
\hline $\begin{array}{c}\text { N. }{ }^{\circ} \\
\text { Linhagens }\end{array}$ & $\begin{array}{l}\text { Comp. } \\
\text { pan. }\end{array}$ & $\begin{array}{l}\text { N. }{ }^{\circ} \\
\text { pan. }\end{array}$ & $\mathrm{C}$ & $\stackrel{\%}{\mathrm{C}}$ & $R$ & $\begin{array}{l}\% \\
\mathrm{R}\end{array}$ & M & $\begin{array}{l}\% \\
M\end{array}$ & Perf. & $\begin{array}{c}\% \\
\text { Perf. }\end{array}$ & $\begin{array}{l}\text { N.o } \\
\text { autof. }\end{array}$ & Sel. \\
\hline-2 & 58 & 39 & 1 & 3 & 3 & 8 & 18 & 46 & 17 & 43 & 7 & \\
\hline $37-31-2 \cdot 5-6-1$ & 64 & 32 & 10 & 31 & 3 & 9 & 10 & 31 & 9 & 29 & 8 & \\
\hline-2 & 64 & 42 & 12 & 29 & 1 & 2 & 17 & 40 & 12 & 29 & 9 & \\
\hline-3 & 58 & 24 & 9 & 38 & 0 & 0 & 4 & 17 & 11 & 45 & 4 & \\
\hline .4 & 59 & 24 & 5 & 21 & 0 & 0 & 15 & 63 & 4 & 16 & 2 & \\
\hline-5 & 64 & 35 & 8 & 23 & 3 & 9 & 10 & 29 & 14 & 39 & 5 & \\
\hline-6 & 65 & 37 & 9 & 24 & 3 & 8 & 9 & 24 & 16 & 44 & 7 & \\
\hline-7 & 60 & 29 & 7 & 24 & 1 & 3 & 9 & 31 & 12 & 42 & 4 & \\
\hline $37-31-2-6-1-1$ & 60 & 24 & 5 & 21 & 4 & 17 & 1 & 4 & 14 & 58 & 9 & \\
\hline & 60 & 28 & 6 & 21 & 6 & 21 & 8 & 29 & 8 & 29 & 5 & \\
\hline-3 & 65 & 13 & 6 & 46 & 2 & 15 & 2 & 15 & 3 & 24 & 3 & \\
\hline-4 & 67 & 7 & 2 & 29 & 2 & 29 & 2 & 29 & 1 & 13 & 1 & \\
\hline $37-31-4-1-1-1$ & 61 & 42 & 6 & 14 & 5 & 12 & 13 & 31 & 18 & 44 & 5 & \\
\hline & 55 & 38 & 6 & 16 & 3 & 8 & 17 & 45 & 12 & 31 & 8 & \\
\hline $37-31-4-1-2-1$ & 63 & 42 & 6 & 14 & 3 & 7 & 19 & 45 & 14 & 33 & 7 & \\
\hline-2 & 64 & 33 & 4 & 12 & 1 & 3 & 15 & 45 & 13 & 40 & 5 & \\
\hline-3 & 61 & 48 & 9 & 19 & 3 & 6 & 13 & 27 & 23 & 48 & 7 & \\
\hline-4 & 62 & 33 & 9 & 27 & 2 & 6 & 11 & 33 & 11 & 34 & 3 & \\
\hline & 61 & 23 & 4 & 17 & 2 & 9 & 9 & 39 & 8 & 35 & 5 & \\
\hline $37-31-4-1-3-1$ & 60 & 50 & 2 & 4 & 6 & 12 & 27 & 54 & 15 & 30 & 5 & \\
\hline .2 & 57 & 19 & 6 & 32 & 1 & 5 & 5 & 26 & 7 & 37 & 3 & \\
\hline-3 & 61 & 26 & 4 & 15 & 2 & 8 & 12 & 46 & 8 & 31 & 3 & \\
\hline $37-31-4-1-4-1$ & 61 & 30 & 9 & 30 & 5 & 17 & 6 & 20 & 10 & 33 & 7 & \\
\hline-2 & 57 & 51 & 6 & 12 & 7 & 14 & 18 & 35 & 20 & 39 & 9 & \\
\hline-3 & 59 & 33 & 8 & 24 & 3 & 9 & 4 & 12 & 18 & 55 & 7 & \\
\hline-4 & 63 & 33 & 6 & 18 & 5 & 15 & 13 & 39 & 9 & 28 & 7 & \\
\hline $37-31-4-6-2-1$ & 53 & 47 & 0 & 0 & 5 & 11 & 23 & 49 & 19 & 40 & 6 & \\
\hline-2 & 56 & 49 & 4 & 8 & 0 & 0 & 12 & 24 & 33 & 68 & 7 & 2 \\
\hline-3 & 57 & 36 & 1 & 3 & 4 & 11 & 7 & 19 & 24 & 67 & 8 & \\
\hline-4 & 57 & 41 & 4 & 10 & 5 & 12 & 11 & 27 & 21 & 51 & 7 & \\
\hline-5 & 59 & 46 & 2 & 4 & 3 & 7 & 12 & 26 & 29 & 63 & 10 & 7 \\
\hline-6 & 55 & 28 & 3 & 11 & 2 & 7 & 10 & 36 & 13 & 47 & 5 & \\
\hline-7 & 56 & 39 & 3 & 8 & 6 & 15 & 14 & 36 & 16 & 41 & 8 & \\
\hline-8 & 53 & 27 & 1 & 4 & 1 & 4 & 10 & 37 & 15 & 55 & 5 & 2 \\
\hline-9 & 55 & 51 & 5 & 10 & $\dot{9}$ & 18 & 15 & 29 & 22 & 43 & 8 & \\
\hline $37-31-4-6-3-1$ & 59 & 35 & 6 & 17 & 0 & 0 & 8 & 23 & 21 & 60 & 7 & \\
\hline-2 & 58 & 26 & 5 & 19 & 3 & 12 & 2 & 8 & 16 & 61 & 7 & \\
\hline-3 & 53 & 46 & 4 & 9 & 0 & 0 & 16 & 35 & 26 & 56 & 8 & 6 \\
\hline $37-31-4-7-1-1$ & 55 & 47 & 3 & 6 & 7 & 15 & 19 & 40 & 18 & 39 & 9 & \\
\hline-2 & 61 & 32 & 3 & 9 & 3 & 9 & 8 & 25 & 18 & 57 & 9 & \\
\hline-3 & 55 & 28 & 0 & $\mathrm{O}$ & 3 & 11 & 10 & 36 & 15 & 53 & 3 & \\
\hline-4 & 57 & 29 & 2 & 7 & 12 & 41 & 7 & 24 & 8 & 28 & 6 & \\
\hline-5 & 63 & 42 & 2 & 5 & 3 & 7 & 13 & 31 & 24 & 57 & 6 & 3 \\
\hline $37-31-4-7-1-6$ & 53 & 28 & 1 & 4 & 3 & 11 & 6 & 21 & 18 & 64 & 6 & \\
\hline-7 & 57 & 29 & 1 & 3 & 2 & 7 & 10 & 34 & 16 & 56 & 6 & 1 \\
\hline .8 & 58 & 28 & 4 & 14 & $\overline{0}$ & 0 & 9 & 32 & 15 & 54 & 5 & \\
\hline-9 & 58 & 22 & 2 & 9 & 2 & 9 & 10 & 45 & 8 & 37 & 5 & \\
\hline-10 & 51 & 9 & 0 & 0 & 0 & 0 & 2 & 22 & 7 & 78 & 0 & \\
\hline-11 & 56 & 27 & 5 & 19 & 2 & 7 & 6 & 22 & 14 & 52 & 6 & \\
\hline $37-31 \cdot 4 \cdot 7-2 \cdot 1$ & 60 & 20 & 1 & 5 & 1 & 5 & 11 & 55 & 7 & 35 & 5 & 1 \\
\hline-2 & 60 & 33 & 6 & 18 & 3 & 9 & 7 & 21 & 17 & 52 & 7 & \\
\hline & 60 & 41 & 4 & 10 & 4 & 10 & 16 & 39 & 17 & 41 & 8 & \\
\hline $37-31-4-7-3-1$ & 60 & 39 & 6 & 15 & 2 & 5 & 22 & 56 & 9 & 24 & 8 & \\
\hline
\end{tabular}




\section{(Continuação)}

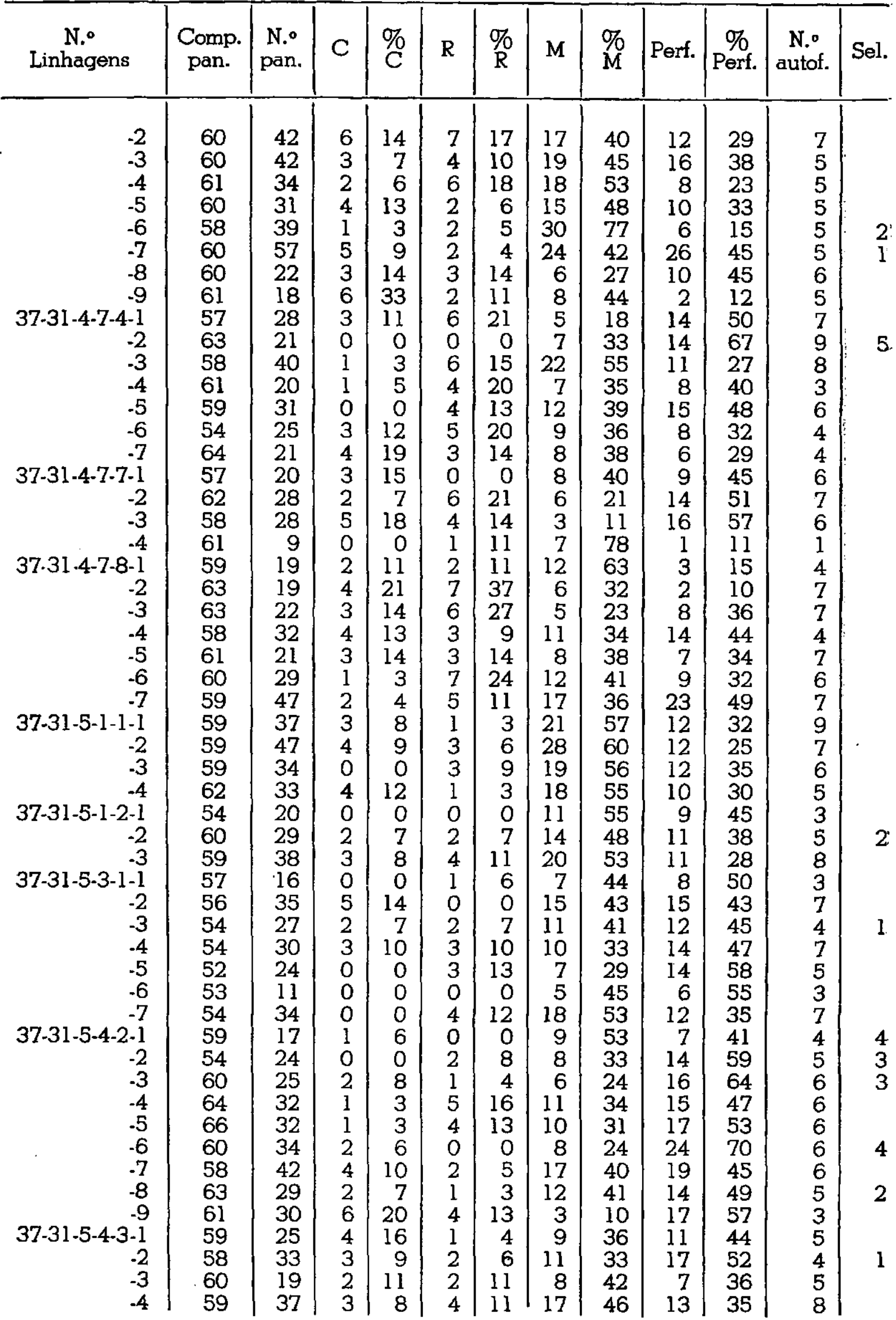


(Continuação)

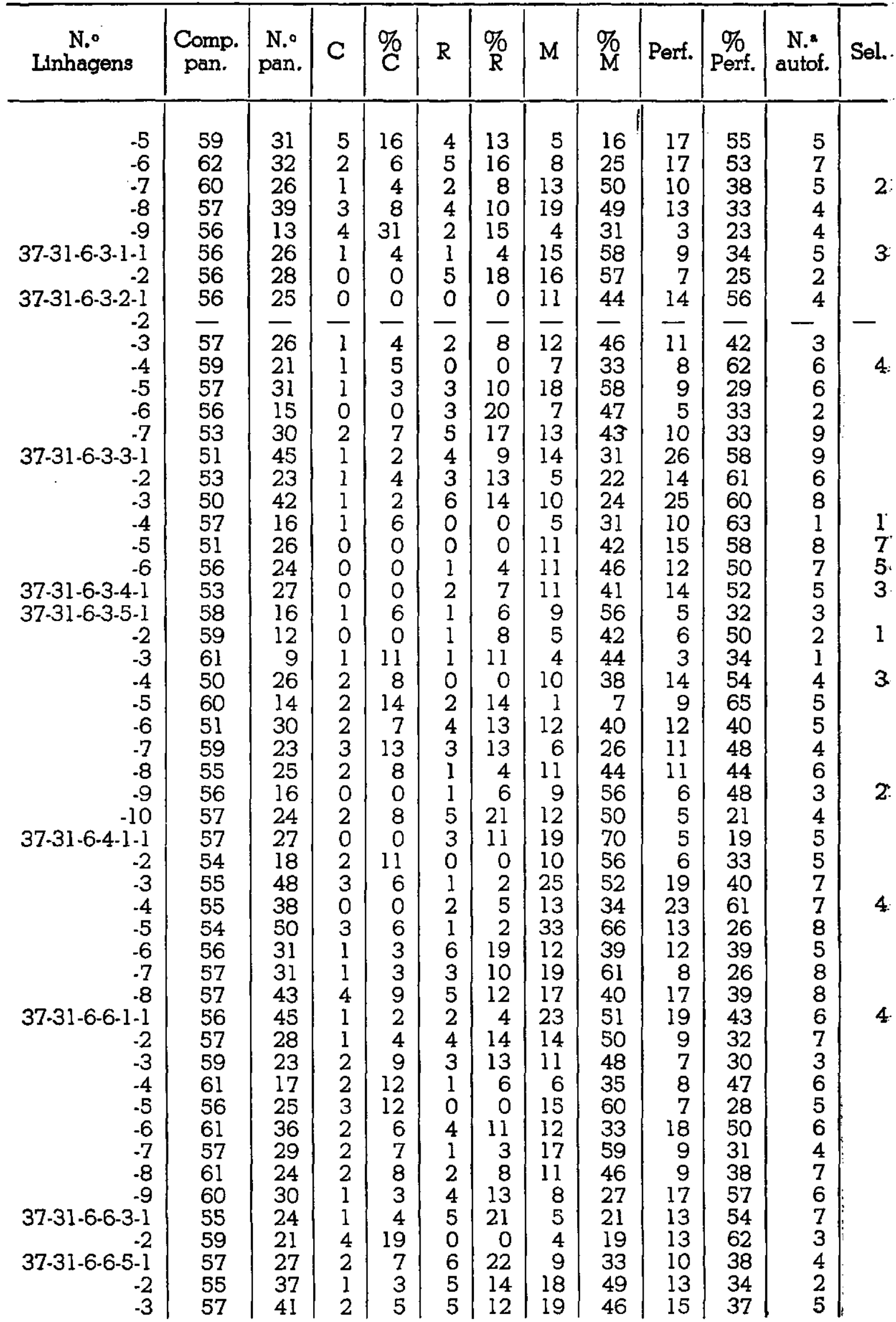


(Continuação)

\begin{tabular}{|c|c|c|c|c|c|c|c|c|c|c|c|c|}
\hline $\begin{array}{c}\text { N.o } \\
\text { Linhagens }\end{array}$ & $\begin{array}{l}\text { Comp. } \\
\text { pan. }\end{array}$ & $\begin{array}{l}\text { N. }{ }^{\circ} \\
\text { pan. }\end{array}$ & C & $\%$ & $\mathrm{R}$ & $\begin{array}{l}\% \\
\mathrm{R}\end{array}$ & $\mathbf{M}$ & $\begin{array}{l}\% \\
M\end{array}$ & Perf. & $\begin{array}{l}\% \\
\text { Perf. }\end{array}$ & $\begin{array}{l}\text { N. } \\
\text { autof. }\end{array}$ & Sel. \\
\hline $\begin{array}{r} \\
-4 \\
-5 \\
37-31-6-9-1-1 \\
-2 \\
-3 \\
-4 \\
-5 \\
-6 \\
-7 \\
-8 \\
-8 \\
-9 \\
37-31-6-9-2-1 \\
-2 \\
-3 \\
-4 \\
37-31-6-9-3-1 \\
-2 \\
-3 \\
-4 \\
-4 \\
-5 \\
4-87-5-3-1 \\
-2 \\
-3 \\
-4 \\
-5 \\
-5\end{array}$ & $\begin{array}{l}56 \\
60 \\
56 \\
55 \\
55 \\
58 \\
61 \\
58 \\
56 \\
58 \\
57 \\
53 \\
59 \\
57 \\
56 \\
57 \\
58 \\
55 \\
57 \\
56 \\
55 \\
53 \\
54 \\
54 \\
53 \\
55 \\
53 \\
54 \\
54\end{array}$ & $\begin{array}{l}35 \\
12 \\
51 \\
37 \\
31 \\
22 \\
27 \\
28 \\
32 \\
27 \\
20 \\
19 \\
20 \\
15 \\
30 \\
20 \\
27 \\
36 \\
19 \\
27 \\
14 \\
23 \\
27 \\
17 \\
20 \\
39 \\
26 \\
21 \\
17\end{array}$ & $\begin{array}{r}5 \\
1 \\
2 \\
0 \\
4 \\
2 \\
1 \\
2 \\
0 \\
2 \\
1 \\
1 \\
.1 \\
0 \\
4 \\
5 \\
1 \\
1 \\
1 \\
6 \\
5 \\
5 \\
13 \\
2 \\
9 \\
10 \\
3 \\
1 \\
10\end{array}$ & $\begin{array}{r}14 \\
8 \\
4 \\
0 \\
13 \\
9 \\
4 \\
7 \\
0 \\
7 \\
5 \\
5 \\
5 \\
0 \\
13 \\
25 \\
4 \\
3 \\
5 \\
22 \\
36 \\
22 \\
48 \\
12 \\
45 \\
26 \\
12 \\
5 \\
59\end{array}$ & $\begin{array}{l}1 \\
0 \\
4 \\
5 \\
1 \\
3 \\
0 \\
0 \\
2 \\
4 \\
2 \\
2 \\
3 \\
5 \\
2 \\
3 \\
2 \\
6 \\
1 \\
2 \\
0 \\
0 \\
0 \\
0 \\
1 \\
2 \\
2 \\
0 \\
0\end{array}$ & $\begin{array}{r}3 \\
0 \\
8 \\
14 \\
3 \\
14 \\
0 \\
0 \\
6 \\
15 \\
10 \\
11 \\
15 \\
33 \\
7 \\
15 \\
7 \\
17 \\
5 \\
7 \\
0 \\
0 \\
0 \\
0 \\
5 \\
5 \\
8 \\
0 \\
0\end{array}$ & $\begin{array}{r}7 \\
5 \\
28 \\
19 \\
14 \\
11 \\
15 \\
11 \\
14 \\
11 \\
7 \\
9 \\
3 \\
3 \\
19 \\
10 \\
8 \\
13 \\
13 \\
16 \\
5 \\
12 \\
10 \\
7 \\
10 \\
24 \\
12 \\
13 \\
5\end{array}$ & $\begin{array}{l}20 \\
42 \\
55 \\
51 \\
45 \\
50 \\
56 \\
39 \\
44 \\
41 \\
35 \\
47 \\
15 \\
20 \\
63 \\
50 \\
30 \\
36 \\
68 \\
59 \\
36 \\
52 \\
37 \\
41 \\
50\end{array}$ & $\begin{array}{r}22 \\
6 \\
17 \\
13 \\
12 \\
6 \\
11 \\
15 \\
16 \\
10 \\
10 \\
7 \\
13 \\
7 \\
5 \\
2 \\
16 \\
16 \\
4 \\
3 \\
4 \\
6 \\
4 \\
8 \\
0 \\
3 \\
9 \\
7 \\
2\end{array}$ & $\begin{array}{r}63 \\
50 \\
33 \\
35 \\
39 \\
27 \\
40 \\
54 \\
50 \\
37 \\
50 \\
37 \\
65 \\
47 \\
17 \\
10 \\
59 \\
44 \\
22 \\
12 \\
38 \\
26 \\
15 \\
47 \\
0 \\
7 \\
35 \\
33 \\
12\end{array}$ & $\begin{array}{r}6 \\
- \\
5 \\
9 \\
6 \\
3 \\
9 \\
4 \\
4 \\
7 \\
5 \\
4 \\
6 \\
4 \\
7 \\
3 \\
7 \\
7 \\
5 \\
4 \\
8 \\
3 \\
6 \\
11 \\
7 \\
7 \\
7 \\
8 \\
8 \\
4\end{array}$ & -1 \\
\hline & & & & & & & & & & & 1562 & 114 \\
\hline
\end{tabular}

